Francisco Adriano de Araújo

\title{
CONTRIBUIÇÃO AO EMPREGO DA MECÂNICA DO DANO PARA A ANÁLISE DO COMPORTAMENTO DINÂMICO NÃO-LINEAR DE VIGAS EM CONCRETO ARMADO
}

Dissertação apresentada à Escola de Engenharia de São Carlos da Universidade de São Paulo, como parte dos requisitos para a obtenção do Título de Mestre em Engenharia de Estruturas.

Orientador: Prof. Dr. Sergio Persival Baroncini Proença

São Carlos 2003 


\section{AGRADECIMENTOS}

A Deus, por mais esta oportunidade e alento nos momentos mais difíceis.

Ao professor Dr. Sergio P. B. Proença, pela excelente orientação fornecida durante a elaboração deste trabalho e extrema paciência.

A minha família, eterna gratidão pelo apoio, amor, carinho e compreensão. Em especial ao meu pai, por seu exemplo de vida e por sua influência decisiva na formação de meu caráter, minha eterna admiração e respeito.

À coordenadoria de Aperfeiçoamento de Pessoal de Nível Superior - CAPES, pela bolsa de estudo concedida.

Aos professores da Universidade Federal do Rio Grande do Norte - UFRN, Olavo Francisco dos Santos Júnior e Roberto José de Medeiros, pela amizade confiança e incentivo, fundamentais ao enfrentamento deste desafio.

A todos os colegas, professores e funcionários do Departamento de Estruturas da EESC/USP, pela colaboração. 
"A única função da educação deve consistir em preparar indivíduos para que estes pensem e hajam como indivíduos independentes e livres"

Albert Einstein 


\section{RESUMO}

ARAÚJO, F. A. (2003). Contribuição ao emprego da Mecânica do Dano para a análise do comportamento dinâmico não-linear de vigas em concreto armado. Dissertação (Mestrado) Escola de Engenharia de São Carlos, Universidade de São Paulo, São Carlos, 2003.

O trabalho trata da formulação e implementação numérica de um modelo de dano para o concreto. O objetivo é o de reproduzir laços de histerese observados experimentalmente em diagramas de tensão-deformação uniaxiais quando, a partir de um certo nível de solicitação, e dano correspondente, passam-se a realizar ciclos de descarregamento e recarregamento. $\mathrm{O}$ modelo propõe que os laços de histerese resultam da dissipação conjunta decorrente do dano evolutivo e do fenômeno de fricção interna nas faces das fissuras. $\mathrm{O}$ fenômeno de fricção interna está relacionado à suposição de que as fissuras não se abrem simplesmente por separação formando faces com superfícies lisas, mas tendem a combinar modos de separação e deslizamento segundo superfícies com uma certa rugosidade. $\mathrm{O}$ deslizamento entre as faces das fissuras dá origem a uma deformação por escorregamento, assumida como responsável por um comportamento plástico com encruamento cinemático não-linear. A abordagem termodinâmica considerada no sentido de contemplar a danificação e a fricção interna leva à dedução de que a tensão total num ponto do meio com dano resulta dividida em uma parcela dita tensão elastodanificada e em uma outra denominada tensão de escorregamento, também dependente do nível de danificação da estrutura. Dois tipos básicos de aplicações são realizadas: as primeiras visam avaliar a influência das variáveis de estado e dos parâmetros do material na forma dos diagramas de tensão-deformação. As outras aplicações são dedicadas à utilização do modelo na análise do comportamento dinâmico de uma viga em concreto armado submetida à vibração forçada. Destaca-se o efeito dos laços de histerese sobre o amortecimento estrutural. Mostra-se que a utilização deste modelo de dano leva à geração de um amortecimento estrutural que com os modelos de dano usuais somente poderia ser obtido a partir da utilização do modelo de amortecimento de Rayleigh, por exemplo, na equação do movimento.

PALAVRAS-CHAVE: Análise dinâmica não-linear, amortecimento histerético, dano, deslizamento com fricção. 


\section{ABSTRACT}

ARAÚJO, F. A. (2003). Contribution to the application of Damage Mechanics in nonlinear dynamic behaviour analysis of reinforced concrete beams. Dissertação (Mestrado) - Escola de Engenharia de São Carlos, Universidade de São Paulo, São Carlos, 2003.

This work deals with numerical formulation and implementation of a damage model to concrete. The aim is to reproduce hysteresis loops observed experimentally in uniaxial stress-strain diagram when cycles of unloading and reloading are produced. The model proposes that the hysteresis loops are due to the coupling between the dissipation of damage process and the internal friction phenomenon between the faces of crack lips. The phenomenon of internal friction is related to the supposition that the crack doesn't open itself by separation mode creating plane lips, but there is a tendency to combine opening and sliding modes across irregular surfaces. The sliding between the crack surfaces generates a sliding strain, which is assumed as responsible by a plastic behaviour with non-linear kinematics hardening. The thermodynamic approach considering damage and internal friction leads to the deduction that the total stress at a point is composted by one component named elasto-damage stress and another named sliding stress, both dependent of the structure damage level. Two basic kinds of simulation are performed: the first one aims to evaluate the influence of the state variables and the material parameters over the stress-strain diagrams. The following simulations are dedicated to the use of the model in dynamic analysis of a reinforced concrete beam subjected to vibration. It is emphasized the effect of the structural damping from hysteresis loops. It is showed that the present damage model generates structural damping that could only be obtained with conventional damage model by using the Rayleigh damping approach in the equation of motion.

KEY WORDS: Non-linear dynamic analysis, hysteretic damping, damage, sliding with friction. 


\section{LISTA DE SÍMBOLOS}

$\mathrm{a}=$ parâmetro característico do material;

$\mathrm{A}_{0}=$ área da configuração indeformada sem dano;

$\overline{\mathrm{A}}_{0}=$ área de aplicação das forças prescritas;

$\widetilde{\mathrm{A}}=$ área efetiva resistente;

$\mathrm{A}_{\mathrm{D}}=$ área dos defeitos;

$\mathrm{A}_{\mathrm{T}}, \mathrm{A}_{\mathrm{C}}=$ parâmetros característicos do material na tração e na compressão, respectivamente;

$\mathrm{b}=$ parâmetro característico do material;

$\underline{\mathrm{B}}=$ correspondência entre deslocamento e deformação;

$\mathrm{B}_{\mathrm{T}}, \mathrm{B}_{\mathrm{C}}=$ parâmetros característicos do material na tração e na compressão, respectivamente;

$\mathrm{B}_{1}, \mathrm{~B}_{2}=$ parâmetros característicos do material na tração e na compressão, respectivamente;

$\mathrm{b}_{\mathrm{s}}=$ largura do estrato;

$\overline{\mathrm{b}}_{0}=$ força distribuída por unidade de volume;

$\mathrm{c}=$ parâmetro característico do material;

$\underline{\mathrm{C}}=$ matriz de amortecimento viscoso;

$\mathrm{d}=$ dano escalar;

$\mathrm{d}_{\mathrm{e}}=$ deslocamento;

$\dot{\mathrm{d}}_{\mathrm{e}}=$ velocidade;

$\ddot{\mathrm{d}}_{\mathrm{e}}=$ aceleração;

$\mathrm{d}_{\mathrm{n}}=$ dano associado à direção $\mathrm{n}$;

$\mathrm{d}_{\mathrm{n}}^{*}=$ dano associado à direção $\mathrm{n}$ relacionado à variação de comprimento; 
$\mathrm{d}_{\mathrm{T}}, \mathrm{d}_{\mathrm{C}}=$ variáveis de dano em tração e em compressão, respectivamente;

$\mathrm{d}_{1}, \mathrm{~d}_{2}=$ variáveis de dano em tração e em compressão, respectivamente;

$\underline{\underline{D}}=$ tensor módulo de rigidez;

$\underline{\underline{\mathrm{D}}}_{0}=$ tensor módulo elástico de rigidez;

$\underline{\underline{D}}(\mathrm{~d})=$ tensor módulo de rigidez danificado;

$\mathrm{E}=$ módulo de elasticidade do material íntegro;

$\widetilde{\mathrm{E}}=$ módulo secante de rigidez elástica do meio danificado;

$\mathrm{E}_{\mathrm{c}}=$ módulo de Young do concreto;

$\mathrm{E}_{\mathrm{s}}=$ módulo de Young do aço;

$\mathrm{E}_{\mathrm{st}}=$ módulo de Young do aço durante o encruamento;

$\mathrm{F}=$ força;

$\mathrm{f}(\hat{\varepsilon}, \mathrm{d})=$ critério de danificação;

$\mathrm{f}(\operatorname{Tr}(\underline{\sigma}))=$ função para fechamento e abertura das fissuras;

$\bar{f}_{i}=$ forças concentradas;

$\mathrm{F}^{\mathrm{ext}}=$ vetor das forças externas;

$\mathrm{F}^{\mathrm{int}}=$ vetor das forças internas;

$\mathrm{f}_{\mathrm{s}}=$ critério de escorregamento;

$\mathrm{f}_{\mathrm{y}}=$ tensão de início de encruamento do aço;

$\mathrm{G}_{1}, \mathrm{G}_{2}=$ funções de encruamento em tração e em compressão, respectivamente;

$\mathrm{H}=$ módulo de encruamento cinemático;

$\mathrm{I}=$ tensor identidade;

$\underline{\mathrm{K}}_{0}=$ matriz de rigidez elástica;

$\underline{K}(d)=$ matriz de rigidez danificada;

$\ell_{0}=$ comprimento indeformado; 
$\underline{\mathrm{M}}=$ matriz de massa;

$\mathbf{n}=$ versor normal;

n = número de estratos na seção;

$\mathrm{nc}=$ número de forças concentradas prescritas;

$\mathrm{P}=$ força prescrita;

$\mathrm{q}=$ vetor dos deslocamentos nodais;

$\dot{\mathrm{q}}=$ vetor das velocidades nodais;

$\ddot{\mathrm{q}}=$ vetor das acelerações nodais;

$\mathrm{r}_{\mathrm{o}}=$ resíduo de forças;

$\mathrm{S}=$ tensor de Piola-Kirchhoff de $2^{\mathrm{a}}$ espécie;

$\mathrm{s}(\mathrm{d})=$ máximo da deformação equivalente a partir de $\hat{\varepsilon}>\varepsilon_{\mathrm{do}}$;

$\operatorname{sign}()=$. operador sinal;

$\mathrm{t}=$ variável de tempo;

$\operatorname{Tr}(\underline{\sigma})=$ primeiro invariante do tensor de tensões;

$\overline{\mathrm{t}}_{0}=$ força por unidade de área;

$\mathrm{V}_{\mathrm{D}}=$ volume da parte danificada;

$\mathrm{V}_{0}=$ volume na configuração indeformada;

$\mathrm{x}=$ variável local de integração;

$X=$ tensão de encruamento;

$\mathrm{X}_{\infty}=$ valor assintótico da tensão de encruamento;

y = variável local de integração;

$Y_{1}, Y_{2}=$ variáveis associadas a $d_{1}$ e $d_{2}$, respectivamente;

$\mathrm{Y}=$ variável associada $\mathrm{a}$;

$\mathrm{Y}_{01}, \mathrm{Y}_{02}=$ variáveis que definem o início da danificação em tração e em compressão, respectivamente; 
$\mathrm{z}_{1}, \mathrm{z}_{2}=$ medidas de dano acumulados em tração e em compressão, respectivamente;

$Z_{1}, Z_{2}=$ variáveis associadas a $z_{1}$ e $z_{2}$, respectivamente;

$\alpha=$ variável associada ao encruamento;

$\alpha_{T}, \alpha_{C}=$ coeficientes de dano na tração e na compressão, respectivamente;

$\alpha_{1}, \alpha_{2}=$ variáveis relacionadas ao dano na tração e na compressão, respectivamente;

$\beta_{1}, \beta_{2}=$ parâmetros característicos relacionados a deformações anelásticas em tração e em compressão, respectivamente;

$\chi=$ energia livre de Gibbs;

$\delta \mathrm{d}_{\mathrm{e}}=$ deslocamento virtual;

$\delta \varepsilon=$ tensor de deformação virtual;

$\Delta_{\mathrm{d}}=$ variação de comprimento associado aos defeitos internos;

$\Delta \ell=$ variação do comprimento;

$\Delta \varepsilon=$ variação da deformação;

$\Delta \lambda=$ multiplicador plástico em passo finito;

$\varepsilon=$ deformação linear nominal;

$\widetilde{\varepsilon}=$ deformação linear efetiva;

$\hat{\varepsilon}=$ deformação equivalente;

$\varepsilon_{\mathrm{do}}=$ deformação correspondente ao pico de tração;

$\varepsilon_{\mathrm{i}}=$ componentes de deformação principal;

$\underline{\varepsilon}=$ tensor total de deformação;

$\underline{\varepsilon}_{\text {an }}=$ parte anelástica do tensor de deformação;

$\underline{\varepsilon}_{\mathrm{e}}=$ parte elástica do tensor de deformação;

$\varepsilon_{\mathrm{s}}=$ deformação de escorregamento;

$\varepsilon_{\mathrm{s}}^{\mathrm{en}}=$ deformação de escorregamento em um ponto na envoltória de carregamento; 
$\varepsilon_{\mathrm{s}}^{+}=$variação total da deformação de escorregamento na etapa de recarregamento;

$\varepsilon_{\mathrm{s}}^{-}=$variação total da deformação de escorregamento na etapa de descarregamento;

$\phi_{\mathrm{i}}=$ autovetores;

$\gamma_{\mathrm{c}}=$ peso específico do concreto;

$\gamma_{\mathrm{s}}=$ peso específico do aço;

$\underline{\varphi}=$ matriz das funções de forma e suas derivadas;

$\lambda_{\mathrm{m}}=$ constante de proporcionalidade da massa no modelo de Rayleigh;

$\lambda_{\mathrm{k}}=$ constante de proporcionalidade da rigidez no modelo de Rayleigh;

$\dot{\lambda}=$ multiplicador plástico;

$\mu=$ coeficiente de amortecimento viscoso;

$v=$ coeficiente de Poisson do material íntegro;

$\rho=$ massa específica;

$\sigma=$ tensão nominal;

$\widetilde{\sigma}=$ tensão efetiva;

$\sigma_{\mathrm{d}}=$ tensão elasto-danificada;

$\sigma_{\mathrm{f}}=$ tensão de fechamento das fissuras;

$\sigma_{\mathrm{s}}=$ tensão de escorregamento;

$\sigma_{\mathrm{t}}=$ tensão de pico na tração;

$\sigma_{y}=$ tensão de referência no escorregamento;

$\langle\underline{\sigma}\rangle_{+},\langle\underline{\sigma}\rangle_{-}=$partes positiva e negativa do tensor de tensão, respectivamente;

$\omega_{\mathrm{i}}=$ freqüências naturais de vibração;

$\xi_{\mathrm{i}}=$ frações do amortecimento crítico;

$\psi=$ energia específica livre de Helmholtz; 
SUMÁRIO

RESUMO

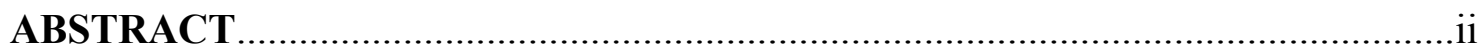

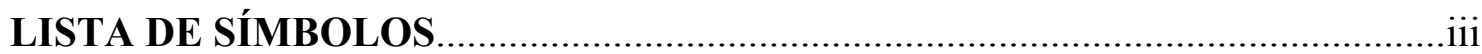

1 INTRODUÇÃO

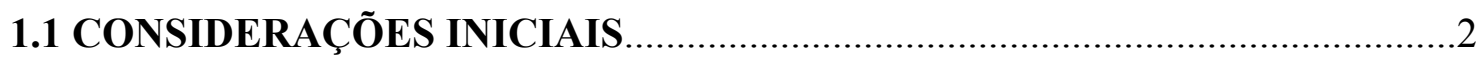

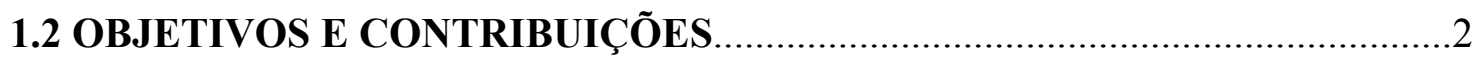

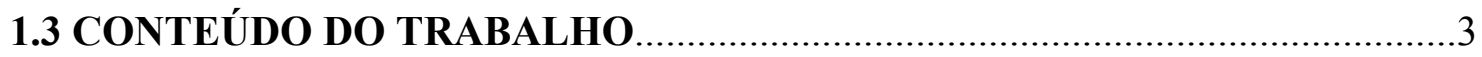

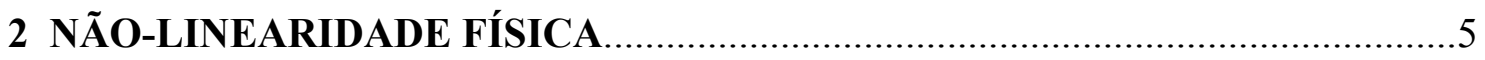

2.1 INTRODUÇÃO

2.2 ELEMENTOS DA MECÂNICA DO DANO_......................................................

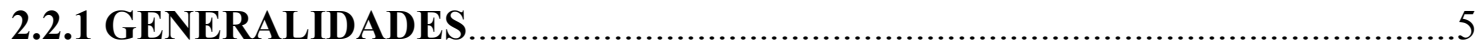

2.2.2 DEFINIÇÃO DO ELEMENTO DE VOLUME REPRESENTATIVO..............7

2.2.3 DEFINIÇÃO DA VARIÁVEL DE DANO E DA TENSÃO EFETIVA.............7

2.2.4 DEFINIÇÃO DA DEFORMAÇÃO EFETIVA..............................................

2.2.5 PRINCÍPIOS GERAIS DE EQUIVALÊNCIA DE RESPOSTAS

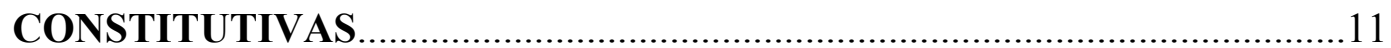

2.2.5.1 RELAÇÕES CONSTITUTIVAS ENVOLVENDO EQUIVALÊNCIA DE

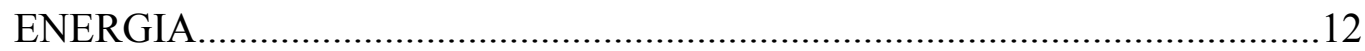

2.2.5.2 RELAÇÕES CONSTITUTIVAS ENVOLVENDO EQUIVALÊNCIA DE

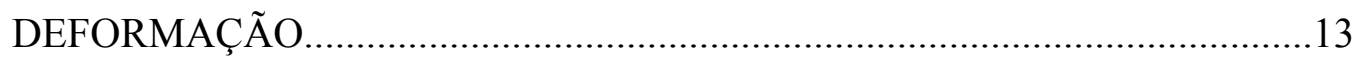

2.2.5.3 RELAÇÕES CONSTITUTIVAS ENVOLVENDO EQUIVALÊNCIA DE

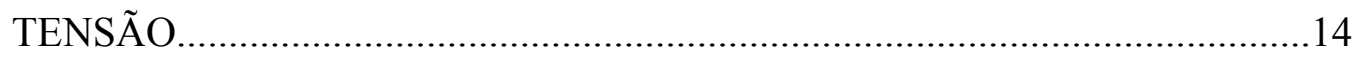

2.2.6 MODELO CONSTITUTIVO DE MAZARS (1984)....................................... 
2.2.7 MODELO CONSTITUTIVO DE LA BORDERIE (1991)............................17

2.3 ANÁLISE DINÂMICA COM NÃO-LINEARIDADE FÍSICA.........................22

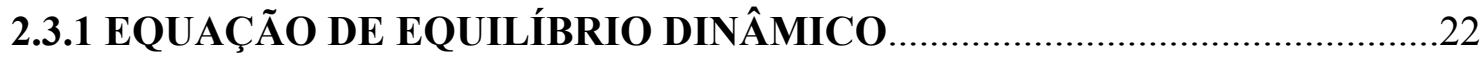

2.3.2 FORMA APROXIMADA PELO MÉTODO DOS ELEMENTOS FINITOS

2.4 INTEGRAÇÃO NUMÉRICA NA SEÇÃO TRANSVERSAL ..........................28

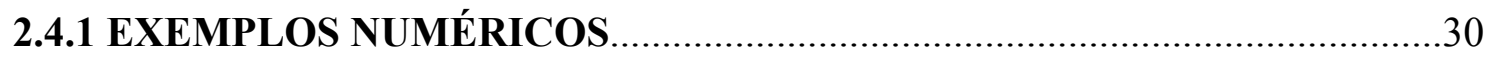

3 ANÁLISE CRÍTICA DO MODELO DE MAZARS ET AL. (2000).....................33

3.1 INTRODUÇÃ

3.2 TERMODINÂMICA DOS SÓLIDOS: CONSIDERAÇÕES GERAIS..............34

3.3 ESTRUTURA TERMODINÂMICA DE ACORDO COM O MÉTODO DO

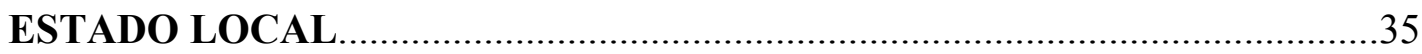

3.4 CRITÉRIOS DE DANO, ESCORREGAMENTO E LEIS DE EVOLUÇÃO

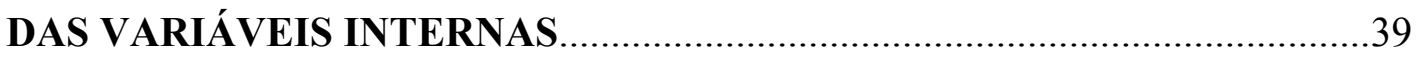

3.5 REALIZAÇÃO DO LAÇO DE HISTERESE..............................................42

3.6 IMPLEMENTAÇÃO PARA O CASO UNIDIMENSIONAL .............................46

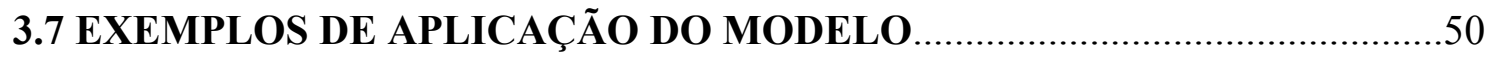

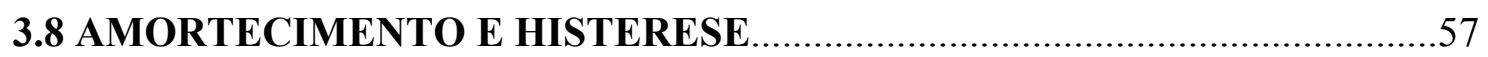

3.9 PROPOSTA PARA A INVERSÃO DO CARREGAMENTO ...........................59

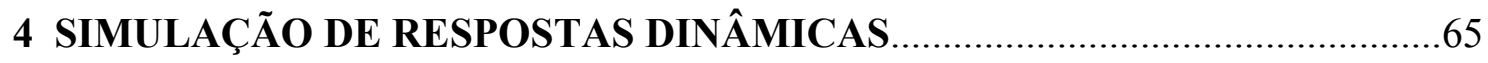

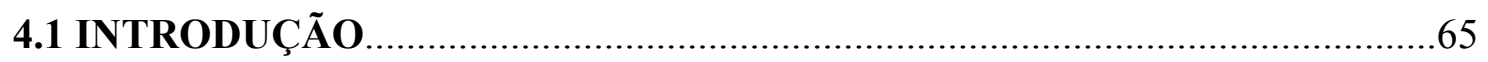

4.2 INTEGRAÇÃO NO DOMÍNIO DO TEMPO..................................................66

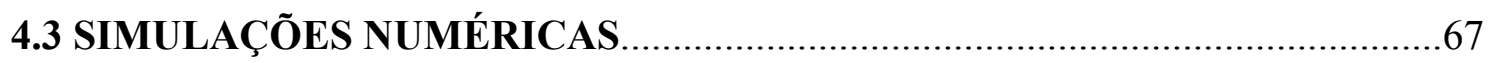

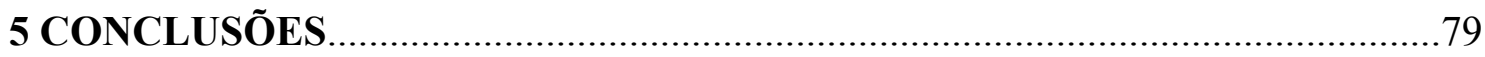




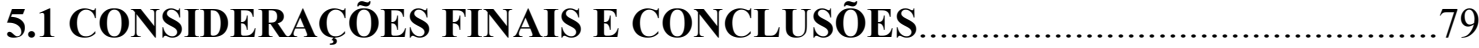

5.2 SUGESTÕES PARA TRABALHOS FUTUROS................................................

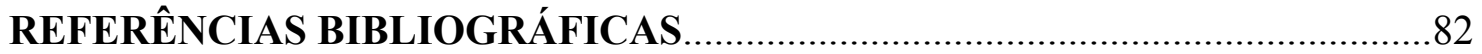




\section{INTRODUÇÃO}

\subsection{CONSIDERAÇÕES INICIAIS}

O estudo das respostas não-lineares dos materiais tem se desenvolvido a cada dia pela busca de modelos mecânico-matemáticos que sejam capazes de simular com melhor precisão tal comportamento. Nesse sentido a Mecânica do Dano é uma ferramenta de grande interesse pois possibilita a consideração dos efeitos da microfissuração difusa sobre a degradação das propriedades mecânicas do material. Pode-se colocar em destaque alguns trabalhos que tratam da formulação da Mecânica do Dano em meios contínuos e sua aplicação a diferentes materiais, e que são de maior interesse para este trabalho: MAZARS (1984), LEMAITRE \& CHABOCHE (1985), LA BORDERIE (1991), LEMAITRE (1992), CHABOCHE (1998a, b), MAZARS et al. (2000), RANGUENEAU et al. (2000) e PAULA \& PROENÇA (2001).

No âmbito da EESC-USP pesquisas têm sido desenvolvidas com relação ao emprego e mesmo à formulação de modelos de dano, destacando-se: ÁLVARES (1993), DRIEMEIER (1995), BOTTA (1998), BALBO (1998), PITUBA (1998), ÁLVARES (1999), DRIEMEIER (1999), NEVES (2000), PAULA (2001) e PITUBA (2003).

O âmbito no qual se insere os recentes desenvolvimentos no tema pode ser melhor caracterizado pela seguinte citação: "Diante do aperfeiçoamento alcançado pelos modelos mecânico-matemáticos que permitem simular numericamente o comportamento estrutural estático não-linear físico e geométrico, nos dias de hoje a atenção na análise estrutural tem se voltado progressivamente para a extensão do estudo para a simulação da resposta dinâmica em campo não-linear”, PAULA (2001). 
No caso da análise dinâmica não-linear um aspecto de interesse é a simulação do amortecimento estrutural por efeito da danificação. Nesse particular, existem divergências quanto à utilização do modelo de Rayleigh para a consideração do amortecimento. Em MAZARS et al. (2000) defende-se que uma aproximação mais realista pode resultar de uma melhor modelagem da dissipação interna. Alega-se, naquela referência, que recentes experimentos em estruturas de concreto armado submetidas a carregamento sísmico conduzem a um entendimento mais claro da forte interação entre estado de ruína e o resultado do amortecimento global. Naquele trabalho propõe-se o desenvolvimento de um modelo de dano capaz de levar em conta a dissipação de energia, em um determinado nível de dano, que ocorre devido ao atrito por deslizamento entre as superfícies das fissuras. Este modelo permite que se leve em conta os laços de histerese, uma característica do concreto quando submetido a carregamento cíclico e de grande importância para a simulação da resposta dinâmica de estruturas.

\subsection{OBJETIVOS E CONTRIBUIÇÕES}

O presente trabalho insere-se no tema da análise dinâmica de estruturas reticulares planas em concreto armado considerando-se a não-linearidade física do concreto através da utilização de modelos matemáticos de dano. Tem-se por objetivo, estender o estudo desenvolvido por PAULA (2001) para a análise não-linear física de pórticos planos em concreto armado, introduzindo um novo modelo de dano que permite reproduzir laços de histerese, bem como fazendo implementações adicionais no programa fonte resultante de seu trabalho.

O trabalho de PAULA (2001) trata da análise não-linear física e geométrica de pórticos planos em concreto armado. O concreto é modelado via mecânica do dano e as análises incluem regimes de comportamento estático e dinâmico. $\mathrm{Na}$ aplicação do método dos elementos finitos, a geração da matriz de rigidez do elemento de barra é feita pela combinação das técnicas de integração que envolvem regras de quadratura e discretização dos elementos em camadas ao longo da altura.

Entre as implementações adicionais, uma primeira contribuição consiste em possibilitar a consideração de seções transversais diferentes da retangular, tais como 
seções em forma de "I" ou "T", discretizadas via a utilização de elementos finitos de barras com múltiplas camadas ao longo da altura. Além disso, o módulo de elasticidade penalizado pelo dano pode apresentar variação linear em cada camada. Esta última consideração tem a vantagem de possibilitar uma melhor aproximação permitindo uma diminuição no número de camadas utilizadas na discretização da seção transversal da estrutura.

Posteriormente, desenvolve-se uma proposta unidimensional para um novo modelo de dano contínuo para o concreto proposto originalmente por MAZARS et al. (2000), com vistas à simulação mais consistente de processos de amortecimento. Tal modelo permite reproduzir laços de histerese no concreto submetido a ciclos de descarga e recarga.

Por fim, implementa-se a proposta unidimensional, para o modelo estudado, no programa desenvolvido por PAULA (2001) para a realização de análises dinâmicas. Essas análises visam confrontar o amortecimento obtido devido à reprodução do comportamento de histerese do concreto com o amortecimento obtido utilizando-se o modelo de amortecimento viscoso de Rayleigh.

\subsection{CONTEÚDO DO TRABALHO}

O conteúdo deste trabalho se encontra organizado como se segue:

No capítulo 2 apresentam-se as bases da Mecânica do Dano e da formulação desenvolvida por PAULA (2001) para a realização da análise não-linear física de estruturas reticulares planas em concreto armado. Inicialmente são apresentados alguns conceitos básicos da Mecânica do Dano no contínuo, tais como: elemento de volume representativo do meio danificado, variável de dano, tensão e deformação efetivas, e os princípios gerais de equivalência das respostas constitutivas dos meios real danificado e contínuo idealizado. Posteriormente são apresentados os modelos de dano de MAZARS (1984) e LA BORDERIE (1991), utilizados por PAULA (2001) para a simulação do comportamento não-linear físico do concreto, e que contém características de interesse para o confronto com o modelo considerado neste trabalho. Apresenta-se então a formulação do equilíbrio dinâmico baseado no Princípio dos Trabalhos Virtuais segundo uma descrição lagrangiana total e a forma aproximada para a consideração 
dessa equação de equilíbrio a partir da aplicação do método dos elementos finitos. Finalmente descreve-se o procedimento empregado para a utilização do elemento finito de barra com múltiplas camadas retangulares e a comparação de resultados experimentais com resultados numéricos para o caso do estudo de vigas com seção simétrica em "I" submetidas a carregamento estático.

$\mathrm{O}$ capítulo 3 relaciona-se, essencialmente, à proposta unidimensional para o modelo de dano de MAZARS et al. (2000). Inicialmente, ilustra-se, simplificadamente, o modelo com uma idéia geral de sua concepção. Posteriormente discutem-se alguns aspectos gerais da Termodinâmica dos Sólidos com o objetivo de facilitar o entendimento da formulação deste modelo, baseada no método do estado local. Apresenta-se, então, a estrutura termodinâmica do modelo, dando-se ênfase à obtenção das relações entre as variáveis de estado, assim como à realização dos laços de histerese, a partir do equacionamento apresentado. Finalmente, explicita-se o algorítimo utilizado na integração das relações constitutivas e realizam-se aplicações para reproduzir os laços de histerese. Adicionalmente, analisa-se a relação amortecimento-laços de histerese e propõe-se uma estratégia simplificada para considerar a possível inversão do sinal do carregamento em aplicações dinâmicas.

No capítulo 4 avalia-se o desempenho da proposta unidimensional para o modelo de MAZARS et al. (2000), desenvolvida neste trabalho, mediante um estudo comparativo entre as respostas dinâmicas com ele obtidas e as respostas disponibilizadas por PAULA (2001) para o caso da vibração forçada de uma viga em concreto armado. No trabalho de PAULA (2001) o amortecimento é simulado pela combinação do modelo de MAZARS (1984) e amortecimento de Rayleigh. Apresentam-se curvas de carga versus deslocamento do ponto central da viga analisando-se a influência do amortecimento por histerese e do amortecimento viscoso de Rayleigh. Finalmente, destaca-se uma avaliação da influência da abertura dos laços de histerese sobre o amortecimento apresentado pela estrutura.

No capítulo 5 são apresentadas as considerações finais, conclusões obtidas e sugestões para trabalhos futuros. 


\subsection{INTRODUÇÃO}

Neste capítulo tem-se por objetivo apresentar as bases da Mecânica do Dano e da formulação desenvolvida por PAULA (2001) para a realização da análise não-linear física de estruturas reticuladas planas em concreto armado. Nesse particular, será adotada aqui uma abordagem bastante resumida tendo-se em vista que detalhes complementares encontram-se naquela referência. O texto apresentado neste capítulo está principalmente baseado em ÁLVARES (1993), MAZARS et al. (2000), PAULA (2001), PITUBA (1998) e reproduz em parte, com algumas adaptações, os trabalhos de PAULA \& PROENÇA (2001) e PROENÇA (2000). Por fim, apresenta-se como contribuição, à utilização de elementos finitos de barra com múltiplas camadas.

\subsection{ELEMENTOS DA MECÂNICA DO DANO}

\subsubsection{GENERALIDADES}

A resposta não-linear dos sólidos, observada macroscopicamente, é uma manifestação de processos irreversíveis que ocorrem em sua microestrutura, tais como: escorregamentos relativos entre cristais, perdas de coesão em planos de clivagem ou contornos dos grãos, mudanças de porosidade, mudanças de fase, difusão de elementos químicos e outros. 
A mecânica do dano em meios contínuos leva em conta os efeitos da degradação, em modo difuso e progressivo, de sólidos submetidos a ações de natureza mecânicas ou não-mecânicas, por meio de redução das propriedades de resistência e rigidez do material. É importante notar desde logo a diferença em relação à Mecânica da Fratura.

Enquanto que a Mecânica da Fratura lida com as condições de propagação de uma fratura macroscópica imersa num meio contínuo íntegro, a Mecânica do Dano se ocupa do efeito, sobre a resposta material, de um processo de microfissuração distribuída que se desenvolve numa etapa preliminar à formação da fissura discreta. Essa teoria permite descrever localmente, com base num elemento de 'volume representativo' de material em torno do ponto considerado, a evolução dos fenômenos que se desenvolvem entre um estado inicial, relativo a uma situação de material íntegro, e um estado final, caracterizado pela formação de uma fissura macroscópica, que equivale à ruptura do elemento de volume.

Em síntese, a diferença entre Mecânica do Dano e Mecânica da Fratura pode ser colocada, segundo JANSON \& HULT (1977), da seguinte forma (ver figura 2.1):

- Na Mecânica do Dano a resistência de uma estrutura carregada é determinada em função da evolução de um campo de defeitos (microfissuras ou poros) considerado continuamente distribuído;

- Na Mecânica da Fratura a resistência de uma estrutura carregada é determinada em função da evolução de um único defeito, como uma fissura pontiaguda pré-definida, num meio mecanicamente intacto.
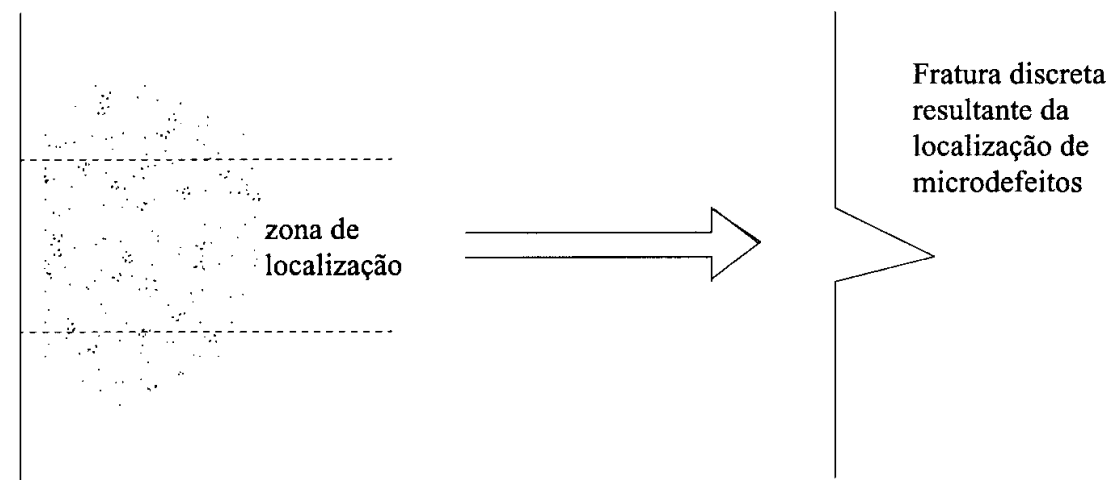

Figura 2.1 - Processo de transição entre dano e fratura, DRIEMEIER (1995) 
A Mecânica do Dano em meio contínuo teve origem em proposta de penalização da rigidez originalmente introduzida por KACHANOV em 1958. Segundo essa teoria, as equações constitutivas são escritas incluindo-se uma variável, a variável de dano, que quantifica o processo de deterioração numa etapa preliminar a formação das fissuras.

\subsubsection{DEFINIÇÃO DE ELEMENTO DE VOLUME REPRESENTATIVO}

Considere-se um sólido com defeitos em sua microestrutura. Um elemento de volume representativo de material em torno de um ponto considerado, possui dimensões suficientemente grandes para que se possa admitir a continuidade e a homogeneidade para a distribuição dos defeitos nele contido. Mas ao mesmo tempo suficientemente pequenas para que se evitem gradientes elevados das grandezas locais de interesse, como a deformação. Dessa forma, pode-se admitir continuidade para as funções representativas dos fenômenos que ocorrem no elemento e as propriedades nele são valores médios que podem ser associados ao ponto material a que ele se refere.

Na figura 2.2 ilustra-se o conceito de elemento de volume representativo em torno de um ponto do meio, orientado a partir de um versor normal de direção n.

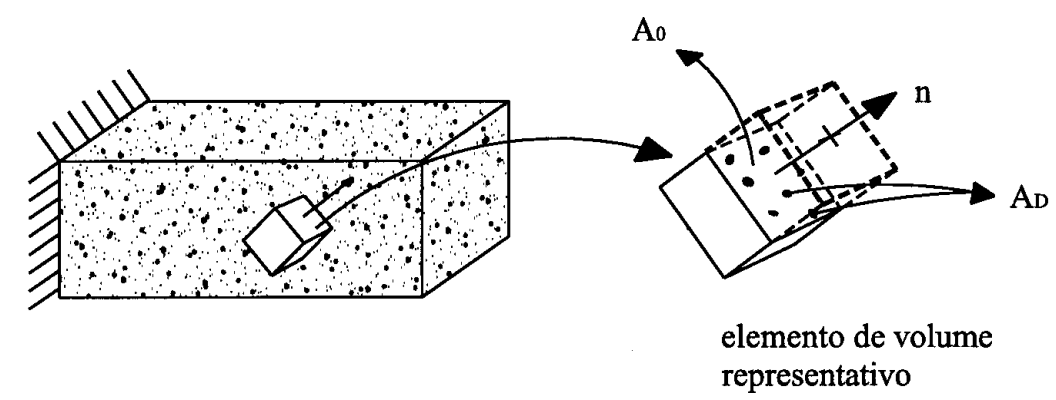

Figura 2.2 - Elemento de volume representativo, adaptado de PAULA (2001)

\subsubsection{DEFINIÇÃO DA VARIÁVEL DE DANO E DA TENSÃO EFETIVA}

Considere-se uma situação de solicitação uniaxial sobre o elemento de volume definido no item anterior, constituída por forças $\mathrm{F}$ aplicadas nas faces opostas entre se e 
com normais paralelas ao versor $\mathbf{n}$. Seja $\mathrm{A}_{0}$ a área nominal da seção transversal média de normal $\mathbf{n}$ no interior do elemento (ver figura 2.2). Nessas condições, $\sigma=F / A_{0}$ é a tensão nominal em qualquer ponto da seção considerada.

Admitindo-se que o conjunto de defeitos seja totalmente incapaz de transferir tensões, pode-se definir uma tensão dita efetiva levando-se em conta somente a parte íntegra da seção do elemento representativo. Nesse sentido, seja Ã a parcela íntegra da área total considerada. Então a diferença:

$$
\mathrm{A}_{\mathrm{D}}=\mathrm{A}_{0}-\widetilde{\mathrm{A}}
$$

define a área dos defeitos $A_{D}$.

Por definição, LEMAITRE \& CHABOCHE (1985) e LEMAITRE (1992), o dano $d_{n}$, no caso associado a um plano de normal $\mathbf{n}$, fica definido pela relação:

$$
\mathrm{d}_{\mathrm{n}}=\frac{\mathrm{A}_{\mathrm{D}}}{\mathrm{A}_{0}}
$$

Nota-se que a variável de dano assume valores contidos no intervalo $0 \leq \mathrm{d}_{\mathrm{n}} \leq 1$, sendo que $d_{n}=0$ tem correspondência com a situação de material íntegro e $d_{n}=1$ indica um estado de total deterioração.

Assim sendo, a parcela de seção efetivamente resistente pode ser expressa em função da variável de dano como:

$$
\widetilde{\mathrm{A}}=\mathrm{A}_{0}-\mathrm{A}_{\mathrm{D}}=\mathrm{A}_{0}\left(1-\mathrm{d}_{\mathrm{n}}\right)
$$

Dessa forma, a tensão efetiva $\widetilde{\sigma}$ é definida por:

$$
\widetilde{\sigma}=\frac{F}{\widetilde{A}}
$$

Levando-se em conta a relação (2.3) obtém-se a relação entre as tensões nominal e efetiva: 


$$
\widetilde{\sigma}=\frac{\sigma}{\left(1-d_{n}\right)}
$$

Como a área íntegra é menor do que a nominal, para uma mesma força aplicada a tensão efetiva num meio danificado resulta comparativamente maior do que a tensão nominal. Em particular, nota-se que:

$$
\begin{aligned}
& \tilde{\sigma}=\sigma \quad \text { para material localmente íntegro; } \\
& \tilde{\sigma} \rightarrow \infty \text { para material totalmente danificado localmente. }
\end{aligned}
$$

Nota-se que no mesmo ponto a variável $d_{n}$ pode assumir valores diferentes de acordo com a orientação da normal n. Essa característica indica uma natureza anisotrópica para a variável que representa o dano no elemento de volume.

O chamado dano escalar tem correspondência com uma situação em que os microdefeitos apresentam no elemento de volume uma distribuição mais ou menos uniforme, de modo que segundo qualquer plano a medida de dano resulta a mesma, ou seja, independentemente da normal $\mathbf{n}$. Em outras palavras, um único valor da variável de dano é suficiente para caracterizar completamente o estado local de deterioração.

$$
\mathrm{d}=\mathrm{d}_{\mathrm{n}} \forall \mathbf{n}
$$

\subsubsection{DEFINIÇÃO DA DEFORMAÇÃO EFETIVA}

Um conceito dual ao de tensão efetiva é o de deformação efetiva que também decorre da análise de uma situação de deformação uniaxial imposta ao elemento de volume orientado segundo uma certa direção definida pelo versor $\mathbf{n}$.

Seja, então, $\Delta \ell$ a variação do comprimento inicial $\ell_{0}$ por efeito da deformação imposta. A medida de deformação linear nominal é definida pela relação: 


$$
\varepsilon=\frac{\Delta \ell}{\ell_{0}}
$$

Entretanto, se o elemento de volume possui defeitos ou descontinuidades internas, elas se abrem de uma certa quantidade, que avaliadas em conjunto produzem uma variação de comprimento representada por $\Delta_{\mathrm{d}}$. Assim sendo, no processo de deformação do elemento, somente a parcela $\Delta \ell-\Delta_{\mathrm{d}}$ é que efetivamente tem correspondência com a deformação, ver figura 2.3 .

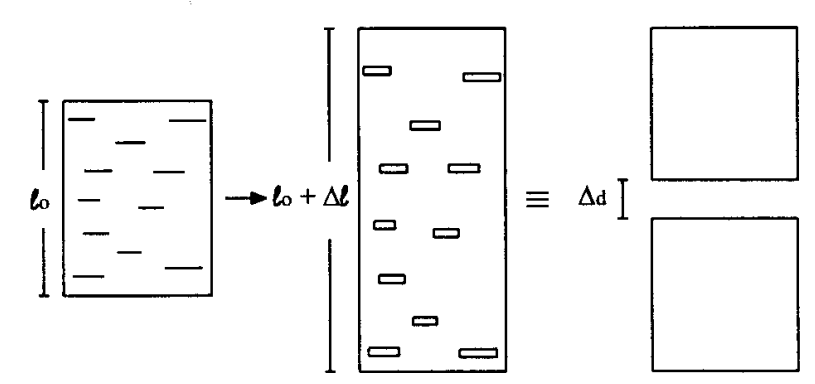

Figura 2.3 - Acréscimo de comprimento devido à abertura de defeitos, PROENÇA (2000)

Segue daí que a medida efetiva da deformação linear pode ser definida como:

$$
\widetilde{\varepsilon}=\frac{\Delta \ell-\Delta_{\mathrm{d}}}{\ell_{0}}
$$

Uma segunda definição para uma variável de dano pode então ser proposta:

$$
\mathrm{d}_{\mathrm{n}}^{*}=\frac{\Delta_{\mathrm{d}}}{\Delta \ell}
$$

Nota-se que essa definição é também associada a uma certa direção $\mathbf{n}$.

Levando-se em conta a nova variável de dano, as medidas nominal e efetiva da deformação linear se relacionam por:

$$
\widetilde{\varepsilon}=\left(1-d_{n}^{*}\right) \varepsilon
$$


As duas variáveis escalares de dano introduzidas pelas equações (2.2) e (2.9) podem ser unificadas se for considerado que o volume correspondente à parte danificada $\mathrm{V}_{\mathrm{D}}$ é o mesmo nos dois casos. Esta consideração é bastante lógica, pois se trata de uma situação de solicitação uniaxial sobre um mesmo volume, onde ora se analisa o equilíbrio das tensões ora a compatibilidade das deformações.

$$
\mathrm{V}_{\mathrm{D}}=\mathrm{A}_{\mathrm{D}} \Delta \ell=\mathrm{A}_{0} \Delta_{\mathrm{d}}
$$

Levando-se em conta as relações (2.2) e (2.9), segue que: $d_{n}=d_{n}^{*}$.

\subsubsection{PRINCÍPIOS GERAIS DE EQUIVALÊNCIA DE RESPOSTAS CONSTITUTIVAS}

Os princípios descritos a seguir permitem que se formulem relações constitutivas para meios contínuos com dano, envolvendo medidas nominais de tensão e de deformação.

No âmbito dos meios contínuos, um axioma constitutivo fundamental é o da ação local, isto é: a resposta constitutiva num ponto não depende daquilo que ocorre nos elementos vizinhos. Estendendo-se esse axioma ao meio com dano, resulta que a relação constitutiva para um ponto na parte íntegra não é afetada pelo dano, porém nessa parte é importante lembrar que devem ser consideradas a tensão efetiva e a deformação efetiva.

Assim sendo, pode-se estabelecer um princípio geral de equivalência da resposta constitutiva:

"A lei constitutiva do meio danificado é obtida da lei constitutiva do meio integro onde o tensor de tensão é substituído pelo tensor de tensão efetiva e o tensor linear de deformações pelo tensor de deformação efetiva”, PROENÇA (2000).

Restringindo-se a análise ainda ao caso uniaxial, e sendo o meio íntegro supostamente elástico linear, o princípio enunciado leva à seguinte relação:

$$
\widetilde{\sigma}=\mathrm{E} \widetilde{\varepsilon}
$$

onde E é o módulo de elasticidade do material íntegro. 


\subsubsection{RELAÇÕES CONSTITUTIVAS ENVOLVENDO EQUIVALÊNCIA DE ENERGIA}

Substituindo-se na relação (2.12) as relações que definem $\widetilde{\varepsilon}$ e $\widetilde{\sigma},(2.10)$ e (2.4) respectivamente, e já levando em conta a (2.6), segue que:

$$
\sigma=(1-d)^{2} E \varepsilon
$$

Essa última relação vale então para o meio contínuo equivalente e envolve quantidades nominais. Nota-se, por outro lado, que:

$$
\widetilde{\sigma} \widetilde{\varepsilon}=\sigma \varepsilon
$$

Portanto, pode-se afirmar que o meio contínuo equivalente reproduz a mesma quantidade de energia de deformação específica no meio danificado.

Por outro lado, observando-se a relação (2.13), pode-se definir o módulo secante de rigidez elástica $\widetilde{\mathrm{E}}$ do meio danificado como:

$$
\widetilde{\mathrm{E}}=(1-\mathrm{d})^{2} \mathrm{E}
$$

A relação anterior coloca em evidência a degradação do módulo de rigidez elástico inicial do material, causada pela danificação. Isolando-se a variável de dano obtém-se:

$$
d=1-\left(\frac{\widetilde{E}}{E}\right)^{\frac{1}{2}}
$$

Essa relação indica que é possível identificar os valores de dano com base em medidas experimentais do módulo secante de rigidez elástico em ensaios uniaxiais com deformação controlada, ver figura 2.4. 


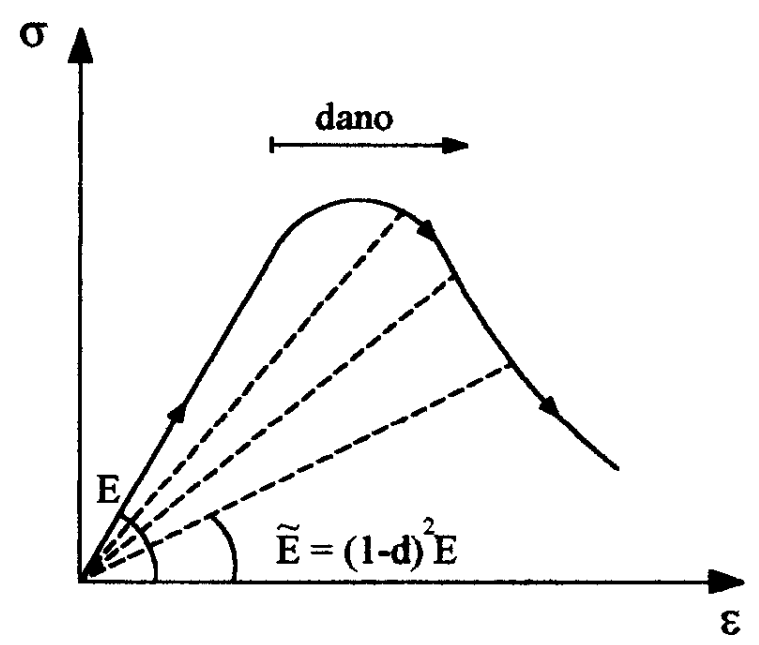

Figura 2.4 - Variação da rigidez secante do meio contínuo equivalente, PROENÇA (2000)

\subsubsection{RELAÇÃO CONSTITUTIVA ENVOLVENDO EQUIVALÊNCIA DE DEFORMAÇÃO}

O princípio da equivalência de deformação, proposto originalmente por LEMAITRE \& CHABOCHE (1985), diz que a deformação do meio íntegro onde atua a tensão efetiva é a mesma do meio danificado, ou seja: $\widetilde{\varepsilon}=\varepsilon$.

Esse princípio pode ser interpretado a partir da idéia de assimilar o meio, para fins da resposta unidimensional em estudo, como um arranjo de infinitas fibras em paralelo com resistências ligeiramente diferentes entre si, às quais se impõe uma mesma deformação. Em função das diferentes resistências as fibras vão progressivamente se rompendo, o que representa o processo de danificação.

Valendo o princípio, a relação (2.12) assume então a forma:

$$
\widetilde{\sigma}=\frac{\sigma}{(1-\mathrm{d})}=\mathrm{E} \varepsilon \quad \text { ou } \quad \sigma=(1-\mathrm{d}) \mathrm{E} \varepsilon
$$

A figura 2.5 dá uma interpretação ao princípio em questão: 


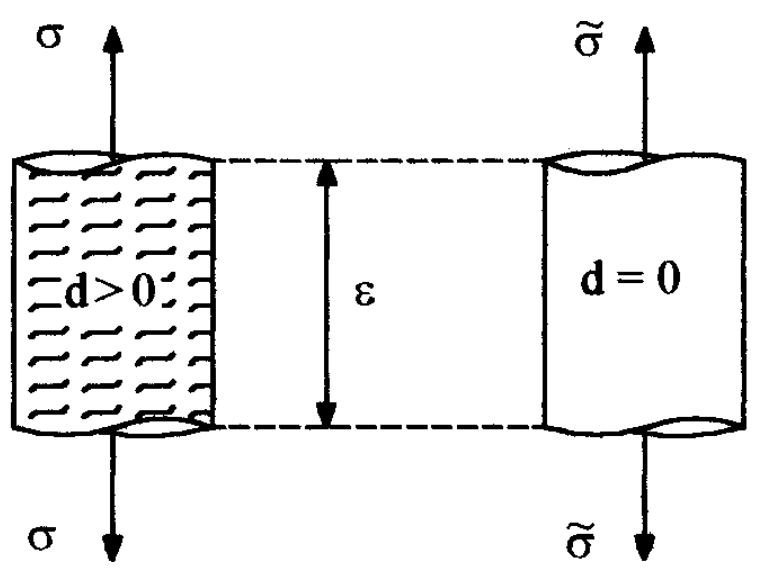

Figura 2.5 - Hipótese de deformação equivalente, adaptado de ÁLVARES (1993)

Dessa forma, o módulo secante de rigidez elástica $\widetilde{\mathrm{E}}$ para um meio contínuo de resposta equivalente ao meio deteriorado resulta:

$$
\widetilde{\mathrm{E}}=(1-\mathrm{d}) \mathrm{E}
$$

A partir da equação (2.18) pode-se identificar a variável de dano por:

$$
d=1-\left(\frac{\widetilde{E}}{E}\right)
$$

\subsubsection{RELAÇÃO CONSTITUTIVA ENVOLVENDO EQUIVALÊNCIA DE TENSÃO}

A forma dual da equivalência anterior consiste em admitir que a tensão do meio íntegro onde atua a deformação efetiva é a mesma do meio danificado, ou seja: $\widetilde{\sigma}=\sigma$. Uma justificativa para essa hipótese é a idealização do meio como um arranjo de estratos superpostos em série na direção do carregamento (sempre tendo-se em vista o caso unidimensional).

Com a nova hipótese de equivalência a relação (2.12) assume a forma: 


$$
\sigma=\mathrm{E} \widetilde{\varepsilon} \quad \text { ou } \quad \sigma=(1-\mathrm{d}) \mathrm{E} \varepsilon
$$

Segue que a variável de dano pode ser identificada por meio de uma relação idêntica à (2.19).

\subsubsection{MODELO CONSTITUTIVO DE MAZARS (1984)}

O modelo apresentado a seguir foi proposto originalmente por MAZARS (1984) e suas hipóteses fundamentais são:

- a influência da microfissuração devido ao carregamento externo é levada em conta mediante uma variável escalar variando de 0 para o material não danificado a 1 para o material completamente danificado;

- o dano decorre exclusivamente da existência de alongamentos;

- as deformações permanentes são desprezadas, sejam elas de natureza plástica, viscosa ou induzidas pelo próprio processo de danificação;

- o carregamento é proporcionalmente crescente.

A deformação equivalente é definida como:

$$
\hat{\varepsilon}=\sqrt{\sum_{\mathrm{i}}\left\langle\varepsilon_{\mathrm{i}}\right\rangle_{+}^{2}} \quad(\mathrm{i}=1, \ldots, 3)
$$

onde $\langle\bullet\rangle_{+}=\frac{1}{2}(\bullet+|\bullet|)$ e $\varepsilon_{\mathrm{i}}$ são componentes de deformação principais.

O critério de danificação é:

$$
f(\hat{\varepsilon}, d)=\hat{\varepsilon}-s(d) \leq 0
$$

onde $\mathrm{s}(\mathrm{d})$ define a evolução do dano, seu valor inicial é $\mathrm{s}(0)=\varepsilon_{\mathrm{do}}$, sendo $\varepsilon_{\mathrm{do}}$ a deformação correspondente ao pico de tensão do material submetido a tração uniaxial.

Durante o carregamento $s(d)$ assume o máximo valor da deformação equivalente alcançada durante toda a história de carregamento. 
A fim de representar a diferença da resposta mecânica do material em tração e em compressão, a variável de dano é composta por duas contribuições:

$$
\mathrm{d}=\alpha_{\mathrm{T}} \mathrm{d}_{\mathrm{T}}+\alpha_{\mathrm{C}} \mathrm{d}_{\mathrm{C}}
$$

onde $\mathrm{d}_{\mathrm{T}}$ e $\mathrm{d}_{\mathrm{C}}$ são as variáveis de dano em tração e em compressão respectivamente, $\alpha_{T}$ e $\alpha_{C}$ quantificam as contribuições aos alongamentos provocadas pelas parcelas de tração e compressão do estado de tensão.

Na Eq.(2.23), respeita-se sempre $\alpha_{T}+\alpha_{C}=1$, sendo, naturalmente, $\alpha_{T}=1$, $\alpha_{\mathrm{C}}=0$ para tração uniaxial e $\alpha_{\mathrm{C}}=1, \alpha_{\mathrm{T}}=0$ para compressão uniaxial. A determinação dos valores correspondentes a casos mais gerais pode ser encontrada em ÁLVARES (1993).

A evolução do dano, se o carregamento é proporcional, é definida pelas fórmulas:

$$
\begin{aligned}
& \mathrm{d}_{\mathrm{T}}(\hat{\varepsilon})=1-\frac{\varepsilon_{\mathrm{d} 0}\left(1-\mathrm{A}_{\mathrm{T}}\right)}{\hat{\varepsilon}}-\frac{\mathrm{A}_{\mathrm{T}}}{\exp \left[\mathrm{B}_{\mathrm{T}}\left(\hat{\varepsilon}-\varepsilon_{\mathrm{d} 0}\right)\right]} \\
& \mathrm{d}_{\mathrm{C}}(\hat{\varepsilon})=1-\frac{\varepsilon_{\mathrm{d} 0}\left(1-\mathrm{A}_{\mathrm{C}}\right)}{\hat{\varepsilon}}-\frac{\mathrm{A}_{\mathrm{C}}}{\exp \left[\mathrm{B}_{\mathrm{C}}\left(\hat{\varepsilon}-\varepsilon_{\mathrm{d} 0}\right)\right]}
\end{aligned}
$$

$\mathrm{Na}$ expressão (2.24) $\mathrm{A}_{\mathrm{T}}, \mathrm{B}_{\mathrm{T}}$ e $\varepsilon_{\mathrm{d} 0}$ são parâmetros característicos do material que podem ser identificados com base em resultados de ensaios de tração uniaxial com deformação controlada. Os parâmetros $\mathrm{A}_{\mathrm{C}}$ e $\mathrm{B}_{\mathrm{C}}$, que aparecem na (2.25), podem ser identificados a partir de resultados de ensaios de compressão uniaxial com deformação controlada, ÁLVARES (1993).

As figuras 2.6a e 2.6b mostram as respostas fornecidas pelo modelo nos casos da tração e da compressão uniaxiais, respectivamente. 


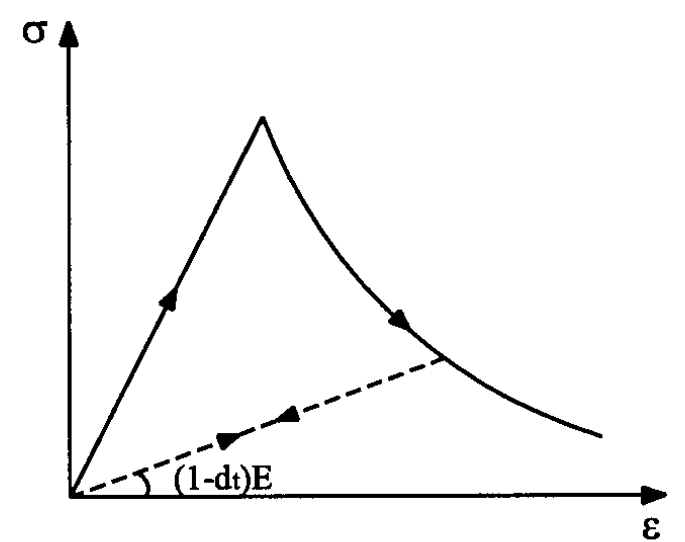

(a)

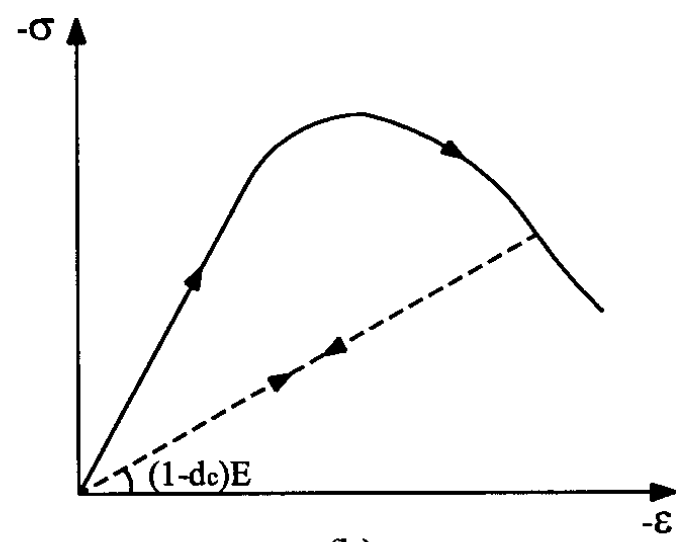

(b)

Figura 2.6 - Resposta uniaxial do modelo de MAZARS (1984): (a) tração, (b) compressão, adaptado de PITUBA (1998)

\subsubsection{MODELO CONSTITUTIVO DE LA BORDERIE (1991)}

Carregamentos dinâmicos que apresentam natureza cíclica, com ou sem inversão de sinal, geram respostas no concreto com características particulares. Nessas situações alguns dos fenômenos mais importantes que devem ser levados em conta são:

- diminuição da rigidez com a abertura das microfissuras;

- recuperação da rigidez com a ocorrência do fechamento das fissuras;

- deformação anelástica simultaneamente à danificação.

O modelo de Mazars proposto em (1984) não é capaz de levar em conta esses dois últimos pontos. Um modelo de danificação mais completo é o modelo de La Borderie proposto originalmente em (1991), este modelo permite a consideração de todos os fenômenos citados anteriormente.

Tendo-se em vista o aspecto unilateral, que se caracteriza pela recuperação da rigidez com o fechamento das fissuras, definem-se duas variáveis escalares de dano, representativas do dano em tração $\mathrm{d}_{1}$ e do dano em compressão $\mathrm{d}_{2}$. A ativação de um ou outro processo de danificação, por efeito do fechamento ou abertura de microfissuras, quando da inversão do processo de carregamento, é feita mediante um controle sobre o sinal das tensões principais. 
O potencial termodinâmico escolhido para derivar as relações de estado é a energia livre de Gibbs, a qual, como função de $\sigma$, é expressa como se segue:

$$
\begin{gathered}
\chi\left(\underline{\sigma}, \mathrm{d}_{1}, \mathrm{~d}_{2}, \mathrm{z}_{1}, \mathrm{z}_{2}\right)=\frac{\langle\underline{\sigma}\rangle_{+}:\langle\underline{\sigma}\rangle_{+}}{2 \mathrm{E}\left(1-\mathrm{d}_{1}\right)}+\frac{\langle\underline{\sigma}\rangle_{-}:\langle\underline{\sigma}\rangle_{-}}{2 \mathrm{E}\left(1-\mathrm{d}_{2}\right)}+\frac{v}{2 \mathrm{E}}\left(\underline{\sigma}: \underline{\sigma}-\operatorname{Tr}^{2}(\underline{\sigma})\right)+ \\
+\frac{\beta_{1} \mathrm{~d}_{1}}{\mathrm{E}\left(1-\mathrm{d}_{1}\right)} \mathrm{f}(\operatorname{Tr}(\underline{\sigma}))+\frac{\beta_{2} \mathrm{~d}_{2}}{\mathrm{E}\left(1-\mathrm{d}_{2}\right)} \operatorname{Tr}(\underline{\sigma})+\mathrm{G}_{1}\left(\mathrm{z}_{1}\right)+\mathrm{G}_{2}\left(\mathrm{z}_{2}\right)
\end{gathered}
$$

onde:

- $\langle\underline{\sigma}\rangle_{+}$é a parte positiva do tensor de tensão;

- $\langle\underline{\sigma}\rangle_{-}$é a parte negativa do tensor de tensão;

- $\operatorname{Tr}(\underline{\sigma})$ é o primeiro invariante do tensor de tensão;

- v é o coeficiente de Poisson do material virgem;

- E é o módulo de elasticidade do material íntegro;

- $\beta_{1}$ e $\beta_{2}$ são parâmetros a serem identificados, relacionados ao aparecimento de deformações anelásticas;

- $z_{1}$ e $z_{2}$ são as medidas de dano acumulado;

- $G_{1}\left(z_{1}\right)$ e $G_{2}\left(z_{2}\right)$ são funções de encruamento;

- $\sigma_{\mathrm{f}}$ é a tensão de fechamento das fissuras, parâmetro a ser identificado;

- $\mathrm{f}(\operatorname{Tr}(\underline{\sigma}))$ é a função que permite levar em conta a abertura e o fechamento de fissuras, ela assume diferentes expressões de acordo com a relação entre os valores de $\operatorname{Tr}(\underline{\sigma})$ e da tensão de fechamento de fissuras.

As expressões propostas para $\mathrm{f}(\operatorname{Tr}(\underline{\sigma}))$ são:

$$
\begin{array}{lrr}
\mathrm{f}(\operatorname{Tr}(\underline{\sigma}))=\operatorname{Tr}(\underline{\sigma}) \quad \text { quando } & \operatorname{Tr}(\underline{\sigma}) \in[0, \infty[ \\
\mathrm{f}(\operatorname{Tr}(\underline{\sigma}))=\left(1+\frac{\operatorname{Tr}(\underline{\sigma})}{2 \sigma_{\mathrm{f}}}\right) \operatorname{Tr}(\underline{\sigma}) \text { quando } & \operatorname{Tr}(\underline{\sigma}) \in]-\sigma_{\mathrm{f}}, 0[
\end{array}
$$




$$
\left.\left.\mathrm{f}(\operatorname{Tr}(\underline{\sigma}))=-\frac{\sigma_{\mathrm{f}}}{2} \operatorname{Tr}(\underline{\sigma}) \quad \text { quando } \quad \operatorname{Tr}(\underline{\sigma}) \in\right]-\infty,-\sigma_{\mathrm{f}}\right]
$$

As leis de estado são derivadas do potencial de estado dado pela Eq. (2.26), e definem as variáveis associadas às variáveis de estado mediante derivadas parciais. Assim, o tensor de deformações resulta de:

$$
\underline{\varepsilon}=\frac{\partial \chi}{\partial \underline{\sigma}}=\underline{\varepsilon}_{\mathrm{e}}+\underline{\varepsilon}_{\mathrm{an}}
$$

sendo $\underline{\varepsilon}_{\mathrm{e}}$ a parcela de deformações elásticas e $\underline{\varepsilon}_{\mathrm{an}}$ o tensor de deformações anelásticas. Tais componentes são dadas, respectivamente, por:

$$
\begin{aligned}
& \underline{\varepsilon}_{\mathrm{e}}=\frac{\langle\underline{\sigma}\rangle_{+}}{\mathrm{E}\left(1-\mathrm{d}_{1}\right)}+\frac{\langle\underline{\sigma}\rangle_{-}}{\mathrm{E}\left(1-\mathrm{d}_{2}\right)}+\frac{\nu}{\mathrm{E}}(\underline{\sigma}-\operatorname{Tr}(\underline{\sigma}) I) \\
& \underline{\varepsilon}_{\mathrm{an}}=\frac{\beta_{1} \mathrm{~d}_{1}}{\mathrm{E}\left(1-\mathrm{d}_{1}\right)} \frac{\partial \mathrm{f}}{\partial \underline{\sigma}}+\frac{\beta_{2} \mathrm{~d}_{2}}{\mathrm{E}\left(1-\mathrm{d}_{2}\right)} I
\end{aligned}
$$

onde $I$ é o tensor identidade.

No trabalho de PAULA (2001), adotaram-se as seguintes expressões, modificadas em relação ao modelo original de La Borderie, propostas em PITUBA et al. (1999), para a determinação das variáveis associadas às variáveis de dano:

$$
\begin{aligned}
& \mathrm{Y}_{1}=\frac{\partial \chi}{\partial \mathrm{d}_{1}}=\frac{\langle\underline{\sigma}\rangle_{+}:\langle\underline{\sigma}\rangle_{+}+2 \beta_{1} \mathrm{f}(\underline{\sigma}) \alpha_{1}}{2 \mathrm{E}\left(1-\mathrm{d}_{1}\right)^{2}} \\
& \mathrm{Y}_{2}=\frac{\partial \chi}{\partial \mathrm{d}_{2}}=\frac{\langle\underline{\sigma}\rangle_{-}:\langle\underline{\sigma}\rangle_{-}+2 \beta_{2} \operatorname{Tr}(\underline{\sigma}) \alpha_{2}}{2 \mathrm{E}\left(1-\mathrm{d}_{2}\right)^{2}}
\end{aligned}
$$

onde os coeficientes $\alpha_{i}(i=1,2)$ assumem o valor unitário quando a variável de dano $d_{i}$ for diferente de zero, caso contrário esses coeficientes são nulos.

As variáveis $\mathrm{Z}_{\mathrm{i}}$, associadas às $\mathrm{Z}_{\mathrm{i}}$, poderiam ser definidas de forma análoga. Tomando-se a variação do potencial em relação a $z_{i}$. Entretanto, em lugar de explicitar 
as $G_{i}$ que aparecem na Eq. (2.26) e a partir delas, por derivação, obter aquelas variáveis, pode-se empregar diretamente as expressões para $Z_{i}$ resultantes de ajustes sobre resultados experimentais. A forma geral dessas expressões é a seguinte:

$$
\mathrm{Z}_{\mathrm{i}}=\left[\mathrm{Y}_{0 \mathrm{i}}+\frac{1}{\mathrm{~A}_{\mathrm{i}}}\left(\frac{\mathrm{d}_{\mathrm{i}}}{1-\mathrm{d}_{\mathrm{i}}}\right)^{1 / \mathrm{B}_{\mathrm{i}}}\right] \quad(i=1,2)
$$

onde $A_{i}, B_{i}$ e $Y_{0 i}$ são parâmetros a serem identificados experimentalmente.

Nota-se que as variáveis $Z_{i}$ tem valores iniciais dados por $Z_{\mathrm{i}}\left(\mathrm{d}_{\mathrm{i}}=0\right)=\mathrm{Y}_{0 \mathrm{i}}$. As expressões (2.33) aparecem, na verdade, nas funções critério de danificação: $\mathrm{f}_{\mathrm{i}}=\mathrm{Y}_{\mathrm{i}}-\mathrm{Z}_{\mathrm{i}}$, as quais caracterizam condições para a evolução ou não do dano em tração ou em compressão. Tais condições são:

- Se $Y_{\mathrm{i}}<Z_{\mathrm{i}}$ então $\dot{\mathrm{d}}_{\mathrm{i}}=0$ e a resposta imediata é elástica linear.

- Se $Y_{i}=Z_{i}$ e $\dot{Y}_{i}>0$, então $\dot{\mathrm{Y}}_{\mathrm{i}}=\dot{\mathrm{Z}}_{\mathrm{i}}$ e $\dot{\mathrm{d}}_{\mathrm{i}} \neq 0$.

Havendo evolução do dano pode-se determinar $d_{i}$ a partir da Eq. (2.34), a qual deriva da Eq. (2.33) fazendo-se $Z_{i}=Y_{i}$ :

$$
\mathrm{d}_{\mathrm{i}}=1-\frac{1}{1+\left[\mathrm{A}_{\mathrm{i}}\left(\mathrm{Y}_{\mathrm{i}}-\mathrm{Y}_{0 \mathrm{i}}\right)\right]^{\mathrm{B}_{\mathrm{i}}}}
$$

$\mathrm{Na}$ figura 2.7 tem-se a resposta tensão-deformação desse modelo para um carregamento uniaxial onde o espécime é submetido inicialmente a tração, descarregado e submetido a compressão, novamente descarregado e volta a ser submetido a tração. 


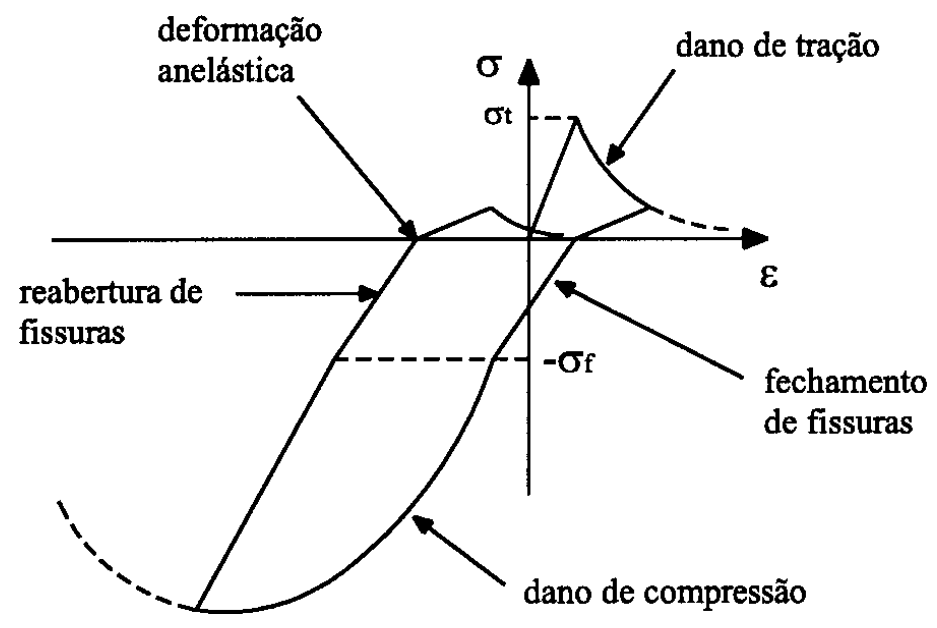

Figura 2.7 - Resposta tensão deformação do modelo de La Borderie, adaptado de MAZARS et al. (2000)

Na figura 2.7 tem-se três fases de comportamento bastante distintas:

- fase 1: quando a tensão varia de 0 a $\sigma_{\mathrm{t}} \mathrm{o}$ dano é representado pela variável de dano em tração $\mathrm{d}_{1}$ enquanto a variável de dano em compressão $\mathrm{d}_{2}$ permanece sem sofrer evolução;

- fase 2: quando a tensão varia de 0 a $-\sigma_{f}$ é utilizada a chamada função de fechamento das fissuras para representar o efeito unilateral de recuperação da rigidez e as variáveis de dano $\mathrm{d}_{1}$ e $\mathrm{d}_{2}$ permanecem constantes;

- fase 3: para tensões inferiores a $-\sigma_{f}$ o dano é representado pela variável de dano em compressão $d_{2}$ enquanto $d_{1}$ permanece constante;

Detalhes sobre a implementação deste modelo para o caso unidimensional são apresentados em PAULA (2001). 


\subsection{ANÁLISE DINÂMICA COM NÃO-LINEARIDADE FÍSICA}

\subsubsection{EQUAÇÃO DE EQUILÍBRIO DINÂMICO}

Levando-se em consideração o princípio de D'Alembert, ARGYRIS \& MLEJNEK (1991), num certo instante de tempo e segundo uma descrição lagrangiana total, a equação de equilíbrio dinâmico pode ser escrita pelo Princípio dos Trabalhos Virtuais na forma:

$$
\begin{gathered}
\int_{\mathrm{V}_{0}} \mathrm{r}_{0} . \delta \mathrm{d}_{\mathrm{e}} \mathrm{dV}_{0}=\int_{\mathrm{V}_{0}} \mathrm{~S} . \delta \varepsilon d \mathrm{~V}_{0}+\int_{\mathrm{V}_{0}}\left(\rho \ddot{\mathrm{d}}_{\mathrm{e}}\right) \delta \mathrm{d}_{\mathrm{e}} \mathrm{dV} \mathrm{V}_{0}+\int_{\mathrm{V}_{0}}\left(\mu \dot{\mathrm{d}}_{\mathrm{e}}\right) \delta \mathrm{d}_{\mathrm{e}} \mathrm{dV} \mathrm{V}_{0}-\int_{\mathrm{V}_{0}} \overline{\mathrm{b}}_{0} \cdot \delta \mathrm{d}_{\mathrm{e}} \mathrm{dV}_{0}- \\
\int_{\overline{\mathrm{A}}_{0}} \overline{\mathrm{t}}_{0} \cdot \delta \mathrm{d}_{\mathrm{e}} \mathrm{dA} \mathrm{A}_{0}-\sum_{\mathrm{i}}^{\mathrm{nc}} \delta \mathrm{d}_{\mathrm{ei}} \overline{\mathrm{f}}_{\mathrm{i}}=0
\end{gathered}
$$

onde:

- $r_{o}$ indica o vetor resíduo de forças;

- $\delta \mathrm{d}_{\mathrm{e}}$ é o vetor de deslocamentos virtuais cinematicamente admissíveis;

- S é o tensor de Piola-Kirchhoff de $2^{\text {a }}$ espécie;

- $\delta \varepsilon$ é o tensor de deformações virtuais compatíveis;

- $\rho$ é a massa específica;

- $\ddot{\mathrm{d}}_{\mathrm{e}}$ é a aceleração do sistema;

- $\dot{\mathrm{d}}_{\mathrm{e}}$ é a velocidade do sistema;

- $\mu$ é o coeficiente de amortecimento viscoso;

- $\overline{\mathrm{b}}_{0}$ é a força distribuída por unidade de volume;

- $\overline{\mathfrak{t}}_{0}$ é a força distribuída por unidade de área;

- $\overline{\mathrm{f}}_{\mathrm{i}}$ representa as forças concentradas aplicadas em $n c$ pontos do sistema;

- $\mathrm{V}_{0}$ é o volume de integração; 
- $\overline{\mathrm{A}}_{0}$ é a área de aplicação das forças prescritas na superfície.

\subsubsection{FORMA APROXIMADA PELO MÉTODO DOS ELEMENTOS FINITOS}

Uma forma aproximada para a Eq. (2.35) pode ser obtida pelo método dos elementos finitos. O elemento de barra empregado possui três graus de liberdade (dois deslocamentos e um giro) atrelados a cada nó de extremidade, conforme ilustrado na Figura 2.8.

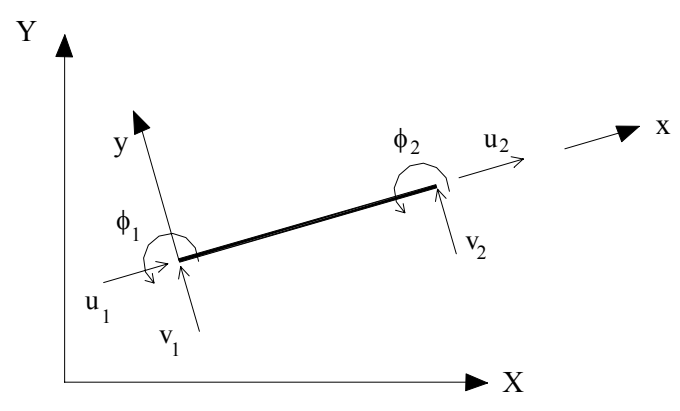

Figura 2.8- Elemento finito de pórtico plano nos sistemas de coordenadas globais e locais, PAULA \& PROENÇA (2001)

Admitindo-se que a estrutura tenha sido discretizada num certo número de elementos, o vetor deslocamento de um ponto genérico de um elemento finito pode ser representado em função dos deslocamentos nodais por meio da seguinte forma matricial, valendo a hipótese de que a seções planas permanecem planas:

$$
\mathrm{d}_{\mathrm{e}}=\underline{\varphi \mathrm{q}}
$$

onde $\underline{\varphi}$ é a matriz que contém as funções de forma e suas derivadas segundo $\mathrm{x}$, coordenada local ao longo do eixo da barra, e $q$ é o vetor dos deslocamentos dos graus de liberdade do elemento finito.

Os vetores velocidade e aceleração resultam:

$$
\dot{\mathrm{d}}_{\mathrm{e}}=\underline{\varphi} \dot{\mathrm{q}} \quad \ddot{\mathrm{d}}_{\mathrm{e}}=\underline{\varphi} \ddot{\mathrm{q}}
$$


Por sua vez, os vetores dos deslocamentos virtuais e das deformações virtuais podem ser interpolados por:

$$
\delta \mathrm{d}_{\mathrm{e}}=\underline{\varphi} \delta \mathrm{q} \quad \text { e } \quad \delta \varepsilon=\underline{\mathrm{B} \delta \mathrm{q}}
$$

onde $\underline{B}$ é o vetor que estabelece a correspondência entre os campos de deslocamento e de deformação .

Substituindo-se as Eqs. (2.37a, b) e (2.38a, b) na Eq. (2.35), obtém-se:

$$
\begin{aligned}
& \int_{\mathrm{V}_{0}} \delta \mathrm{q}^{\mathrm{T}} \underline{\mathrm{B}}^{\mathrm{T}} \mathrm{SdV} \mathrm{V}_{0}+\int_{\mathrm{V}_{0}} \delta \mathrm{q}^{\mathrm{T}} \underline{\varphi}^{\mathrm{T}} \rho \underline{\varphi} \underline{\mathrm{q}} \mathrm{dV} \mathrm{V}_{0}+\int_{\mathrm{V}_{0}} \delta \mathrm{q}^{\mathrm{T}} \underline{\varphi}^{\mathrm{T}} \mu \underline{\varphi} \dot{\mathrm{q}} \mathrm{dV} \mathrm{V}_{0}- \\
& \int_{\mathrm{V}_{0}} \delta \mathrm{q}^{\mathrm{T}} \underline{\varphi}^{\mathrm{T}} \overline{\mathrm{b}}_{0} \mathrm{dV} \mathrm{V}_{0}-\int_{\overline{\mathrm{A}}_{0}} \delta \mathrm{q}^{\mathrm{T}} \underline{\varphi}^{\mathrm{T}} \overline{\mathrm{t}}_{0} \mathrm{dA} \mathrm{A}_{0}-\sum_{\mathrm{i}}^{\mathrm{nc}} \delta \mathrm{q}^{\mathrm{T}} \overline{\mathrm{f}}_{\mathrm{i}}=0
\end{aligned}
$$

Dada a arbitrariedade dos deslocamentos virtuais nodais, a nulidade expressa pela Eq. (2.39) pode ser verificada a partir da seguinte condição:

$$
\int_{\mathrm{V}_{0}} \underline{\mathrm{B}}^{\mathrm{T}} \mathrm{S} \mathrm{dV} \mathrm{V}_{0}+\int_{\mathrm{V}_{0}} \underline{\varphi}^{\mathrm{T}} \rho \underline{\varphi} \underline{\mathrm{q}} \mathrm{dV} \mathrm{V}_{0}+\int_{\mathrm{V}_{0}} \underline{\varphi}^{\mathrm{T}} \mu \underline{\varphi} \underline{\mathrm{q}} \mathrm{dV} \mathrm{V}_{0}-\int_{\mathrm{V}_{0}} \underline{\varphi}^{\mathrm{T}} \overline{\mathrm{b}}_{0} \mathrm{dV}-\int_{\overline{\mathrm{A}}_{0}} \underline{\varphi}^{\mathrm{T}} \overline{\mathrm{t}}_{0} \mathrm{dA} \mathrm{A}_{0}-\sum_{\mathrm{i}}^{\mathrm{nc}} \overline{\mathrm{f}}_{\mathrm{i}}=0
$$

A relação anterior pode então ser escrita segundo o arranjo proposto por ARGYRIS \& MLEJNEK (1991):

$$
\underline{\mathrm{M}} \ddot{\mathrm{q}}+\underline{\mathrm{C}} \dot{\mathrm{q}}+\mathrm{F}^{\mathrm{int}}=\mathrm{F}^{\mathrm{ext}}
$$

onde:

$$
\begin{aligned}
& \underline{\mathrm{M}}=\int_{\mathrm{V}_{0}} \underline{\varphi}^{\mathrm{T}} \rho \underline{\varphi} \mathrm{dV}_{0} \quad \text { - é a matriz de massa } \\
& \underline{\mathrm{C}}=\int_{\mathrm{V}_{0}} \underline{\varphi}^{\mathrm{T}} \mu \underline{\varphi} \mathrm{dV}_{0} \quad \text { - é a matriz de amortecimento }
\end{aligned}
$$




$$
\begin{aligned}
& F^{\text {int }}=\int_{V_{0}} \underline{B}^{T} \mathrm{SdV}_{0} \quad \text { - é o vetor das forças internas } \\
& \mathrm{F}^{\mathrm{ext}}=\int_{\mathrm{V}_{0}} \underline{\varphi}^{\mathrm{T}} \overline{\mathrm{b}}_{0} \mathrm{dV} \mathrm{V}_{0}+\int_{\mathrm{A}_{0}} \underline{\varphi}^{\mathrm{T}} \overline{\mathrm{t}}_{0} \mathrm{dA} \mathrm{A}_{0}+\sum_{\mathrm{i}}^{\mathrm{nc}} \overline{\mathrm{f}}_{\mathrm{i}} \text { - é o vetor das forças externas }
\end{aligned}
$$

Em particular, num regime de pequenos deslocamentos e considerando-se uma relação elástica entre os tensores de Piola-Kirchhoff e de Green $(S=\underline{\underline{D} \varepsilon})$, segue que a matriz de rigidez tangente para o elemento de pórtico plano pode ser expressa na forma:

$$
\underline{K}_{0}=\int_{V_{0}} \underline{B}^{T} \underline{\underline{D}}_{0} \underline{B} d V_{0}
$$

onde $\underline{\underline{D}}_{0}$ é o tensor dos módulos elásticos de rigidez. Nesse caso, pode-se empregar, com suficiente precisão, a parte simétrica do tensor de deformação de Green.

Em princípio, a matriz de amortecimento do elemento de barra pode ser obtida pela integração da Eq. (2.43), porém a determinação da magnitude do parâmetro $\mu$ de amortecimento viscoso do material é um tanto difícil. Uma alternativa para contornar essa dificuldade, consiste na utilização do modelo de amortecimento viscoso de Rayleigh, COOK et al. (1989), onde uma matriz de amortecimento é introduzida envolvendo frações específicas do amortecimento crítico. $\mathrm{O}$ amortecimento de Rayleigh consiste então na combinação linear entre as matrizes de rigidez e de massa da seguinte forma:

$$
\underline{\mathrm{C}}=\lambda_{\mathrm{m}} \underline{\mathrm{M}}+\lambda_{\mathrm{k}} \underline{\mathrm{K}}_{0}
$$

onde $\lambda_{\mathrm{m}}$ e $\lambda_{\mathrm{k}}$ são constantes que ponderam as contribuições das matrizes de massa $\underline{\mathrm{M}}$ e de rigidez inicial elástica $\underline{\mathrm{K}}_{0}$, respectivamente.

A relação existente entre as constantes $\lambda_{\mathrm{m}}$ e $\lambda_{\mathrm{k}}$, e a fração de amortecimento crítico $\xi$ para uma dada freqüência natural de vibração $\omega$, COOK et al. (1989), pode ser expressa na forma: 


$$
\xi_{\mathrm{i}}=\frac{1}{2}\left(\lambda_{\mathrm{k}} \omega_{\mathrm{i}}+\frac{\lambda_{\mathrm{m}}}{\omega_{\mathrm{i}}}\right)
$$

Tomando-se frações de amortecimento crítico para duas freqüências naturais de vibração, as constantes de amortecimento podem ser determinadas pelas seguintes relações:

$$
\begin{aligned}
& \lambda_{\mathrm{k}}=\frac{2\left(\xi_{2} \omega_{2}-\xi_{1} \omega_{1}\right)}{\left(\omega_{2}^{2}-\omega_{1}^{2}\right)} \\
& \lambda_{\mathrm{m}}=\frac{2 \omega_{1} \omega_{2}\left(\xi_{1} \omega_{2}-\xi_{2} \omega_{1}\right)}{\left(\omega_{2}^{2}-\omega_{1}^{2}\right)}
\end{aligned}
$$

De acordo com COOK et al. (1989) para $\omega_{1}$ pode-se adotar a menor freqüência natural de vibração da estrutura e para $\omega_{2}$ a freqüência relacionada com o carregamento externo de maior importância ou, então, a freqüência subseqüente à $\omega_{1}$.

Por sua vez, as freqüências naturais de vibração podem ser obtidas através dos autovalores da equação de equilíbrio do sistema estrutural, livre de carregamento e de amortecimento, dada por:

$$
\underline{M} \ddot{q}+\underline{K}_{0} q=0
$$

De acordo com BATHE (1996) a equação (2.51) pode ser colocada na forma:

$$
\left[\underline{\mathrm{K}_{\mathrm{o}}}-\omega_{\mathrm{i}}^{2} \underline{\mathrm{M}}\right] \phi_{\mathrm{i}}=0
$$

onde os autovalores $\omega_{\mathrm{i}}^{2}$ são o quadrado das freqüências naturais e os vetores $\phi_{\mathrm{i}}$ são os autovetores correspondentes.

Com relação às frações do amortecimento crítico, as mesmas são função do tipo de material e do tipo de sistema estrutural empregado, observando-se que o amortecimento crítico tem valor de referência unitário, $\xi_{\mathrm{i}}=1$. Assim sendo, para estruturas convencionais o valor de $\xi$ é sempre menor que a unidade; por exemplo, para estruturas de aço adota-se $0.5 \%<\xi_{\mathrm{i}}<5.0 \%$ e para estruturas em concreto 
$2.0 \%<\xi_{i}<15.0 \%$. Em seu estudo PAULA (2001) utilizou $\xi_{\mathrm{i}}=3 \%$ e $\xi_{\mathrm{i}}=10 \%,(\mathrm{i}=1,2)$.

A não-linearidade, levada em conta neste trabalho, refere-se aos efeitos da danificação progressiva representada por um processo de microfissuração difusa no material. Esse processo pode ser introduzido no modelo por meio de uma penalização, ou redução das propriedades elásticas de rigidez, utilizando-se de uma variável escalar d dita variável de dano. A cada instante de tempo os valores dessa variável são determinados por uma lei de evolução envolvendo parâmetros que devem ser identificados, de acordo com o material, com base em resultados de ensaios em laboratório. Os modelos constitutivos de dano diferem entre si essencialmente pela lei de evolução proposta para a variável de dano e também pelo tipo de variável considerada, escalar ou tensor.

Portanto, levando-se em conta a danificação, o tensor de rigidez elástica passa a ser uma função da variável de dano: $\underline{\underline{\mathrm{D}}}=\underline{\underline{\mathrm{D}}}(\mathrm{d})=(1-\mathrm{d}) \underline{\underline{D}}_{0}$, sendo $\underline{\underline{\mathrm{D}}}=\underline{\underline{\mathrm{D}}}_{0}$ para $\mathrm{d}=0$.

Quando usada a equação do movimento com o amortecimento de Rayleigh, por ele envolver a matriz de rigidez, também a matriz de amortecimento passa a ser uma função do dano. Entretanto, a forma de considerar a influência da danificação sobre o amortecimento nesse caso não é única. PAULA \& PROENÇA (2001), analisam as seguintes formas para a matriz de amortecimento $\underline{C}$ :

$$
\begin{aligned}
& \underline{\mathrm{C}}=\lambda_{\mathrm{m}}(\mathrm{d}) \underline{\mathrm{M}}+\lambda_{\mathrm{k}}(\mathrm{d}) \underline{\mathrm{K}}_{0} \\
& \underline{\mathrm{C}}=\lambda_{\mathrm{m}}(\mathrm{d}) \underline{\mathrm{M}} \\
& \underline{\mathrm{C}}=\lambda_{\mathrm{m}}(\mathrm{d}) \underline{\mathrm{M}}+\lambda_{\mathrm{k}}(\mathrm{d}) \underline{\mathrm{K}}(\mathrm{d})
\end{aligned}
$$

Observa-se que nessas condições, $\lambda_{\mathrm{m}}(\mathrm{d})$ e $\lambda_{\mathrm{k}}(\mathrm{d})$ são calculados conforme as Eqs. (2.49) e (2.50), porém, as freqüências são obtidas através dos autovalores da seguinte equação:

$$
\underline{\mathrm{M}} \ddot{\mathrm{q}}+\underline{\mathrm{K}}[\mathrm{d}(\mathrm{t})] \mathrm{q}=0
$$


Por outro lado, o modelo de dano com histerese proposto originalmente por MAZARS et al. (2000) permite introduzir o amortecimento sem que seja necessário o modelo de Rayleigh, ou mesmo a parcela de amortecimento viscoso na equação do movimento. Os resultados das simulações numéricas, no capítulo 4, irão apresentar um confronto entre esses modelos.

\subsection{INTEGRAÇÃO NUMÉRICA NA SEÇÃO TRANSVERSAL}

No trabalho de PAULA (2001) a integração das expressões (2.42), (2.44) e (2.46) foram feitas, no caso da análise dinâmica, através das quadraturas de Gauss e Gauss-Lobatto. Já na análise estática também foi utilizada a técnica através da qual a seção transversal do elemento é dividida em várias camadas ou estratos. A restrição naquele trabalho foi a imposição de mesma espessura e largura para todas as camadas possibilitando apenas a consideração de seções retangulares. Além disso, na integração das expressões (2.44) e (2.46) considerou-se constante ao longo da altura de cada camada, o módulo de elasticidade penalizado pelo dano.

No presente trabalho implementa-se a possibilidade de adoção de camadas com espessuras e larguras variáveis, mas sempre com a limitação de que a seção transversal possua simetria em relação ao plano de flexão. Além disso, quando da consideração do modelo de MAZARS (1984), na integração das expressões (2.44) e (2.46), considera-se que o módulo de elasticidade penalizado pelo dano possua variação linear ao longo da espessura de cada camada. Conforme indica a figura 2.9, sendo a expressão para seu cálculo dada por:

$$
\widetilde{E}(y)=\left(\widetilde{E}_{i+1}-\widetilde{E}_{i}\right) \cdot\left(\frac{y-y_{i}}{y_{i+1}-y_{i}}\right)+\widetilde{E}_{i}
$$

onde $\widetilde{E}_{\mathrm{i}}=\mathrm{E} \cdot\left(1-\mathrm{d}_{\mathrm{i}}\right)$ e $\mathrm{d}_{\mathrm{i}}$ corresponde ao dano calculado para $\mathrm{y}=\mathrm{y}_{\mathrm{i}}$.

$\mathrm{Na}$ figura 2.9 tem-se a representação de uma seção transversal dividida em estratos e da variação apresentada pelo módulo de elasticidade penalizado pelo dano. 


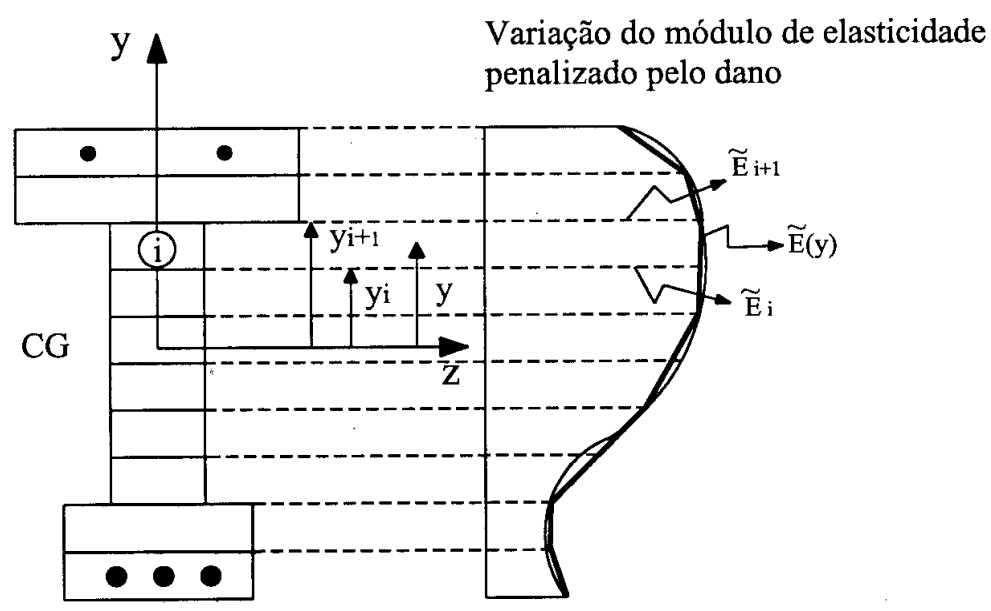

Figura 2.9 - Sistema de estratos e variação do módulo de elasticidade ao longo da espessura

Nas integrações das expressões de interesse aparecem as seguintes relações:

$$
\begin{aligned}
& \int_{V 0} \widetilde{E}(y) d V_{0}=\int_{x}\left[\sum_{i=1}^{n+1} b s(i) \frac{1}{2}\left(\widetilde{E}_{i+1}+\widetilde{E}_{i}\right)\left(y_{i+1}-y_{i}\right)\right] d x \\
& \int_{V 0} \widetilde{E}(y) y d V_{0}=\int_{X}\left[\sum _ { i = 1 } ^ { n + 1 } \frac { - b s ( i ) } { 6 } \left[\widetilde{E}_{i+1}\left(y_{i}{ }^{2}+y_{i} y_{i+1}-2 y_{i+1}{ }^{2}\right)+\right.\right. \\
& \left.+\widetilde{\mathrm{E}}_{\mathrm{i}}\left(2 \mathrm{y}_{\mathrm{i}}^{2}-\mathrm{y}_{\mathrm{i}} \mathrm{y}_{\mathrm{i}+1}-\mathrm{y}_{\mathrm{i}+1}^{2}\right)\right] \mathrm{dx} \\
& \int_{\mathrm{V} 0} \widetilde{\mathrm{E}}(\mathrm{y}) \mathrm{y}^{2} \mathrm{dV} \mathrm{V}_{0}=\int_{\mathrm{x}}\left[\sum _ { \mathrm { i } = 1 } ^ { \mathrm { n } + 1 } \frac { - \mathrm { bs } ( \mathrm { i } ) } { 1 2 } \left[\widetilde{\mathrm{E}}_{\mathrm{i}+1}\left(\mathrm{y}_{\mathrm{i}}{ }^{3}+\mathrm{y}_{\mathrm{i}}{ }^{2} \mathrm{y}_{\mathrm{i}+1}+\mathrm{y}_{\mathrm{i}} \mathrm{y}_{\mathrm{i}+1}{ }^{2}-3 \mathrm{y}_{\mathrm{i}+1}{ }^{3}\right)+\right.\right. \\
& \left.+\widetilde{E}_{i}\left(3 y_{i}^{3}-y_{i}^{2} y_{i+1}-y_{i} y_{i+1}^{2}-y_{i+1}^{3}\right)\right] d x
\end{aligned}
$$

onde bs(i) é a largura do estrato i e n é o número de estratos no qual a seção é dividida. 


\subsubsection{EXEMPLOS NUMÉRICOS}

A nova forma de integração foi implementada nos programas de análises estática e dinâmica desenvolvidos por PAULA (2001) e testada mediante o confronto com dois resultados experimentais de vigas com carregamento estático. Os resultados obtidos simularam o comportamento não-linear das estruturas, utilizando-se os modelos de dano de MAZARS (1984) e de LA BORDERIE (1991).

Para simular o comportamento elastoplástico do aço empregou-se o modelo com encruamento linear cinemático. A tolerância com a qual se verificou a convergência do processo incremental iterativo foi fixada em $10^{-6}$ para as normas euclidianas dos deslocamentos e dos esforços.

Os exemplos referem-se a vigas bi-apoiadas e diferem entre si pelas taxas de armadura longitudinal (os resultados experimentais foram fornecidos pelo laboratório de estruturas da EESC/USP). Os dados geométricos e a distribuição das armaduras encontram-se indicados na figura 2.10. Os demais dados necessários são:

Propriedades do concreto: $\mathrm{E}_{\mathrm{c}}=30672,46 \mathrm{MPa} ; \mathrm{v}=0,2$.

Propriedades do aço: $\mathrm{E}_{\mathrm{s}}=168890 \mathrm{MPa}$; tensão de encruamento fy $=608 \mathrm{MPa}$; $\mathrm{E}_{\mathrm{st}}=\frac{\mathrm{E}_{\mathrm{s}} \mathrm{H}}{\mathrm{E}_{\mathrm{s}}+\mathrm{H}}=3077 \mathrm{MPa} ;$ módulo de encruamento cinemático $\mathrm{H}=3134 \mathrm{MPa}$.

Parâmetros do modelo de MAZARS (1984): At $=0.995 ; \mathrm{Bt}=8000 ; \mathrm{Ac}=0,85$; $\mathrm{Bc}=1050$ e $\varepsilon_{\mathrm{do}}=0,00007$

Parâmetros do modelo de LA BORDERIE (1991): $\beta_{1}=1 \mathrm{MPa} ; \beta_{2}=-10 \mathrm{MPa}$; $\mathrm{y}_{01}=3,05 \times 10^{-4} \mathrm{MPa} ; \mathrm{y}_{02}=5 \times 10^{-3} \mathrm{MPa} ; \mathrm{A}_{1}=3,5 \times 10^{3} \mathrm{MPa}^{-1} ; \mathrm{A}_{2}=6,8 \mathrm{MPa}^{-1}$; $\mathrm{B}_{1}=0,95 ; \mathrm{B}_{2}=0,7705$ e $\sigma_{\mathrm{f}}=2,6 \mathrm{MPa}$. 


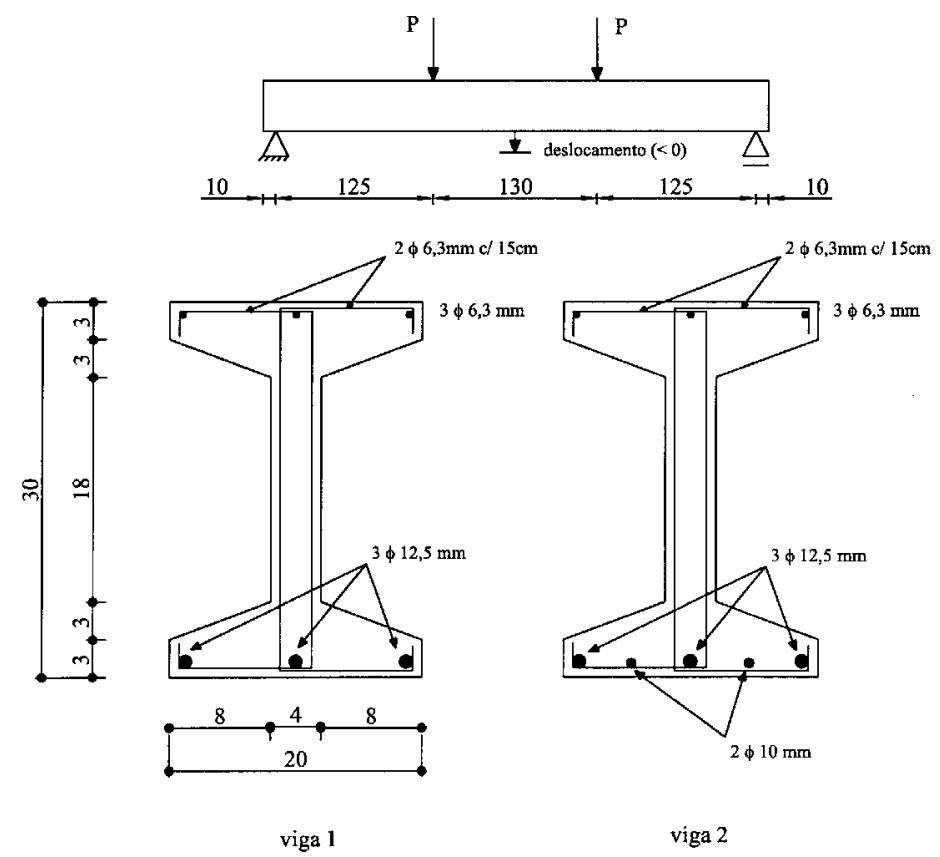

Figura 2.10 - Geometria e armação das vigas com seção em I

Os parâmetros aqui utilizados nos modelos tanto de Mazars quanto de La Borderie foram os mesmos utilizados por PAULA (2001) em seus exemplos.

As estruturas foram discretizadas em 18 elementos finitos, sem consideração de simetria. Para a integração numérica ao longo do comprimento dos elementos foram utilizadas quadraturas de Gauss-Lobatto com 6 pontos sendo adotada a discretização da seção transversal ilustrada na figura 2.11a. Na figura $2.11 \mathrm{~b}$ tem-se a representação de como é feita a consideração da armadura longitudinal da estrutura.

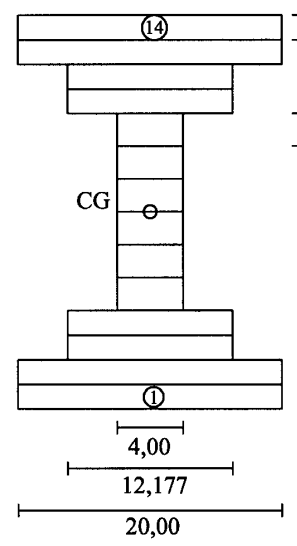

(a)
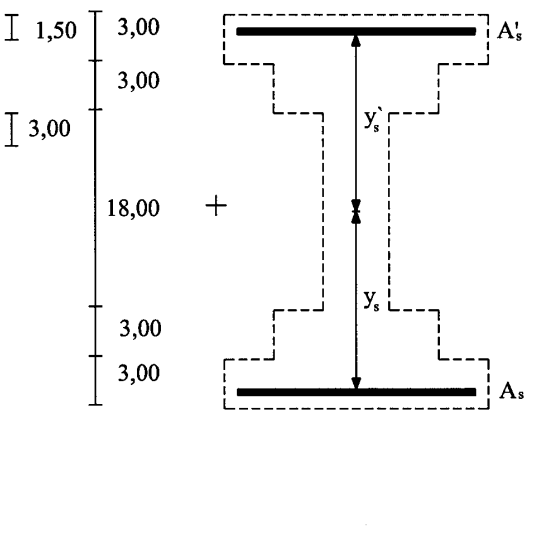

(b)

Figura 2.11 - Discretização em estratos da viga com seção em I: (a) contribuição do concreto,

(b) contribuição da armadura longitudinal 
Nos gráficos das figuras 2.12 e 2.13 comparam-se os resultados experimentais e numéricos, relativos ao deslocamento do ponto central da viga. Observa-se uma boa concordância entre as respostas, o que evidencia a eficiência do elemento finito com múltiplas camadas.

Viga 1

$3 \phi 12,5 \mathrm{~mm}$

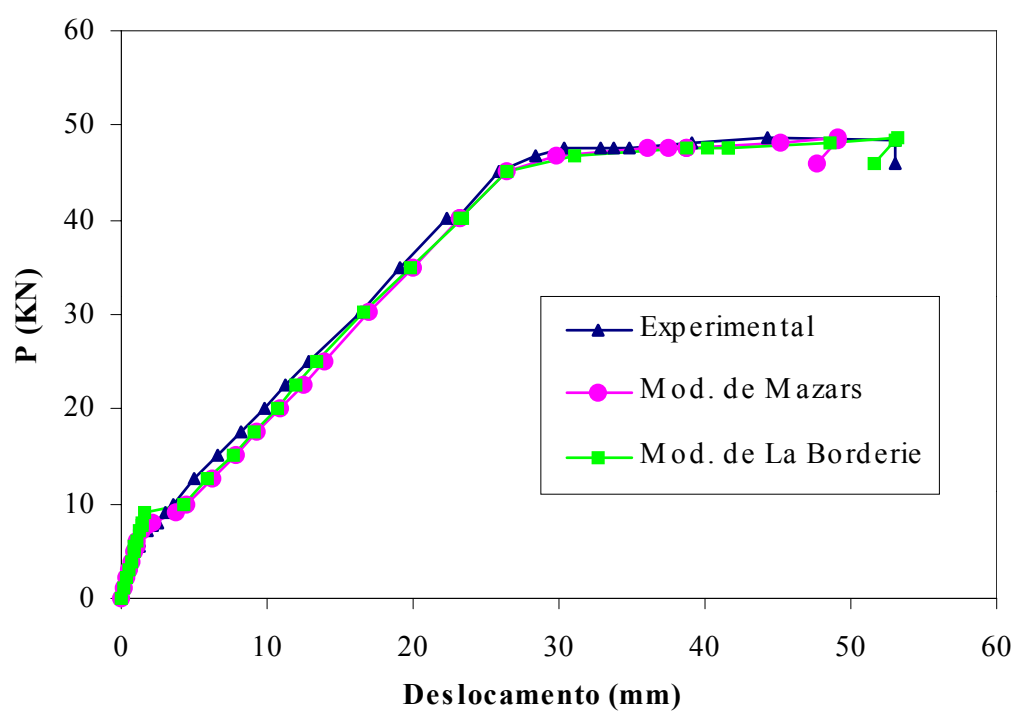

Figura 2.12 - Curva carga/deslocamento - viga 1: $3 \phi 12,5 \mathrm{~mm}$

Vig a 2

$3 \phi 12,5 \mathrm{~mm}+2 \phi 10 \mathrm{~mm}$

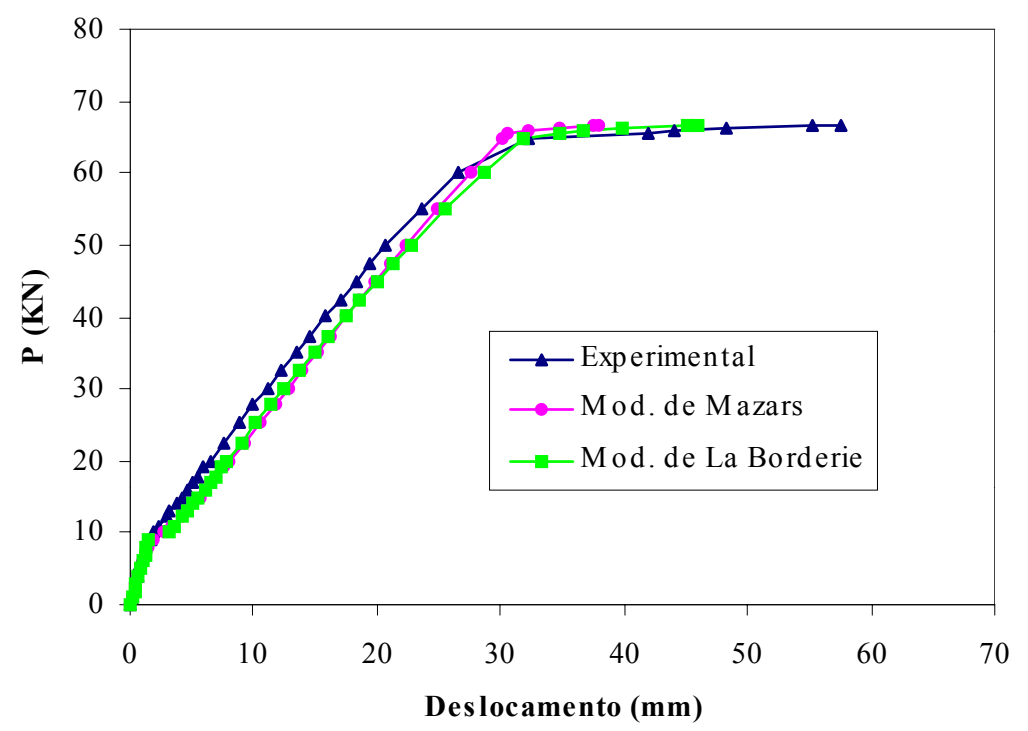

Figura 2.13-Curva carga/deslocamento - viga 2: $3 \phi 12,5 \mathrm{~mm}+2 \phi 10 \mathrm{~mm}$ 


\subsection{INTRODUÇÃO}

Este capítulo tem por objetivo descrever e analisar a versão unidimensional do modelo de dano contínuo de MAZARS et al. (2000), proposto para a aplicação ao estudo do comportamento dinâmico de estruturas em concreto armado. Essas estruturas apresentam o aumento do amortecimento em decorrência da evolução do estado de fissuração do material como tendência geral de sua resposta dinâmica. O modelo em análise visa reproduzir esta tendência de comportamento. Para alcançar tal objetivo o modelo propõe a realização de laços de histerese pela consideração da dissipação conjunta decorrente do dano evolutivo e do fenômeno de fricção interna nas faces das fissuras.

Em sua forma original o modelo foi proposto descrevendo-se o dano mediante um tensor de segunda ordem, porém para viabilizar uma análise mais detalhada conforme os objetivos deste trabalho, tal descrição foi aqui substituída considerando-se o dano por meio de uma variável escalar. Por outro lado, assim como no modelo original, o fenômeno de fricção interna está relacionado à suposição de que as fissuras não se abrem simplesmente por separação formando faces com superfícies lisas, mas tendem a combinar modos de separação e deslizamento segundo superfícies com uma certa rugosidade. O deslizamento entre as faces das fissuras dá origem a uma deformação por escorregamento, assumida como responsável por um comportamento plástico com encruamento cinemático não-linear do meio danificado.

No sentido de contemplar a danificação e a fricção interna a tensão total num ponto do meio com dano é dividida em uma parcela dita tensão elasto-danificada e em 
outra denominada tensão de escorregamento, também dependente do nível de dano da estrutura. Em correspondência à parcela de tensão de escorregamento introduz-se uma nova variável cinemática: a deformação de escorregamento $\varepsilon_{\mathrm{s}}$. Como mencionado anteriormente essa variável tem a ver com a consideração da fricção interna e tem seu significado associado à movimentação entre as faces das fissuras. A deformação $\varepsilon_{\mathrm{s}}$ é responsável, juntamente com a variável de dano, pela não-linearidade da resposta tensão-deformação do concreto. Diferentemente da variável de dano a deformação por escorregamento pode evoluir tanto no processo de carregamento quanto nos ciclos de descarregamento e recarregamento, sendo este aspecto um dos responsáveis pela realização dos laços de histerese.

Dois critérios são então introduzidos no modelo: um critério de danificação, que indica a possibilidade de evolução da variável de dano, e um de escorregamento, que indica a possibilidade de evolução da deformação de escorregamento e da variável associada ao encruamento não-linear cinemático. Vale observar que somente ocorrerá escorregamento se a estrutura estiver danificada. O critério de danificação é estabelecido em função do estado de deformação, enquanto o critério de escorregamento é estabelecido em função do estado de tensão.

A formulação do modelo segue uma abordagem termodinâmica aplicada aos sólidos, LEMAITRE (1992). Nesse sentido, adota-se como potencial termodinâmico a energia específica livre de Helmholtz e para o potencial de dissipação emprega-se uma abordagem não associativa, em decorrência do fenômeno de ficção interna.

\subsection{TERMODINÂMICA DOS SÓLIDOS: CONSIDERAÇÕES GERAIS}

Neste item alguns conceitos gerais são apresentados no sentido de tornar mais compreensível a estrutura termodinâmica do modelo.

Considere-se um dado sólido, ou parte dele, observado num determinado instante. Um axioma fundamental é que o sólido, ou sistema, possui energia interna. Uma entidade física mensurável, necessária para determinar univocamente a energia interna do sistema, no instante considerado, é denominada variável de estado. Admite-se que seja suficiente um número finito de variáveis de estado para determinar a energia interna do sistema. 
As variáveis de estado estão relacionadas aos fenômenos a serem descritos pelo modelo e podem ser divididas em dois grupos: as observáveis e as internas. As variáveis observáveis são aquelas que podem ser quantificadas experimentalmente por medidas diretas. Já as variáveis internas não podem ser diretamente medidas. Ao se formular modelos constitutivos de acordo com os princípios da Termodinâmica dos Sólidos é possível, macroscopicamente, por meio da definição de variáveis internas, levar em conta fenômenos irreversíveis que provocam mudanças na microestrutura do sistema considerado.

O chamado método do estado local fornece uma metodologia consistente para a formulação de modelos constitutivos gerais, e se baseia num axioma fundamental: "Num certo instante, o estado termodinâmico de um meio material é completamente definido pelo conhecimento dos valores de um número finito de variáveis de estado que dependem apenas do ponto considerado no sistema”, LEMAITRE (1992).

Entre os aspectos característicos da metodologia proposta pelo método do estado local está a verificação das leis de balanço de energia da Termodinâmica, imposta mediante a validade da inequação de Clausius-Duhem, que estabelece a positividade da energia dissipada. Além disso, o método postula a existência de dois potenciais: o termodinâmico e o dissipativo, os quais governam as relações constitutivas. O potencial termodinâmico estabelece as leis de estado, enquanto o potencial dissipativo estabelece as leis de evolução das variáveis internas, completando o modelo constitutivo.

\subsection{ESTRUTURA TERMODINÂMICA DE ACORDO COM O MÉTODO DO ESTADO LOCAL}

Adotando-se como potencial termodinâmico a energia específica livre de Helmholtz $\rho \psi$ (por unidade de volume), de acordo com RAGUENEAU et al. (2000) propõe-se para ela a seguinte relação:

$$
\rho \psi=\frac{1}{2}(1-\mathrm{d}) \varepsilon \mathrm{E} \varepsilon+\frac{1}{2}\left(\varepsilon-\varepsilon_{\mathrm{s}}\right) \operatorname{Ed}\left(\varepsilon-\varepsilon_{\mathrm{s}}\right)+\frac{1}{2} \mathrm{~b} \alpha^{2}
$$

onde: 
- $\rho$ é a massa específica;

- $\psi$ é o potencial de estado (por unidade de massa);

- E é o módulo de Young;

- d é a variável escalar de dano;

- $\varepsilon$ é a deformação total;

- $\varepsilon_{\mathrm{s}}$ é a deformação de escorregamento;

- $\alpha$ é a variável associada ao encruamento;

- b é um parâmetro do material.

Cabe observar que a energia livre é a parcela de energia que, após um determinado processo de deformação, o sistema pode disponibilizar para a realização de trabalho.

A primeira parcela do lado direito da equação (3.1) corresponde à energia livre do meio com danificação, a segunda parcela corresponde à energia livre para o meio que apresenta deformação residual por escorregamento e a terceira parcela corresponde à energia livre associada ao encruamento.

A escolha de introduzir o dano na parcela de energia correspondente ao escorregamento é proposital e pretende reproduzir o acoplamento entre dano e escorregamento. A justificativa decorre da evidência de que todo fenômeno anelástico no concreto resulta do aparecimento e evolução de microfissuras, RAGUENEAU et al. (2000).

A fim de definir as leis de estado, o modelo deve ser termodinamicamente admissível. Essa condição é verificada impondo-se a desigualdade de Clausius-Duhem. Nesse sentido, ignorando-se qualquer efeito térmico, vale a relação:

$$
\sigma \dot{\varepsilon}-\rho \dot{\psi} \geq 0
$$

onde a primeira parcela é a taxa de energia interna e o ponto sobre uma variável designa a derivada desta em relação ao tempo.

Assumindo que o potencial termodinâmico possa ser linearizado ao redor dos valores correntes de todas as variáveis de estado, segue que: 


$$
\dot{\psi}=\frac{\partial \psi}{\partial \varepsilon} \dot{\varepsilon}+\frac{\partial \psi}{\partial \varepsilon_{\mathrm{s}}} \dot{\varepsilon}_{\mathrm{s}}+\frac{\partial \psi}{\partial \mathrm{d}} \dot{\mathrm{d}}+\frac{\partial \psi}{\partial \alpha} \dot{\alpha}
$$

Pode-se agora substituir o potencial linearizado na Eq. (3.2) resultando:

$$
\left(\sigma-\rho \frac{\partial \psi}{\partial \varepsilon}\right) \dot{\varepsilon}-\rho \frac{\partial \psi}{\partial \varepsilon_{\mathrm{s}}} \dot{\varepsilon}_{\mathrm{s}}-\rho \frac{\partial \psi}{\partial \mathrm{d}} \dot{\mathrm{d}}-\rho \frac{\partial \psi}{\partial \alpha} \dot{\alpha} \geq 0
$$

A última inequação deve ser válida para qualquer processo, inclusive um puramente reversível em que: $\dot{\varepsilon}_{\mathrm{s}}=\dot{\mathrm{d}}=\dot{\alpha}=0$. Segue daí a seguinte condição:

$$
\sigma=\rho \frac{\partial \psi}{\partial \varepsilon}=E(1-d) \varepsilon+E d\left(\varepsilon-\varepsilon_{s}\right)
$$

que define $\sigma$ como a variável termodinâmica associada a $\varepsilon$. Por analogia, podem ser definidas variáveis termodinâmicas associadas às outras variáveis de estado:

$$
\begin{aligned}
& \sigma_{\mathrm{s}}=-\rho \frac{\partial \psi}{\partial \varepsilon_{\mathrm{s}}}=\operatorname{Ed}\left(\varepsilon-\varepsilon_{\mathrm{s}}\right) \\
& Y=\rho \frac{\partial \psi}{\partial \mathrm{d}}=-\frac{\mathrm{E} \varepsilon_{\mathrm{s}}}{2}\left(2 \varepsilon-\varepsilon_{\mathrm{s}}\right) \\
& X=\rho \frac{\partial \psi}{\partial \alpha}=\mathrm{b} \alpha
\end{aligned}
$$

Assim, $\sigma_{\mathrm{s}}, \mathrm{Y}$ e X são as variáveis termodinâmicas associadas respectivamente às variáveis internas $\varepsilon_{s}$, d e $\alpha$. Em particular, $X$ será aqui denominada por tensão de encruamento cinemático.

O que se pode observar das equações (3.5) e (3.6) é que a tensão total resulta dividida em duas parcelas: uma componente elasto-danificada e uma componente dita de escorregamento, pois está associada à deformação de escorregamento, e que somente existe se houver danificação. Então $\sigma=\sigma_{\mathrm{d}}+\sigma_{\mathrm{s}}$, com: 


$$
\sigma_{\mathrm{d}}=\mathrm{E}(1-\mathrm{d}) \varepsilon \quad \text { e } \quad \sigma_{\mathrm{s}}=\mathrm{Ed}\left(\varepsilon-\varepsilon_{\mathrm{s}}\right)
$$

Considerando-se a inequação de Clausius-Duhem e as leis de estado previamente definidas, a positividade da energia dissipada pode ser expressa como:

$$
\sigma_{\mathrm{s}} \dot{\varepsilon}_{\mathrm{s}}-\mathrm{Y} \dot{\mathrm{d}}-\mathrm{X} \dot{\alpha} \geq 0
$$

Em relação às parcelas de deslizamento, pode-se demonstrar que a dissipação positiva é automaticamente verificada uma vez que as leis de evolução das variáveis internas associadas a esse fenômeno sejam derivadas de um potencial de dissipação convexo, como será feito no próximo item, RAGUENEAU et al. (2000). Considerandose a parcela de dissipação devido ao dano, é necessário assegurar que $-\mathrm{Y} \dot{\mathrm{d}} \geq 0$, pois tal fenômeno pode existir sem estar acompanhado da fricção interna. Como para o modelo em análise a variável de dano pode apenas crescer $(\dot{\mathrm{d}}>0)$, a obediência a positividade da dissipação é assegurada pela inequação $-\mathrm{Y} \geq 0$, ou:

$$
\varepsilon_{\mathrm{s}} \mathrm{E}\left(2 \varepsilon-\varepsilon_{\mathrm{s}}\right) \geq 0
$$

Portanto, a condição de dissipação positiva impõe uma relação entre a deformação total e a deformação de escorregamento, o que é fisicamente coerente, RAGUENEAU et al. (2000). Uma representação reológica de tal modelo pode ser encontrada na figura 3.1 .

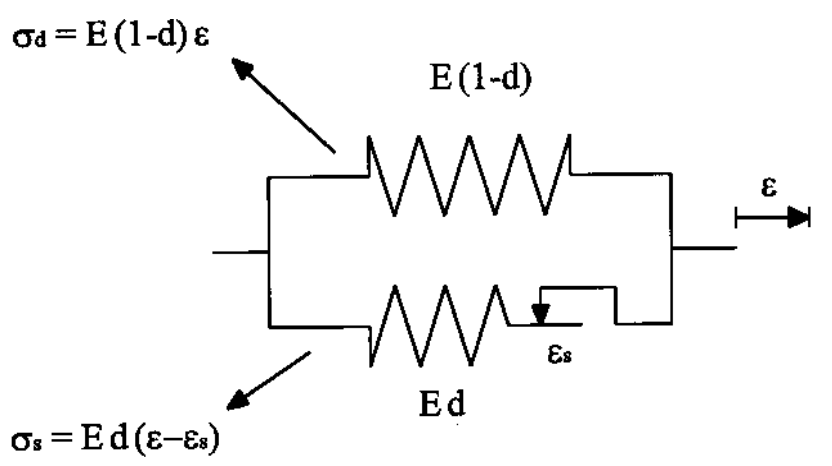

Figura 3.1 - Representação reológica do modelo, RAGUENEAU et al. (2000) 
Nos modelos reológicos quando num trecho os elementos estão numa disposição em série, a deformação total neste trecho é igual a soma das deformações em cada elemento. No entanto a tensão é a mesma em todo o trecho. Porém, quando os elementos estão dispostos em paralelo a deformação é a mesma em ambos, enquanto a tensão total é dada pela soma da tensão em cada um dos elementos. Na figura 3.1 observa-se que o modelo é representado por duas molas associadas em paralelo, a primeira possui rigidez $\mathrm{E}(1-\mathrm{d})$, na qual atua a tensão elasto-danificada $\sigma_{\mathrm{d}}$, enquanto a segunda mola possui rigidez Ed e nela atua a chamada tensão de escorregamento $\sigma_{\mathrm{s}}$. A segunda mola está, por sua vez, associada em série com um elemento que representa o escorregamento, de forma que ela apresenta parte da deformação total $\varepsilon$ aplicada na estrutura. De fato, uma vez que o elemento de escorregamento apresenta uma deformação $\varepsilon_{\mathrm{s}}$, a deformação resultante na segunda mola é dada por $\left(\varepsilon-\varepsilon_{\mathrm{s}}\right)$. Como as molas estão associadas em paralelo a tensão total será: $\sigma=\sigma_{\mathrm{d}}+\sigma_{\mathrm{s}}$.

Neste modelo o dano é controlado apenas pela tensão elasto-danificada enquanto que a deformação de escorregamento é associada à parte da tensão de escorregamento. Este tipo de partição, levando à definição de dois critérios de análise (um para o dano e outro para o escorregamento), permite, como se verá, a descrição dos ciclos de histerese.

\subsection{CRITÉRIOS DE DANIFICAÇÃO, ESCORREGAMENTO E LEIS DE EVOLUÇÃO DAS VARIÁVEIS INTERNAS}

Nesta proposta o critério e as leis de evolução do dano são os mesmos sugeridos no modelo de MAZARS (1984) descritos no item 2.2.6.

O critério de escorregamento utilizado para esta versão unidimensional é expresso na forma:

$$
\mathrm{f}_{\mathrm{s}}=\left|\sigma_{\mathrm{s}}-\mathrm{X}\right|-\sigma_{\mathrm{y}} \leq 0
$$

onde $\sigma_{\mathrm{y}}$ é uma tensão de referência, da qual maiores detalhes serão apresentados a seguir. 
A inequação (3.12) estabelece que em correspondência a um certo estado de deformação os níveis totais de tensão por escorregamento e encruamento serão admissíveis se $\mathrm{f}_{\mathrm{s}} \leq 0$. Este critério aplica-se nas etapas de carregamento, descarregamento e recarregamento. Como se verá mais adiante, na estratégia de resolução, a violação da condição $\mathrm{f}_{\mathrm{s}} \leq 0$, servirá para caracterizar a evolução ou não do processo de escorregamento no presente passo de carga.

Do mesmo modo como na plasticidade clássica, define-se um potencial dissipativo para se obter as leis de evolução das variáveis internas associadas ao deslizamento, expressas por relações para $\dot{\varepsilon}_{\mathrm{s}}$ e $\dot{\alpha}$. Normalmente, postulando-se a validade da regra da associatividade, tal potencial é feito coincidir com a relação que descreve o critério de escorregamento na condição de igualdade $\left(f_{s}=0\right)$. No entanto, neste modelo, a expectativa de um encruamento não-linear impõe o uso de uma lei nãoassociativa. Uma alternativa para contemplar essa condição, é representar o potencial por uma expressão que possa vir a ser particularizada para o caso associativo, recuperando a relação do critério de escorregamento.

Nessas condições, propõe-se para o potencial dissipativo a seguinte forma:

$$
\phi_{\mathrm{s}}=\left|\sigma_{\mathrm{s}}-\mathrm{X}\right|+\frac{3}{4} \mathrm{a} \mathrm{X}^{2}+\frac{\mathrm{c} \sigma_{\mathrm{s}}}{3}-\sigma_{\mathrm{y}}
$$

onde a e c são parâmetros do material. A parcela $\frac{3}{4}$ a $X^{2}$ é responsável pela nãolinearidade do encruamento, enquanto a parcela $\frac{\mathrm{c} \sigma_{\mathrm{s}}}{3}$ foi mantida, do modelo original, por uma questão de compatibilidade com a formulação geral multi-axial. Na formulação multi-axial essa parcela é responsável pela representação da dilatância, que é o aumento do volume de massas granulares quando submetidas a deformações por escorregamento impostas, fenômeno comum em materiais como o concreto, areias e rochas.

Impondo-se então uma condição de normalidade, LEMAITRE (1992), as leis de evolução das variáveis internas resultam:

$$
\dot{\varepsilon}_{\mathrm{s}}=\dot{\lambda} \frac{\partial \phi_{\mathrm{s}}}{\partial \sigma_{\mathrm{s}}} \quad \text { e } \quad \dot{\alpha}=-\dot{\lambda} \frac{\partial \phi_{\mathrm{s}}}{\partial \mathrm{X}}
$$


onde $\dot{\lambda}$ é denominado multiplicador plástico, e o sinal negativo na expressão de $\dot{\alpha}$ garante dissipação positiva.

A tensão de encruamento cinemático não-linear tem a forma apresentada na figura 3.2 onde $\mathrm{X}_{\infty}$ é o valor assintótico de $\mathrm{X}$ calculado para altas deformações. Para a obtenção deste valor considere-se a relação (3.8) que fornecerá: $\dot{X}=b \dot{\alpha}$, e considerando-se (3.14b) e (3.13) obtém-se:

$$
\dot{\mathrm{X}}=\mathrm{b} \dot{\lambda}\left(\operatorname{sign}\left(\sigma_{\mathrm{s}}-\mathrm{X}\right)-\frac{3}{2} \mathrm{aX}\right)
$$

admitindo-se que $\operatorname{sign}\left(\sigma_{\mathrm{s}}-\mathrm{X}\right)=1 \quad$ e uma vez que $\frac{3}{2} \mathrm{aX} \rightarrow 1 \Rightarrow \dot{\mathrm{X}} \rightarrow 0 \Rightarrow \mathrm{X} \rightarrow \mathrm{X}_{\infty}=\frac{2}{3 \mathrm{a}}$. A curva apresentada na figura 3.2 é obtida a partir da integração da expressão (3.15) a qual será detalhada no item relativo a implementação.

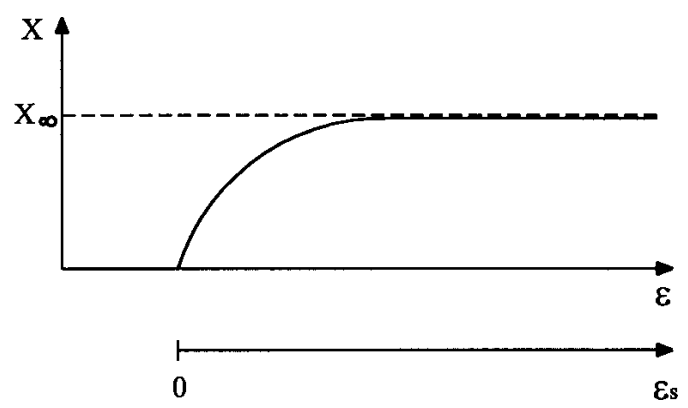

Figura 3.2 - Tensão de encruamento

É importante comentar algo relativamente à tensão de referência $\sigma_{\mathrm{y}}$ que aparece nas expressões (3.12) e (3.13). Enquanto nos metais a tensão total na qual ocorre o início da plastificação é um valor alto, o que equivale a um $\sigma_{\mathrm{y}}$ alto, neste modelo, devido ao acoplamento imposto com a danificação, a tensão de escorregamento associada ao início do encruamento é um valor comparativamente mais baixo, o que equivale a um $\sigma_{\mathrm{y}}$ mais baixo e que deve ser identificado experimentalmente. $\mathrm{O}$ significado da tensão $\sigma_{\mathrm{y}}$ neste modelo está apresentado na figura 3.3, onde estão apresentadas também as outras parcelas de tensão que compõem o modelo. 


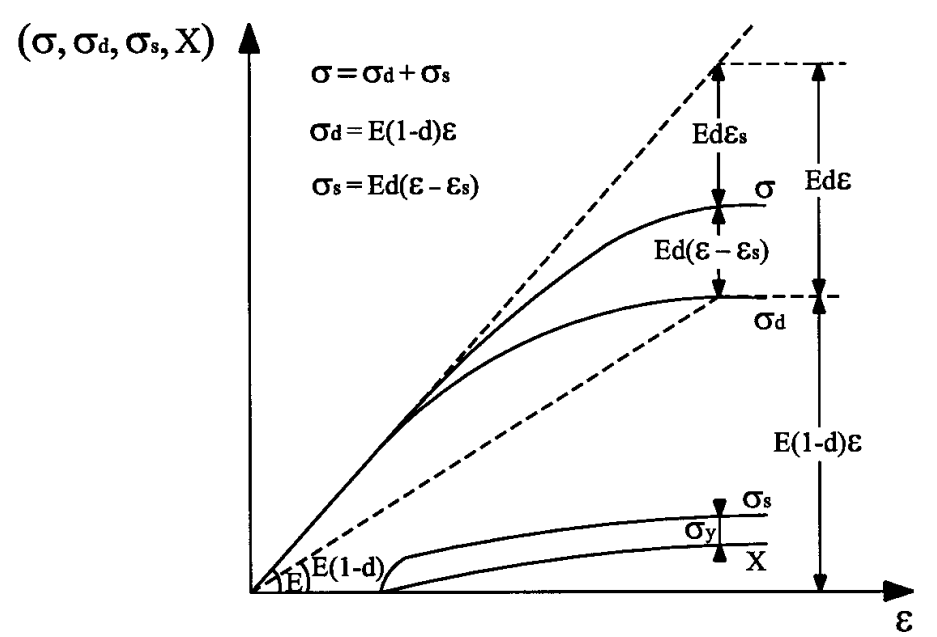

Figura 3.3 - Parcelas de tensão apresentadas no modelo

\subsection{REALIZAÇÃO DO LAÇO DE HISTERESE}

A histerese é aqui caracterizada pelo laço resultante da não coincidência das curvas definidas nas etapas de descarregamento e recarregamento no diagrama tensãodeformação do concreto.

Quando um espécime de concreto é submetido a um processo controlado de carregamento cíclico por compressão ou tração uniaxial, o diagrama tensão-deformação apresenta laços de histerese como pode ser observado nas figuras 3.4a e 3.4b.

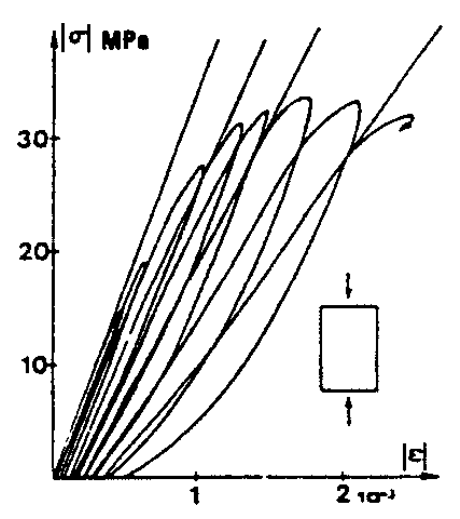

(a)

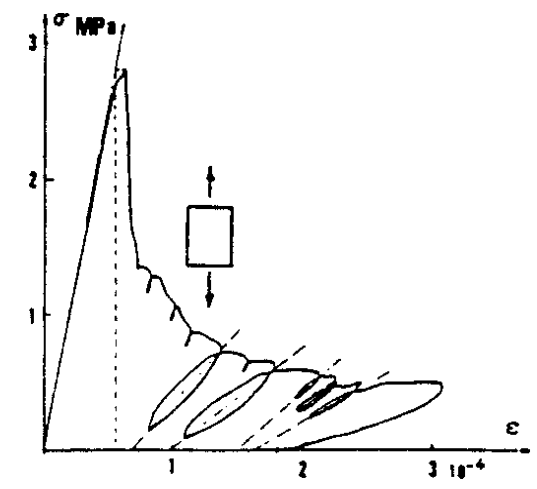

(b)

Figura 3.4 - Observação experimental dos laços de histerese em espécimes de concreto:

(a) em compressão, (b) em tração, ÁLVARES (1993) 
O modelo em análise permite reproduzir o laço de histerese gerado num ciclo de descarregamento e recarregamento, como indicado na figura 3.5a. Na descrição do laço são essenciais as variáveis de dano e deformação por escorregamento. Uma suposição básica é que a variável d está relacionada com o número e o tamanho das fissuras, enquanto a variável $\varepsilon_{\mathrm{s}}$ reflete um efeito dependente da forma que essas fissuras apresentam. Portanto uma variação para d tem correspondência com uma alteração no número e/ou no tamanho das fissuras, enquanto $\varepsilon_{\mathrm{s}}$ varia em decorrência de alterações nas formas resultantes de processos de abertura ou fechamento das fissuras. A partir dessas suposições o modelo considera que durante o descarregamento e o recarregamento somente a forma das fissuras se altera, por isso num ciclo d se mantém constante enquanto $\varepsilon_{\mathrm{s}}$ varia.

(a)

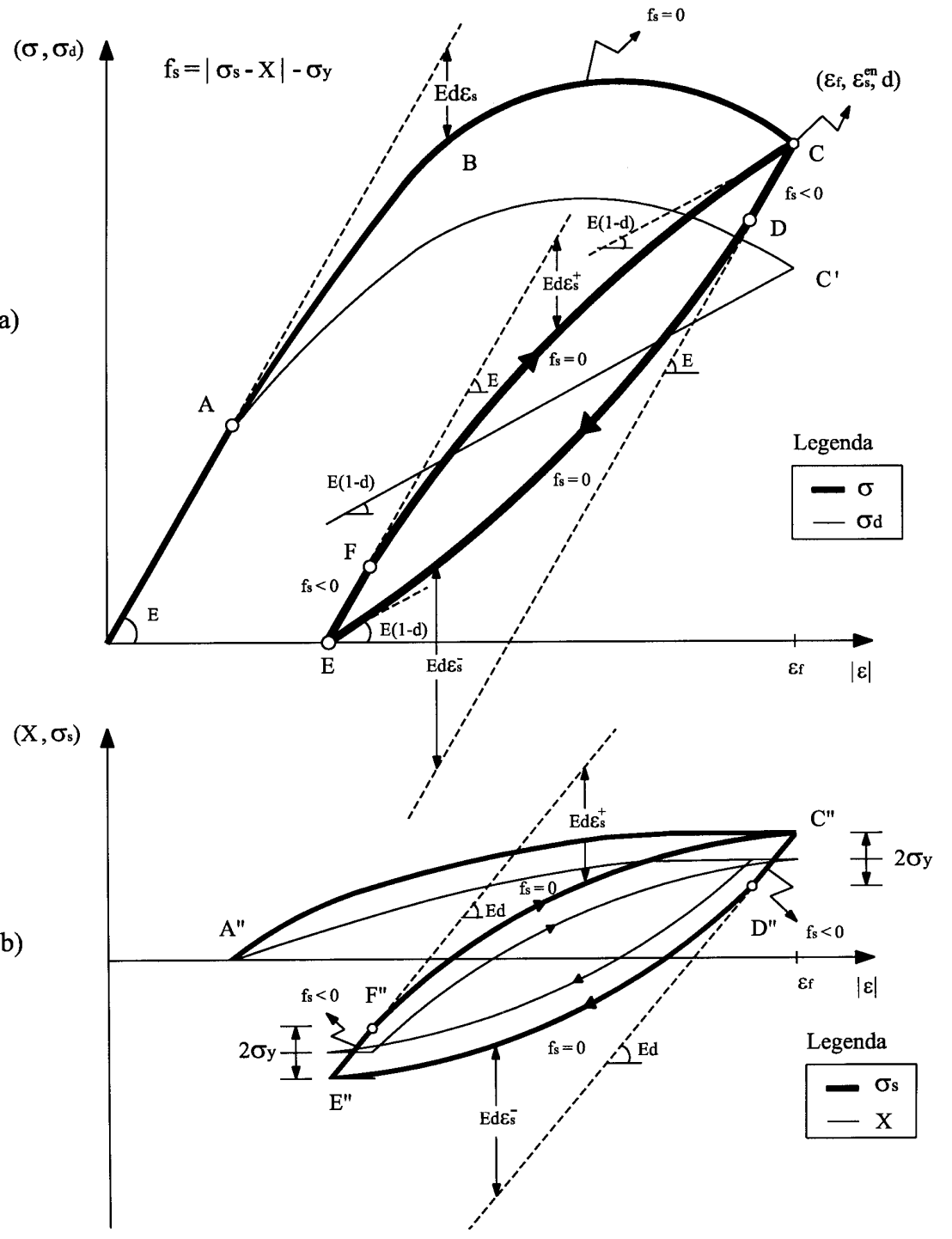

Figura 3.5 - Execução do laço de histerese: (a) tensões $\sigma$ e $\sigma_{\mathrm{d}}$, (b) tensões $\sigma_{\mathrm{s}}$ e X 
Observa-se na figura 3.5a que:

* Durante a etapa de carregamento (descrita pelo trecho $A-B-C$ ), uma vez que haja danificação $(\mathrm{d}>0)$ haverá a evolução da deformação por escorregamento. Num certo nível de deformação, como o indicado no ponto $\mathrm{B}$, a deformação $\varepsilon_{\mathrm{s}}$ será tal que as tensões $\sigma_{\mathrm{s}}$ e $\mathrm{X}$ atendam ao critério: $\mathrm{f}_{\mathrm{s}}=\left|\sigma_{\mathrm{s}}-\mathrm{X}\right|-\sigma_{\mathrm{y}}=0$. A tensão total pode ser dada pela expressão $\sigma=\mathrm{E} \varepsilon-\mathrm{Ed} \varepsilon_{\mathrm{s}}$ e portanto a parcela $-\mathrm{Ed} \varepsilon_{\mathrm{s}}$ é responsável por sua não-linearidade;

* Ao se iniciar o descarregamento (ponto $C$ ) num nível de deformação $\varepsilon_{\mathrm{f}}$, a correspondente deformação por escorregamento vale $\varepsilon_{\mathrm{s}}^{\mathrm{en}}$. Por sua vez o dano apresenta valor d e permanecerá constante durante toda a execução do laço, pois o critério de danificação deixa de ser violado. De fato, observando-se a curva da tensão elastodanificada $\sigma_{\mathrm{d}}$ (descrita na figura 3.5a por uma linha em traço fino), a partir do ponto $\left(C^{\prime}\right)$ passa-se a percorrer uma reta com inclinação $\mathrm{E}(1-\mathrm{d})$, tanto no descarregamento quanto no recarregamento;

* No trecho inicial de descarregamento (trecho $C-D$ ), a inclinação da curva que o descreve vale E. De fato, a relação que descreve o trecho é: $\sigma=\mathrm{E} \varepsilon-\mathrm{Ed} \varepsilon_{\mathrm{s}}$ e o produto $\mathrm{d} \varepsilon_{\mathrm{s}}$ é constante uma vez que os critérios de danificação e escorregamento deixam de ser violados. A deformação $\varepsilon_{\mathrm{s}}$ se manterá no valor $\varepsilon_{\mathrm{s}}^{\mathrm{en}}$ enquanto $\mathrm{o}$ critério de escorregamento não voltar a ser ultrapassado;

* Na figura 3.5b inclui-se a curva de X em traço fino. Procura-se ilustrar com o trecho ( $C$ ”- $D$ ”), o intervalo de variação da diferença $\left|\sigma_{\mathrm{s}}-\mathrm{X}\right|$ dentro do qual a critério não é violado;

* O laço se inicia no ponto $(D)$, a partir do qual o critério de escorregamento volta a ser violado. A deformação por escorregamento passa a diminuir e tem valor total dado pela expressão: $\varepsilon_{\mathrm{s}}=\varepsilon_{\mathrm{s}}^{\mathrm{en}}-\varepsilon_{\mathrm{s}}^{-}$, onde $\varepsilon_{\mathrm{s}}^{-}$é a parcela de deformação por escorregamento 
acumulada no descarregamento. A correspondente tensão por escorregamento diminui continuamente sendo calculada por $\sigma_{\mathrm{s}}=\mathrm{Ed} \varepsilon-\mathrm{Ed} \varepsilon_{\mathrm{s}}^{\mathrm{en}}+\mathrm{Ed} \varepsilon_{\mathrm{s}}^{-}$. A tensão por encruamento $\mathrm{X}$ também diminui devido ao decréscimo da deformação por escorregamento, conforme ilustrado na figura 3.5b. A tensão total, por sua vez, passa a ser calculada por $\sigma=\mathrm{E} \varepsilon-\mathrm{Ed} \varepsilon_{\mathrm{s}}^{\mathrm{en}}+\mathrm{Ed} \varepsilon_{\mathrm{s}}^{-}$. Observa-se que a parcela $\mathrm{Ed} \varepsilon_{\mathrm{s}}^{-}$é responsável pela não-linearidade da resposta global no descarregamento;

* Prosseguindo-se o descarregamento a tensão por encruamento, devido a lei de evolução adotada, apresenta tendência a um valor assintótico $X_{\infty}$. Em razão da retificação do critério com $\mathrm{f}_{\mathrm{s}}=\left|\sigma_{\mathrm{s}}-\mathrm{X}\right|-\sigma_{\mathrm{y}}=0$, a tensão por escorregamento também tenderá a um limite constante. Portanto a inclinação da curva da tensão total tenderá ao mesmo valor $\mathrm{E}(1-\mathrm{d})$ (no ponto $E$ da figura 3.5a) correspondente à inclinação da curva da tensão danificada, pois $\sigma=\sigma_{d}+\sigma_{s}$;

* Iniciando-se o recarregamento, o critério de escorregamento deixa de ser violado novamente (ao longo do trecho $E-F$ ). Com isso a deformação por escorregamento permanece com o valor calculado no fim do descarregamento (no ponto $E$ ), a curva da tensão por escorregamento apresenta inclinação Ed enquanto a curva da tensão total tem inclinação E;

* Prosseguindo-se o recarregamento o critério de escorregamento volta a ser violado a partir do ponto $(F)$, e disso resulta uma nova evolução da deformação por escorregamento. Essa deformação passa a ser representada por $\varepsilon_{\mathrm{s}}=\left(\varepsilon_{\mathrm{s}}^{\mathrm{en}}-\varepsilon_{\mathrm{s}}^{-}\right)+\varepsilon_{\mathrm{s}}^{+}$, onde $\varepsilon_{\mathrm{s}}^{+}$é a parcela da deformação por escorregamento gerada no recarregamento. A tensão total resulta a partir da expressão: $\sigma=\mathrm{E} \varepsilon-\operatorname{Ed}\left(\varepsilon_{\mathrm{s}}^{\mathrm{en}}-\varepsilon_{\mathrm{s}}^{-}\right)-\mathrm{Ed} \varepsilon_{\mathrm{s}}^{+}$, onde a parcela $-\mathrm{Ed} \varepsilon_{\mathrm{s}}^{+}$é a correção responsável por sua não-linearidade. A tensão por escorregamento passa a ser representada pela expressão: $\sigma_{\mathrm{s}}=\operatorname{Ed} \varepsilon-\operatorname{Ed}\left(\varepsilon_{\mathrm{s}}^{\mathrm{en}}-\varepsilon_{\mathrm{s}}^{-}\right)-\mathrm{Ed}_{\mathrm{s}}^{+}$; 
* No final do recarregamento a tensão por encruamento tende novamente a uma valor assintótico e devido a imposição de $\mathrm{f}_{\mathrm{s}}=\left|\sigma_{\mathrm{s}}-\mathrm{X}\right|-\sigma_{\mathrm{y}}=0$ a tensão por escorregamento tende a um valor constante. Assim a inclinação da curva da tensão total tenderá ao mesmo valor $\mathrm{E}(1-\mathrm{d})$ correspondente a inclinação da curva da tensão danificada.

* Quando a deformação retorna para o valor $\varepsilon_{f}$, e uma vez que $X$ tenda para $X_{\infty}$, a deformação por escorregamento volta a ter o valor $\varepsilon_{\mathrm{s}}^{\text {en }}$, uma vez que neste nível de deformação $\varepsilon_{\mathrm{s}}^{+}=\varepsilon_{\mathrm{s}}^{-}$. Portanto, conclui-se que toda a variação na deformação $\varepsilon_{\mathrm{s}}$ e nas tensões $\sigma, \sigma_{\mathrm{s}}$ e X, durante o descarregamento, é desfeita no recarregamento.

\subsection{IMPLEMENTAÇÃO PARA O CASO UNIDIMENSIONAL}

Como já foi comentado anteriormente, algumas modificações sobre o modelo originalmente proposto foram adotadas para viabilizar uma análise mais detalhada possibilitando a aplicação desse modelo no programa desenvolvido por PAULA (2001), o qual trabalha com modelos de dano escalar.

Uma das modificações adotadas consiste em quantificar o dano mediante uma variável escalar e para o seu cálculo adota-se uma lei exponencial igual a do modelo de MAZARS (1984). Porém, a determinação paramétrica muda em relação àquele modelo, uma vez que, no modelo de MAZARS et al. (2000), a tensão total é igual a soma da tensão elasto-danificada com a tensão por escorregamento.

Por outro lado, como no modelo original, a integração para a obtenção da deformação por escorregamento pode ser feita a partir de um algoritmo iterativo, composto de etapas de previsão e correção, originalmente proposto por ORTIZ \& SIMO (1986).

Para o cálculo de $\varepsilon_{\mathrm{s} n+1}^{(\mathrm{i}+1)}$, onde $\mathrm{i}+1$ refere-se à iteração e $\mathrm{n}+1$ ao passo de carga, a superfície representativa do critério de deslizamento $\left(f_{s}=0\right)$ é linearizada a partir do valor corrente das variáveis de estado na iteração i do mesmo passo, MAZARS et al. (2000): 


$$
\mathrm{f}_{\mathrm{s}}^{(\mathrm{i}+1)}=\mathrm{f}_{\mathrm{s}}^{(\mathrm{i})}+\left.\frac{\partial \mathrm{f}_{\mathrm{s}}}{\partial \sigma_{\mathrm{s}}}\right|^{(\mathrm{i})}\left(\sigma_{\mathrm{s}}{ }^{(\mathrm{i}+1)}-\sigma_{\mathrm{s}}{ }^{(\mathrm{i})}\right)+\left.\frac{\partial \mathrm{f}_{\mathrm{s}}}{\partial \mathrm{X}}\right|^{(\mathrm{i})}\left(\mathrm{X}^{(\mathrm{i}+1)}-\mathrm{X}^{(\mathrm{i})}\right)=0
$$

Sabendo-se que:

$$
\dot{\mathrm{X}}^{(\mathrm{i})}=\mathrm{b} \dot{\alpha}^{(\mathrm{i})}=-\mathrm{b}\left(\dot{\lambda} \frac{\partial \phi_{\mathrm{s}}}{\partial \mathrm{X}}\right)^{(\mathrm{i})}
$$

e

$$
\dot{\sigma}_{\mathrm{s}}^{(\mathrm{i})}=-\mathrm{Ed} \dot{\varepsilon}_{\mathrm{s}}^{(\mathrm{i})}=-\mathrm{Ed}\left(\dot{\lambda} \frac{\partial \phi_{\mathrm{s}}}{\partial \sigma_{\mathrm{s}}}\right)^{(\mathrm{i})}
$$

onde, d se refere a variável de dano calculada no passo $n+1$, e adotando-se uma relação explícita tal que: $\dot{\mathrm{X}}^{(\mathrm{i})} \Delta \mathrm{t}=\mathrm{X}^{(\mathrm{i}+1)}-\mathrm{X}^{(\mathrm{i})}$ e $\dot{\sigma}_{\mathrm{s}}{ }^{(\mathrm{i})} \Delta \mathrm{t}=\sigma_{\mathrm{s}}{ }^{(\mathrm{i}+1)}-\sigma_{\mathrm{s}}{ }^{(\mathrm{i})}$, pela substituição das equações (3.17) e (3.18) na equação (3.16), obtém-se o multiplicador plástico:

$$
\Delta \lambda^{(\mathrm{i})}=\dot{\lambda}^{(\mathrm{i})} \Delta \mathrm{t}=\frac{\left.\left.\frac{\partial \mathrm{f}_{\mathrm{s}}}{\partial \sigma_{\mathrm{s}}}\right|^{(\mathrm{i})} \mathrm{Ed} \frac{\partial \phi_{\mathrm{s}}}{\partial \sigma_{\mathrm{s}}}\right|^{(\mathrm{i})}+\left.\left.\frac{\partial \mathrm{f}_{\mathrm{s}}}{\partial \mathrm{X}}\right|^{(\mathrm{i})} \mathrm{b} \frac{\partial \phi_{\mathrm{s}}}{\partial \mathrm{X}}\right|^{(\mathrm{i})}}{}
$$

No quadro 3.1 resume-se o algorítimo utilizado na integração do modelo constitutivo.

Sejam conhecidos do final do passo anterior: $\varepsilon_{\mathrm{n}}, \mathrm{X}_{\mathrm{n}}, \mathrm{d}_{\mathrm{n}}$, e $\varepsilon_{\mathrm{s} n}$. Dado o incremento de deformação total: $\Delta \varepsilon_{\mathrm{n}+1}$, seguem os seguintes passos:

Passo 1: Atualização da deformação;

$$
\varepsilon_{\mathrm{n}+1}=\varepsilon_{\mathrm{n}}+\Delta \varepsilon_{\mathrm{n}+1}
$$

Passo2: Atualização do dano 


$$
\begin{aligned}
& \hat{\varepsilon}_{\mathrm{n}+1}=\hat{\varepsilon}\left(\varepsilon_{\mathrm{n}+1}\right) \\
& \mathrm{f}(\hat{\varepsilon}, d)_{n+1}=\hat{\varepsilon}_{\mathrm{n}+1}-s(d)_{\mathrm{n}} \leq 0 ?
\end{aligned}
$$

OBS: $\mathrm{s}(0)=\varepsilon_{\mathrm{do}}$ e se no passo $\mathrm{n} \hat{\varepsilon}>\varepsilon_{\mathrm{do}} \Rightarrow \mathrm{s}(\mathrm{d})_{\mathrm{n}}=\hat{\varepsilon}_{\mathrm{n}}$; em geral no caso unidimensional, $\hat{\varepsilon}=\varepsilon$ se $\varepsilon>0$ e $\hat{\varepsilon}=-\nu \sqrt{2} \varepsilon$ se $\varepsilon<0$.

Se $f(\hat{\varepsilon}, d)_{n+1}>0$ então faça:

$$
\begin{aligned}
& \mathrm{s}(\mathrm{d})_{\mathrm{n}+1}=\hat{\varepsilon}_{\mathrm{n}+1} \\
& \text { Se } \varepsilon>0 \Rightarrow \mathrm{d}_{\mathrm{n}+1}=1-\frac{\varepsilon_{\mathrm{d} 0}\left(1-\mathrm{A}_{\mathrm{T}}\right)}{\hat{\varepsilon}_{\mathrm{n}+1}}-\frac{\mathrm{A}_{\mathrm{T}}}{\exp \left[\mathrm{B}_{\mathrm{T}}\left(\hat{\varepsilon}_{\mathrm{n}+1}-\varepsilon_{\mathrm{d} 0}\right)\right]} \\
& \text { Se } \varepsilon<0 \Rightarrow \mathrm{d}_{\mathrm{n}+1}=1-\frac{\varepsilon_{\mathrm{d} 0}\left(1-\mathrm{A}_{\mathrm{C}}\right)}{\hat{\varepsilon}_{\mathrm{n}+1}}-\frac{\mathrm{A}_{\mathrm{C}}}{\exp \left[\mathrm{B}_{\mathrm{C}}\left(\hat{\varepsilon}_{\mathrm{n}+1}-\varepsilon_{\mathrm{d} 0}\right)\right]}
\end{aligned}
$$

Caso contrário faça:

$$
\mathrm{d}_{\mathrm{n}+1}=\mathrm{d}_{\mathrm{n}}
$$

Passo 3: Cálculo da tensão danificada

$$
\sigma_{\mathrm{d} n+1}=\mathrm{E}\left(1-\mathrm{d}_{\mathrm{n}+1}\right) \varepsilon_{\mathrm{n}+1}
$$

Passo 4: Etapa de previsão

$$
\begin{aligned}
& \text { Primeira iteração } i=1 \\
& \varepsilon_{\mathrm{s}}^{(\mathrm{i})}{ }_{\mathrm{n}+1}=\varepsilon_{\mathrm{s} n} \\
& \mathrm{X}^{(\mathrm{i})}{ }_{\mathrm{n}+1}=\mathrm{X}_{\mathrm{n}}
\end{aligned}
$$




$$
\begin{aligned}
& \sigma_{\mathrm{s}}^{(\mathrm{i})}{ }_{\mathrm{n}+1}=\mathrm{Ed}_{\mathrm{n}+1}\left(\varepsilon_{\mathrm{n}+1}-\varepsilon_{\mathrm{s} n+1}^{(\mathrm{i})}\right) \\
& \sigma_{\mathrm{n}+1}^{(\mathrm{i})}=\sigma_{\mathrm{d} n+1}+\sigma_{\mathrm{s} n+1}^{(\mathrm{i})}
\end{aligned}
$$

Passo5: Verificação da previsão

$$
\mathrm{f}_{\mathrm{s}}^{(\mathrm{i})}{ }_{\mathrm{n}+1}=\left|\sigma_{\mathrm{s}}^{(\mathrm{i})}{ }_{\mathrm{n}+1}-\mathrm{X}^{(\mathrm{i})}{ }_{\mathrm{n}+1}\right|-\sigma_{\mathrm{y}} \leq 0 \quad ?
$$

$\mathrm{SIM} \Rightarrow$ a previsão está correta, sair deste algoritmo e ir para a etapa global de verificação do equilíbrio.

$\mathrm{NÃO} \Rightarrow$ fazer a correção nos valores adotados na previsão, dentro do passo 6

Passo6: Cálculo do multiplicador plástico e correção

$$
\Delta \lambda_{n+1}^{(i)}=\frac{f_{s}^{(i)} f_{n}}{\left.\left.\frac{\partial f_{s}}{\partial \sigma_{s}}\right|_{n+1} ^{(i)} E d_{n+1} \frac{\partial \phi_{s}}{\partial \sigma_{s}}\right|_{n+1} ^{(i)}+\left.\left.\frac{\partial f_{s}}{\partial X}\right|_{n+1} ^{(i)} b \frac{\partial \phi_{s}}{\partial X}\right|_{n+1} ^{(i)}}
$$

onde:

$$
\begin{aligned}
& \left.\frac{\partial \mathrm{f}_{\mathrm{s}}}{\partial \sigma_{\mathrm{s}}}\right|_{\mathrm{n}+1} ^{(\mathrm{i})}=\operatorname{sign}\left(\sigma_{\mathrm{s}}{ }^{(\mathrm{i})}{ }_{\mathrm{n}+1}-\mathrm{X}^{(\mathrm{i})}{ }_{\mathrm{n}+1}\right) ; \\
& \left.\frac{\partial \phi_{\mathrm{s}}}{\partial \sigma_{\mathrm{s}}}\right|_{\mathrm{n}+1} ^{(\mathrm{i})}=\operatorname{sign}\left(\sigma_{\mathrm{s}}{ }^{(\mathrm{i})}{ }_{\mathrm{n}+1}-\mathrm{X}^{(\mathrm{i})}{ }_{\mathrm{n}+1}\right)+\frac{\mathrm{c}}{3} ; \\
& \left.\frac{\partial \mathrm{f}_{\mathrm{s}}}{\partial \mathrm{X}}\right|_{\mathrm{n}+1} ^{(\mathrm{i})}=-\operatorname{sign}\left(\sigma_{\mathrm{s}}{ }^{(\mathrm{i})} \mathrm{n+1}-\mathrm{X}^{(\mathrm{i})}{ }_{\mathrm{n}+1}\right) ; \\
& \left.\frac{\partial \phi_{\mathrm{s}}}{\partial \mathrm{X}}\right|_{\mathrm{n}+1} ^{(\mathrm{i})}=-\operatorname{sign}\left(\sigma_{\mathrm{s}}{ }^{(\mathrm{i})}{ }_{\mathrm{n}+1}-\mathrm{X}^{(\mathrm{i})}{ }_{\mathrm{n}+1}\right)+\frac{3}{2} \mathrm{a} \mathrm{X}^{(\mathrm{i})}{ }_{\mathrm{n}+1}
\end{aligned}
$$




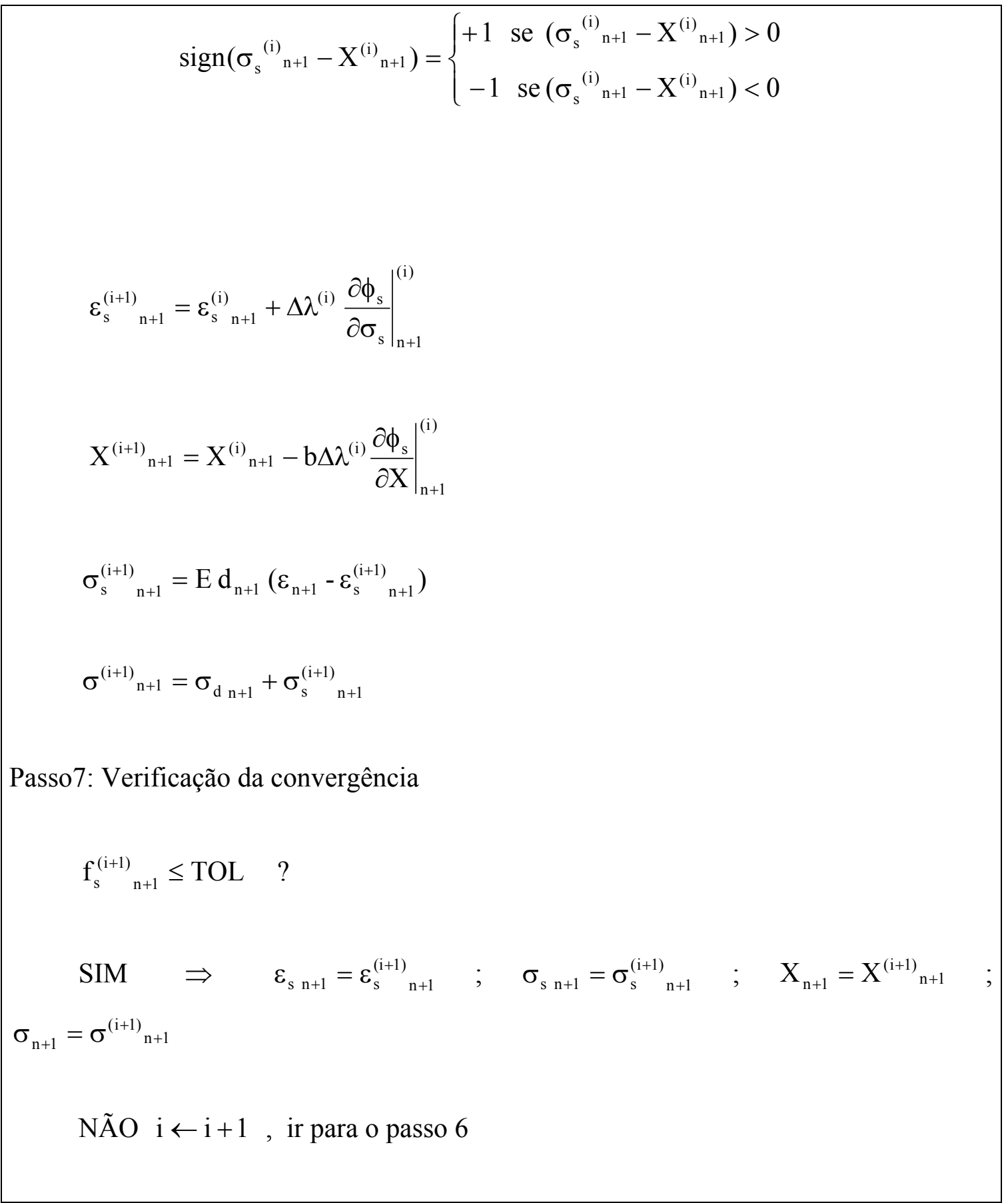

Quadro 3.1 - Algoritmo para integração do modelo constitutivo com dano contínuo e escorregamento, no caso unidimensional.

\subsection{EXEMPLOS DE APLICAÇÃO DO MODELO}

A primeira aplicação do modelo é feita no sentido de representar os ciclos de histerese de espécimes submetidos a tração e a compressão uniaxial. Na figura 3.6 tem- 
se as curvas apresentadas por MAZARS et al. (2000) para demonstrar a habilidade do modelo em reproduzir laços de histerese.
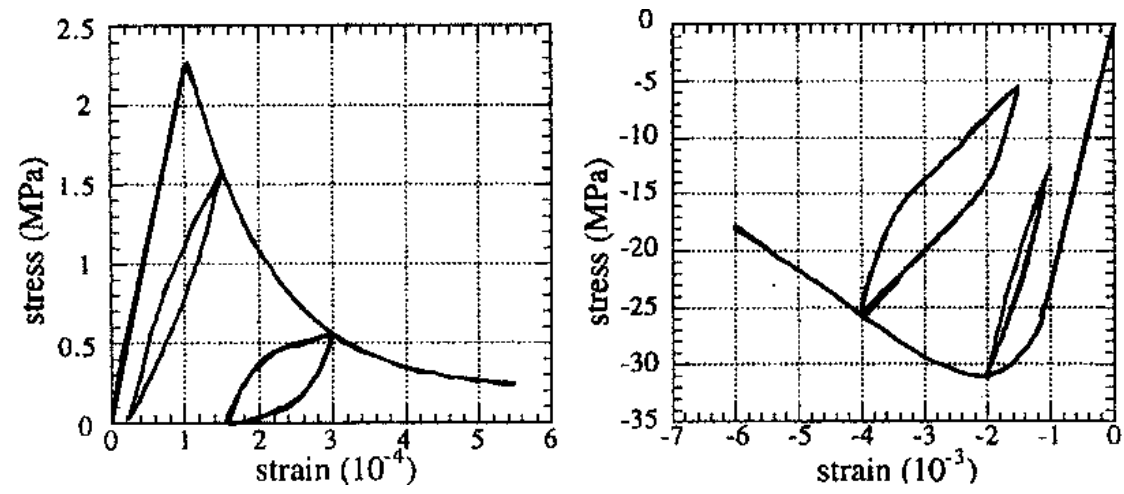

Figura 3.6 - Resposta tensão/deformação, MAZARS et al. (2000)

As curvas apresentadas na figura 3.7 têm por objetivo reproduzir os mesmos resultados apresentados por MAZARS et al. (2000), porém com a versão adaptada conforme as modificações descritas neste trabalho. Para tal, os parâmetros utilizados foram:

- Concreto: $\mathrm{E}_{\mathrm{c}}=23000 \mathrm{MPa}, v=0,24$.

- Escorregamento: $\mathrm{c}=0,09 ; \sigma_{\mathrm{y} \text { tração }}=0,17 \mathrm{MPa} ; \sigma_{\mathrm{y} \text { compressão }}=0,30 \mathrm{MPa}$; $b_{\text {tração }}=1000 \mathrm{MPa} ; b_{\text {compressão }}=4000 \mathrm{MPa} ; a_{\text {tração }}=5 \mathrm{MPa}^{-1} ; a_{\text {compressão }}=0,39 \mathrm{MPa}^{-1}$;

- Dano: $\varepsilon_{\mathrm{do}}=0,0001 ; \mathrm{At}=0,995 ; \mathrm{Bt}=15500 ; \mathrm{Ac}=0,995 ; \mathrm{Bc}=1000$.
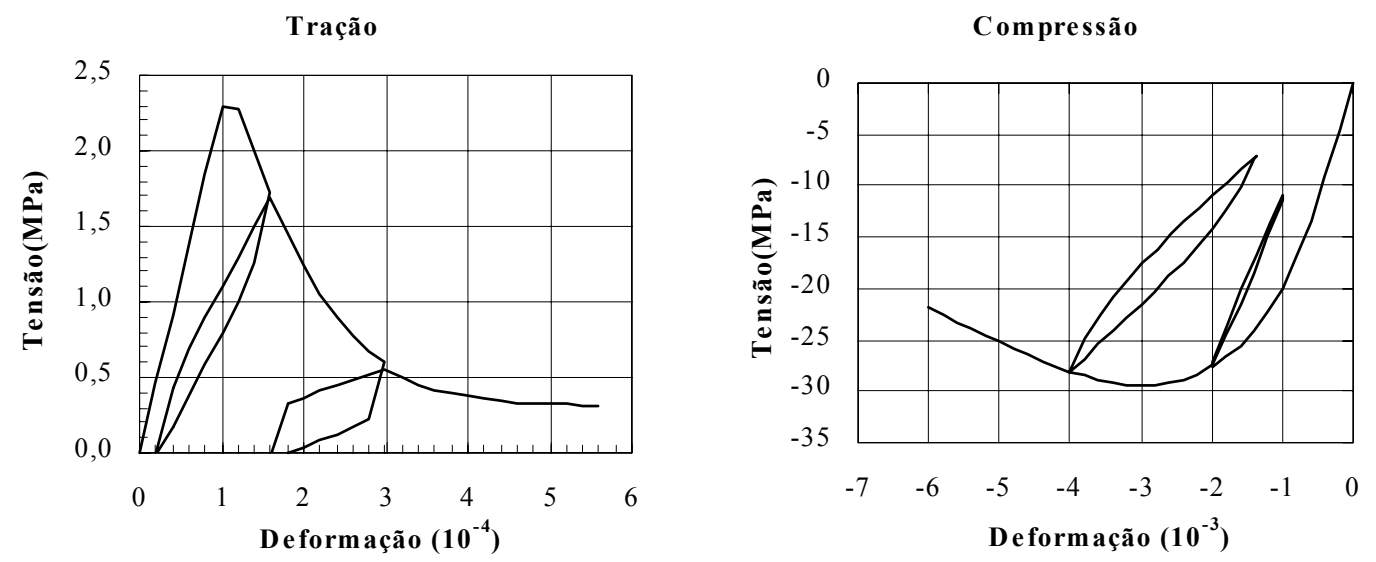

Figura 3.7 - Resposta tensão/deformação, considerando-se a proposta deste trabalho 
As variáveis de dano e escorregamento utilizadas na obtenção das curvas da figura 3.7 foram calibradas no sentido de se chegar o mais próximo possível das curvas apresentadas na figura 3.6. A comparação entre as curvas das figuras 3.6 e 3.7 mostra que há uma boa concordância entre os resultados apresentados, apesar de, neste trabalho, o dano estar sendo descrito segundo uma variável escalar.

Os Parâmetros adotados para a obtenção das curvas das figuras 3.8; 3.9; 3.10; 3.11 e 3.12, são:

- Concreto: $\mathrm{E}_{\mathrm{c}}=29200 \mathrm{MPa}, v=0,20$.

- Escorregamento: $\sigma_{\mathrm{y}}$ tração $=0,17 \mathrm{MPa} ; \sigma_{\mathrm{y}}$ compressão $=0,30 \mathrm{MPa}$; $b_{\text {tração }}=1000 \mathrm{MPa} ; b_{\text {compressão }}=5000 \mathrm{MPa} ; a_{\text {tração }}=5 \mathrm{MPa}^{-1} ; a_{\text {compressão }}=0,39 \mathrm{MPa}^{-1}$; $\mathrm{c}=0,09$.

- Dano: $\varepsilon_{\mathrm{do}}=0,00007 ; \mathrm{At}=0,995 ; \mathrm{Bt}=9500 ; \mathrm{Ac}=0,865 ; \mathrm{Bc}=1125$.
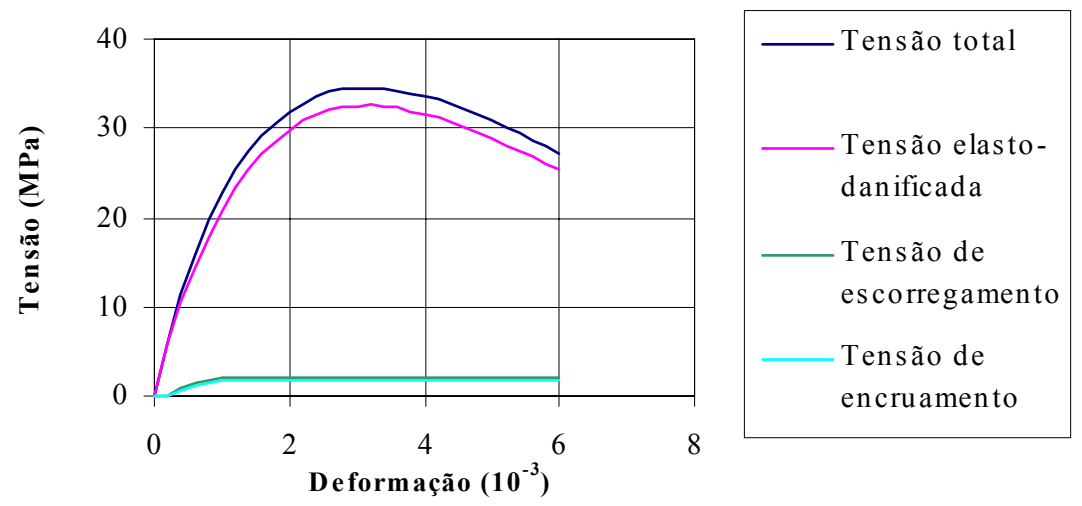

(a)

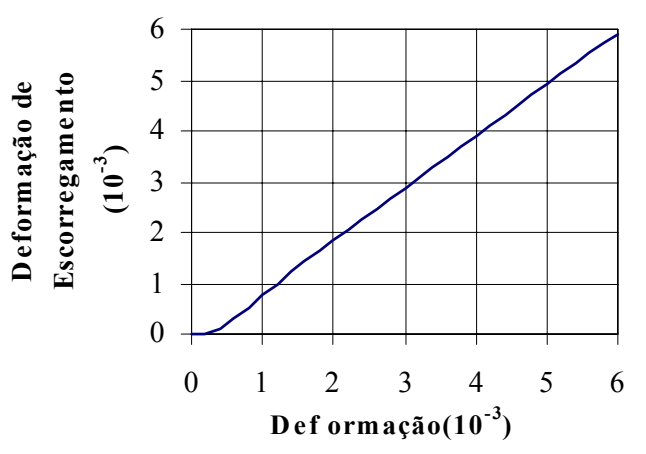

(b)

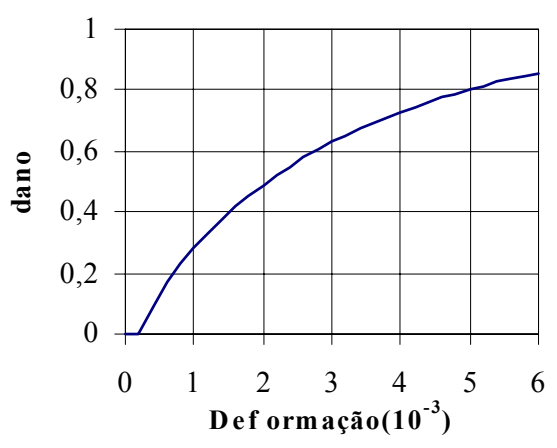

(c)

Figura 3.8 - Comportamento das variáveis para o caso da compressão uniaxial: (a) parcelas de tensão, (b) deformação por escorregamento, (c) variável escalar de dano 
Nas curvas da figura 3.8 tem-se a representação do comportamento das diferentes componentes da tensão total (a), da deformação por escorregamento (b) e do dano (c), para o caso de um espécime submetido à compressão uniaxial. Enquanto nas curvas da figura 3.9 o caso estudado foi o de um espécime submetido à tração uniaxial.

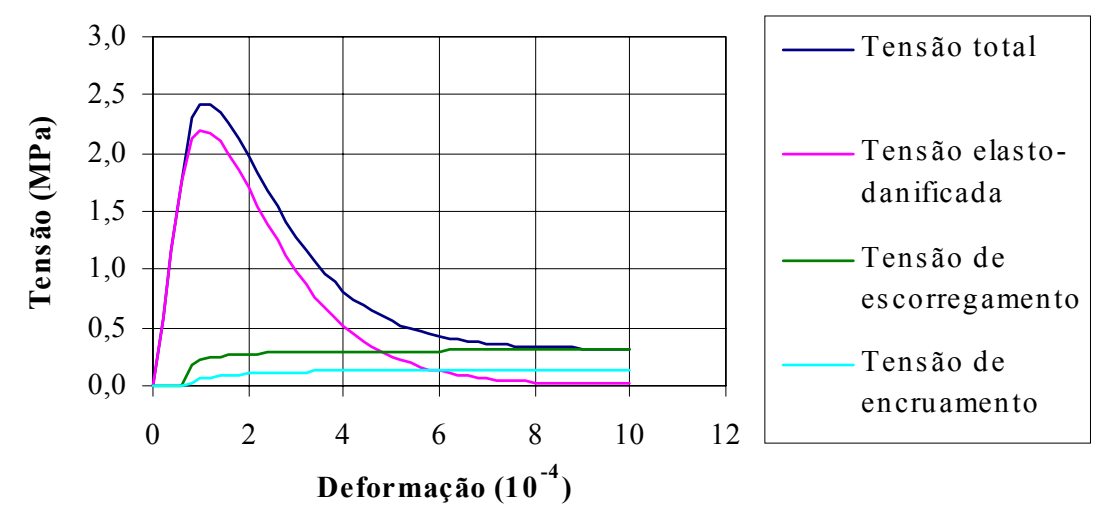

(a)

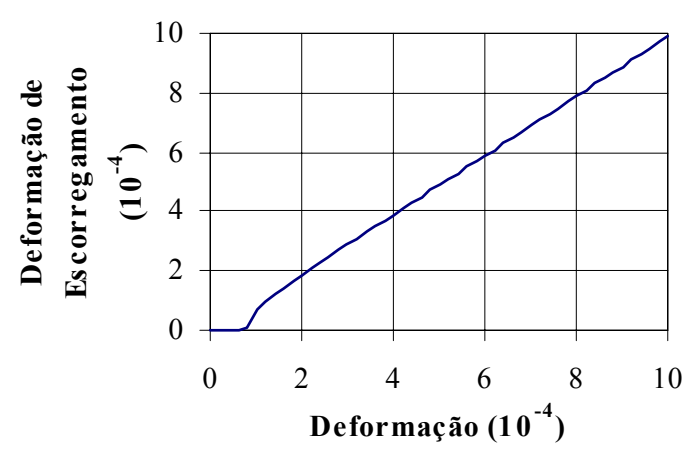

(b)

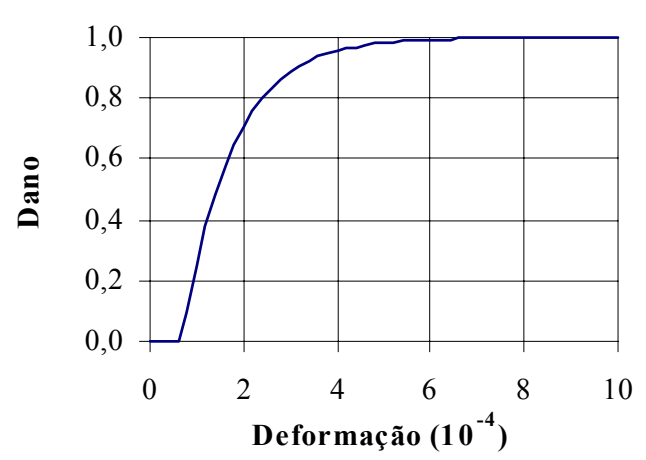

(c)

Figura 3.9 - Comportamento das variáveis para o caso da tração uniaxial: (a) parcelas de tensão, (b) deformação por escorregamento, (c) variável escalar de dano

No segundo exemplo, procura-se detalhar mais as componentes de tensão do modelo, mas ainda considerando-se casos uniaxiais de tração e compressão.

Nas curvas da figura 3.10 ilustra-se o comportamento das diferentes componentes de tensão, e deformação por escorregamento para o caso da execução de um laço em tração uniaxial. Observa-se que os resultados estão de acordo com o esquema apresentado na figura 3.5. 


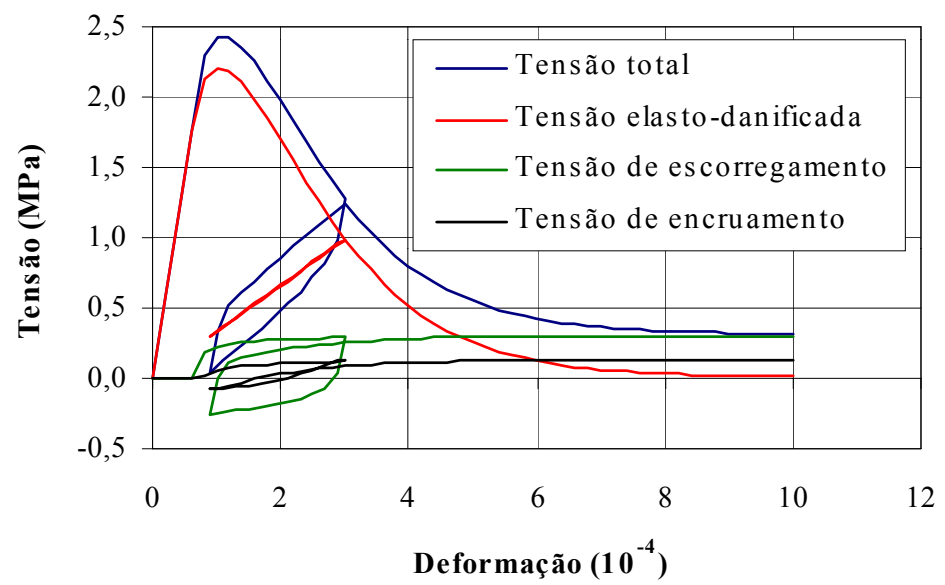

(a)

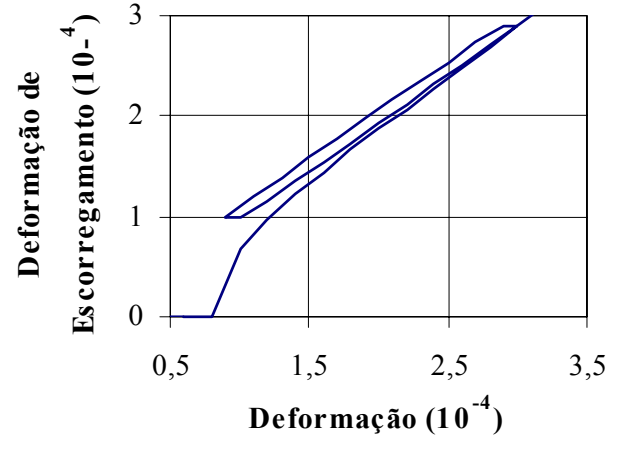

(b)

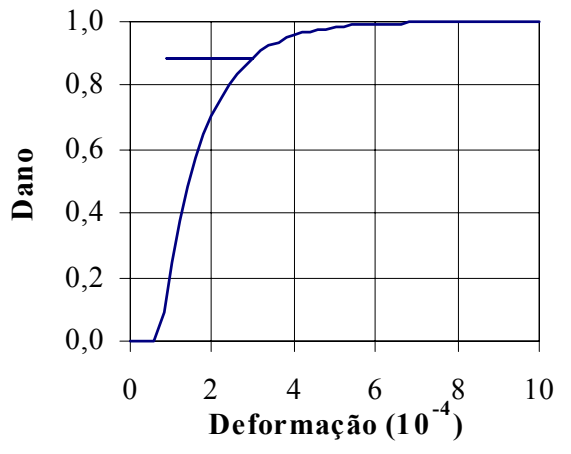

(c)

Figura 3.10 - Laço em tração: (a) Parcelas de tensão, (b) deformação por escorregamento, (c) dano

Nas figuras 3.11 e 3.12 tem-se a execução de vários laços para o caso de espécimes submetidos à compressão e a tração uniaxial respectivamente.

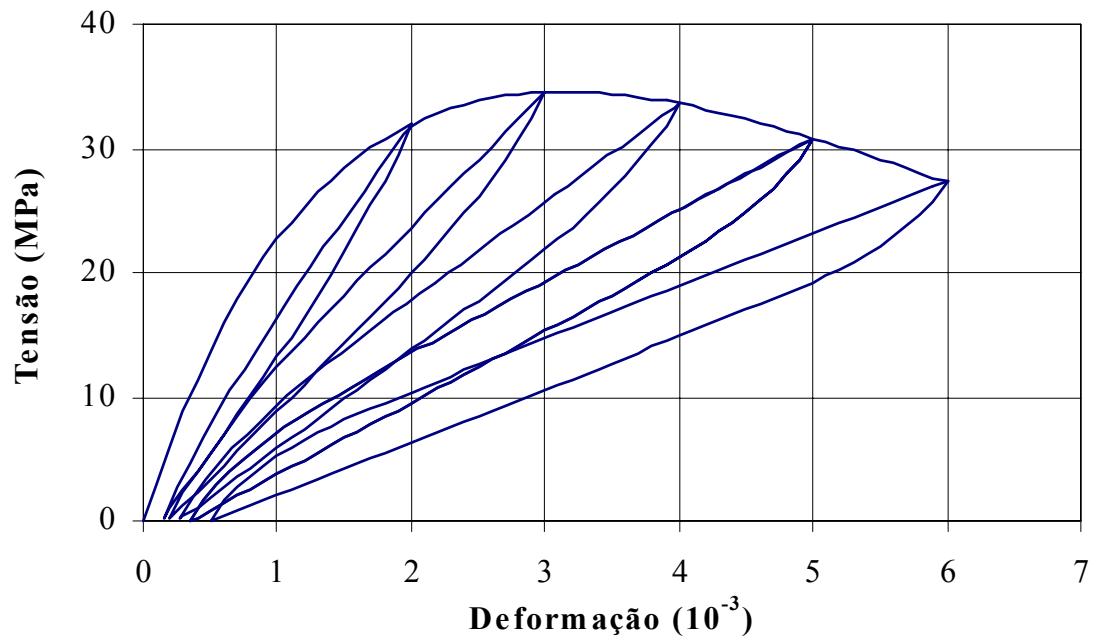

Figura 3.11 - Vários laços em compressão 


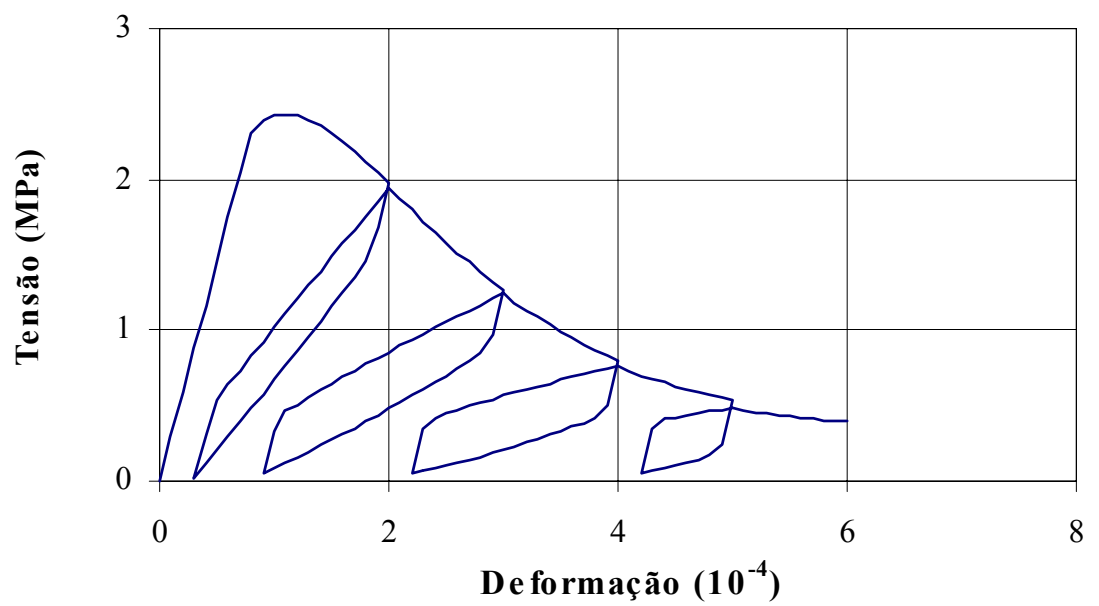

Figura 3.12 - Vários laços em tração

Nos últimos exemplos tem-se por objetivo avaliar a influência dos parâmetros $a$ e $b$, que aparecem nas leis de evolução da tensão por encruamento $\mathrm{X}$, e que estão presentes nas expressões (3.13) e (3.15), são apresentadas as respostas em termos das tensões total e de encruamento.

Na figura 3.13 tem-se a análise da influência do parâmetro $a$, enquanto que na figura 3.14 analisa-se a influência do parâmetro $b$. Em ambos os casos apresenta-se também a curva da tensão total tendo-se em vista que esta é influenciada pela tensão de encruamento. As análises foram feitas considerando-se o caso da tração, porém para o caso da compressão os comportamentos são análogos. Os parâmetros básicos utilizados estão apresentados abaixo. Durante a análise da influência de um parâmetro os outros são mantidos constantes.

- Concreto: $\mathrm{E}_{\mathrm{c}}=29200 \mathrm{MPa}, v=0,20$.

- Escorregamento: $\sigma_{\mathrm{y} \text { tração }}=0,05 \mathrm{MPa} ; b_{\text {tração }}=6000 \mathrm{MPa} ; a_{\text {tração }}=1,3 \mathrm{MPa}^{-1}$; $\mathrm{c}=0,09$.

- Dano: $\varepsilon_{\mathrm{do}}=0,00007 ; \mathrm{At}=0,995 ; \mathrm{Bt}=9500$. 
Tração

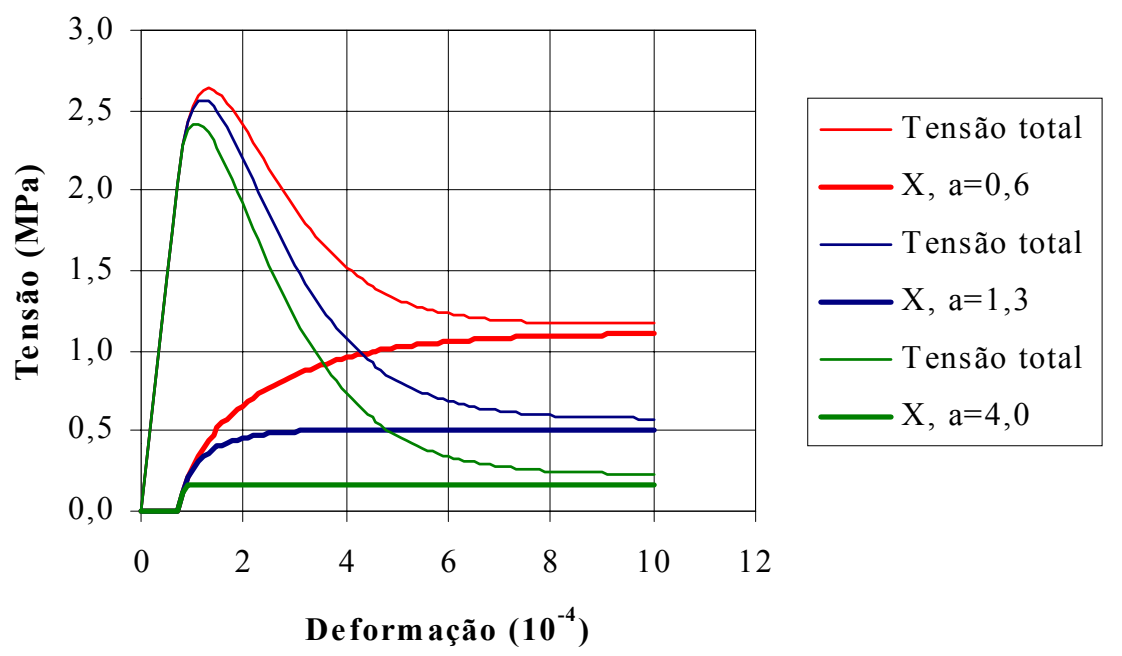

Figura 3.13 - Influência do parâmetro $a$

Para a análise da figura 3.13 é importante lembrar que: $X_{\infty}=\frac{2}{3 \mathrm{a}}$.

Tração
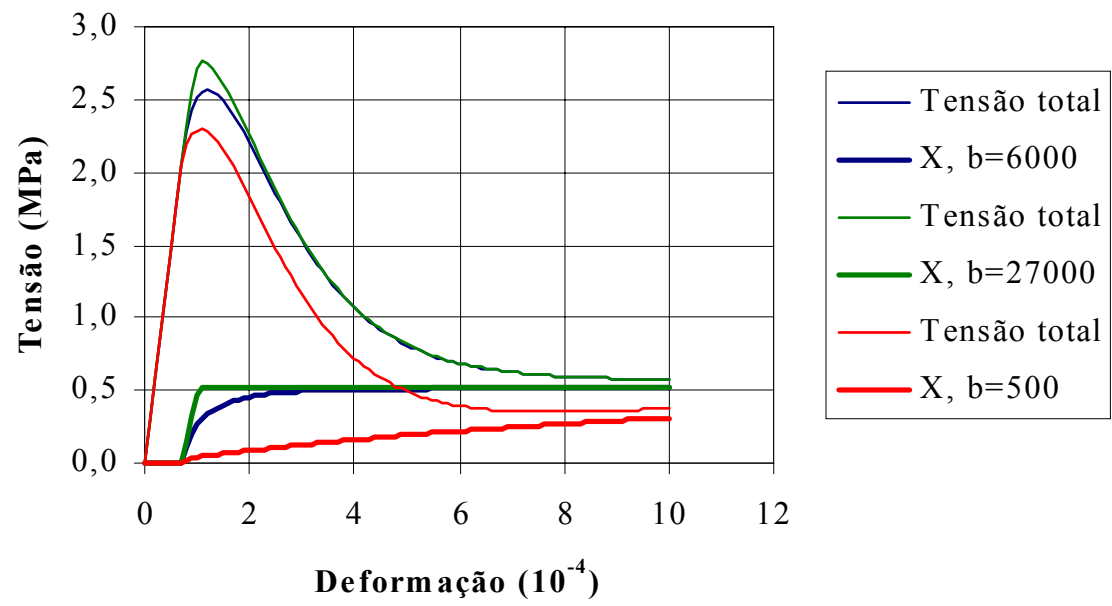

Figura 3.14 - Influência do parâmetro $b$

Vale lembrar que a influência da tensão X na tensão total é devido ao fato de que com a evolução do escorregamento se estabelece: $\mathrm{f}_{\mathrm{s}}=\left|\sigma_{\mathrm{s}}-\mathrm{X}\right|-\sigma_{\mathrm{y}}=0$, e a tensão total é dada por: $\sigma=\sigma_{\mathrm{d}}+\sigma_{\mathrm{s}}$. 


\subsection{AMORTECIMENTO E HISTERESE}

Neste item tem-se por objetivo analisar a capacidade do modelo constitutivo em estudo em descrever o amortecimento de uma estrutura em regime de solicitação dinâmica. Para tal, estuda-se o comportamento simulado para a estrutura apresentada na figura 3.15, carregada por uma força aplicada subitamente e mantida constante durante toda a análise.

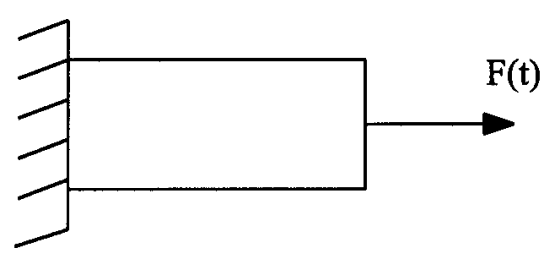

Figura 3.15 - Estrutura submetida a carregamento dinâmico

Como resposta geral esperada, após atingir um deslocamento máximo a estrutura passa a apresentar um movimento oscilatório com amortecimento, devido à danificação, tendendo para a posição de equilíbrio estático. Durante este movimento ocorrem sucessivos ciclos de descarregamento e recarregamento.

Inicialmente, considere-se que o modelo constitutivo do material seja o modelo de MAZARS (1984), cuja expressão para o cálculo da tensão é: $\sigma=\mathrm{E}(1-\mathrm{d}) \varepsilon$. Para este modelo a não-linearidade no diagrama tensão-deformação decorre exclusivamente da evolução da variável $\mathrm{d}$, a qual pode evoluir somente durante a resposta inicial até a estrutura atingir o deslocamento máximo, mantendo-se constante durante os ciclos de descarregamento e recarregamento. Isso significa que durante o descarregamento e recarregamento o modelo não é capaz de representar uma dissipação adicional de energia. Com isso toda a energia recuperada no descarregamento pode ser utilizada no recarregamento possibilitando que a estrutura retorne ao mesmo nível de deslocamento máximo.

Portanto, conclui-se que com esse modelo, não é possível reproduzir o amortecimento na resposta de uma estrutura submetida à solicitação dinâmica, que poderia ser esperado exclusivamente em razão da danificação. É necessário fazer uso da 
parcela de amortecimento viscoso na equação do movimento para simular algum amortecimento estrutural. Este fato foi verificado por PAULA (2001).

Considere-se agora que o modelo de MAZARS et al. (2000) representa o modelo constitutivo do material da estrutura em análise. Neste caso a expressão de cálculo da tensão é: $\sigma=\mathrm{E}(1-\mathrm{d}) \varepsilon+\mathrm{Ed}\left(\varepsilon-\varepsilon_{\mathrm{s}}\right)$. Observa-se que para este modelo a não-linearidade no diagrama tensão-deformação é devida tanto à evolução da variável d quanto da deformação de escorregamento $\varepsilon_{\mathrm{s}}$. Do mesmo modo, como no modelo anterior, a variável d evolui apenas no carregamento, porém a variável $\varepsilon_{\mathrm{s}}$ evolui tanto no carregamento quanto nos ciclos de descarregamento e recarregamento. Uma vez que a deformação $\varepsilon_{\mathrm{s}}$ permite levar em conta o fenômeno de fricção interna nas faces das fissuras, isso significa que o modelo é capaz de representar a dissipação adicional de energia que ocorre tanto no descarregamento quanto no recarregamento devido a esse fenômeno de fricção.

Portanto, conclui-se que este modelo é capaz de introduzir amortecimento sobre a resposta de uma estrutura submetida à solicitação dinâmica sem que seja necessário introduzir a parcela de amortecimento viscoso na equação do movimento. $O$ amortecimento fornecido pelo modelo decorre da dissipação de energia ocasionada pela fricção interna nas superfícies das fissuras durante as fases de descarrecamento e recarregamento.

Na figura 3.16 tem-se a representação da deformação apresentada pela estrutura da figura 3.15, ao longo do tempo, uma vez que se considerem os modelo de MAZARS (1984) e MAZARS et al. (2000). É importante ressaltar que em ambos os casos não há a consideração de amortecimento viscoso. Nas figuras $3.17 \mathrm{a}$ e $3.17 \mathrm{~b}$ tem-se a representação dos respectivos diagramas tensão-deformação. Observa-se na figura $3.17 \mathrm{~b}$ que os ciclos de histerese vão se fechando tendendo a obtenção de um nível de tensão e de deformação correspondentes ao equilíbrio estático. 


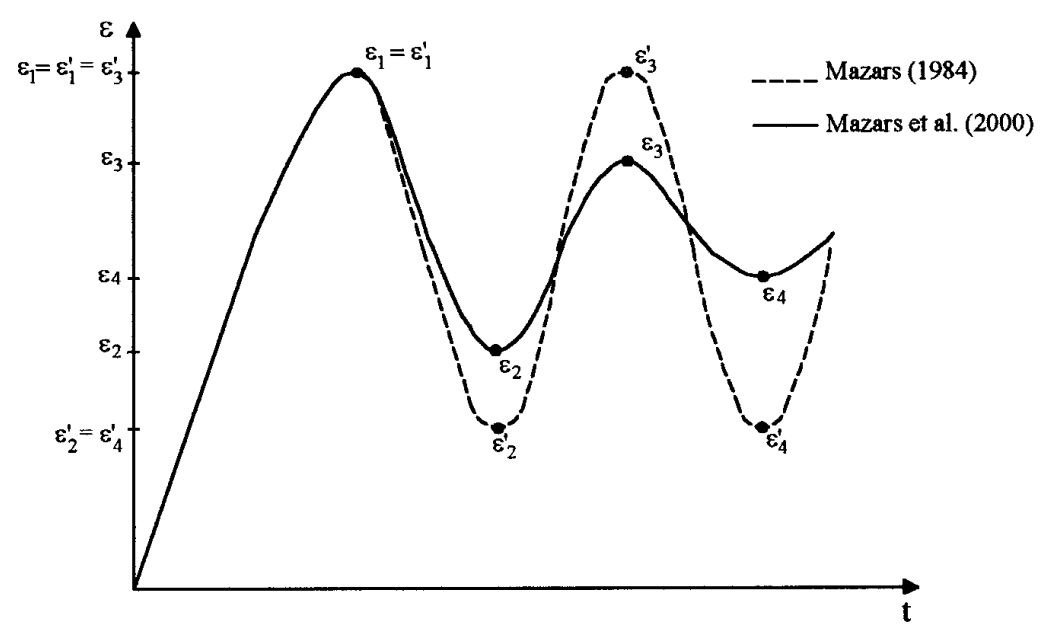

Figura 3.16 - Diagrama da deformação versus tempo de análise

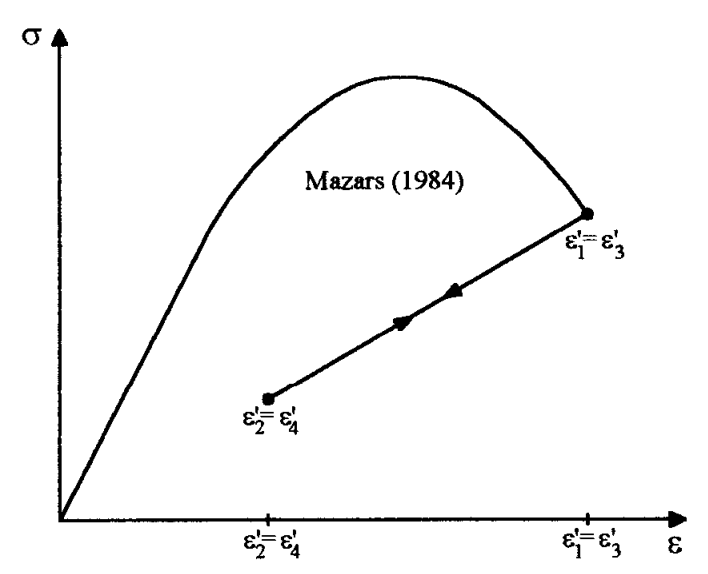

(a)

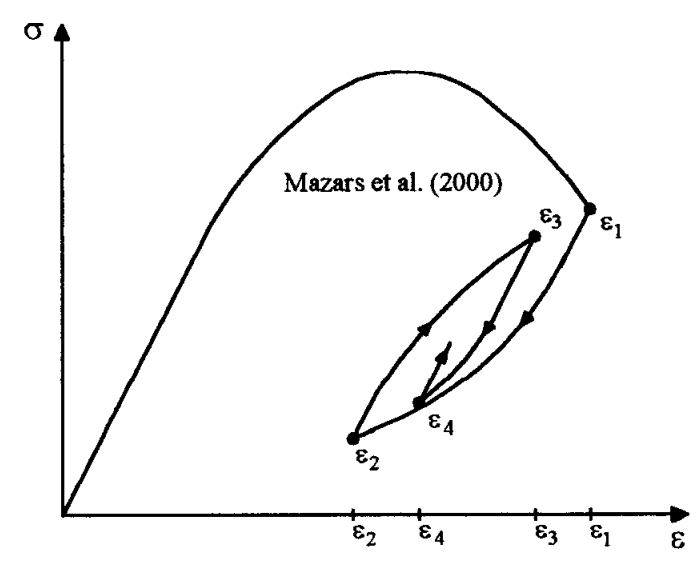

(b)

Figura 3.17 - Diagrama tensão-deformação: (a) modelo de MAZARS (1984),

(b) modelo de MAZARS et al. (2000)

\subsection{PROPOSTA PARA A INVERSÃO DO CARREGAMENTO}

$\mathrm{Na}$ proposta original apresentada por MAZARS et al. (2000) não foi mencionado nenhum procedimento a ser seguido, especificamente, para simular situações com inversão do carregamento. Nessas situações, considerações adicionais precisam ser levadas em conta para definir o comportamento das variáveis que representam o dano, a tensão de encruamento e a tensão $\sigma_{\mathrm{y}}$. 
Pretende-se, neste item, apresentar uma proposta simplificada que possibilite incluir a consideração da inversão do carregamento sem abrir mão da coerência com as considerações feitas até aqui sobre o escorregamento. Para alcançar tal objetivo, duas hipóteses básicas devem ser consideradas:

* O efeito unilateral será considerado a partir da inversão do sinal da deformação, que coincide com a inversão do sinal da tensão elasto-danificada $\sigma_{d}$, sendo adotadas duas variáveis de dano: $d_{t}$ e $d_{c}$. A primeira aparece na relação da tensão elasto-danificada em tração, enquanto que a outra aparece na relação da tensão elastodanificada em compressão. Ambas as variáveis de dano apresentam leis independentes de evolução em função da deformação. Neste trabalho, propõe-se a adoção em forma das mesmas leis experimentais descritas no modelo de MAZARS (1984);

* Para possibilitar a compatibilização da tensão total com a utilização de uma ou outra variável de dano, consideram-se parâmetros únicos para o escorregamento, independente da tensão elasto-danificada ser de tração ou de compressão.

Na figura 3.18a tem-se a representação do diagrama tensão-deformação para a tensão total considerando-se o caso da inversão do carregamento conforme a presente proposta. Inicialmente o espécime é submetido a tração, no ponto $(A)$ passa a ocorrer a evolução do dano e do escorregamento sendo $d_{t}$ a variável de dano associada. No trecho $(B-C)$ é feito o descarregamento, no tercho $(C-D)$ a tensão é mantida constante até que haja a compatibilização das curvas. No ponto $(E)$ a variável de dano em compressão $\mathrm{d}_{\mathrm{c}}$ passa a evoluir juntamente com o escorregamento. No trecho $(F-G)$ é feito o descarregamento, no trecho $(G-B)$ a variável de dano considerada volta a ser $\mathrm{d}_{\mathrm{t}}$, no trecho $(B-H)$ a variável $\mathrm{d}_{\mathrm{t}}$ volta a evoluir.

Na figura 3.18b tem-se a representação da evolução da tensão elasto-danificada. $\mathrm{Na}$ figura $3.18 \mathrm{c}$ tem-se a representação do comportamento da tensão por encruamento. Em ambos os casos são apresentados pontos de identificação correspondentes aos pontos da figura $3.18 \mathrm{a}$. 

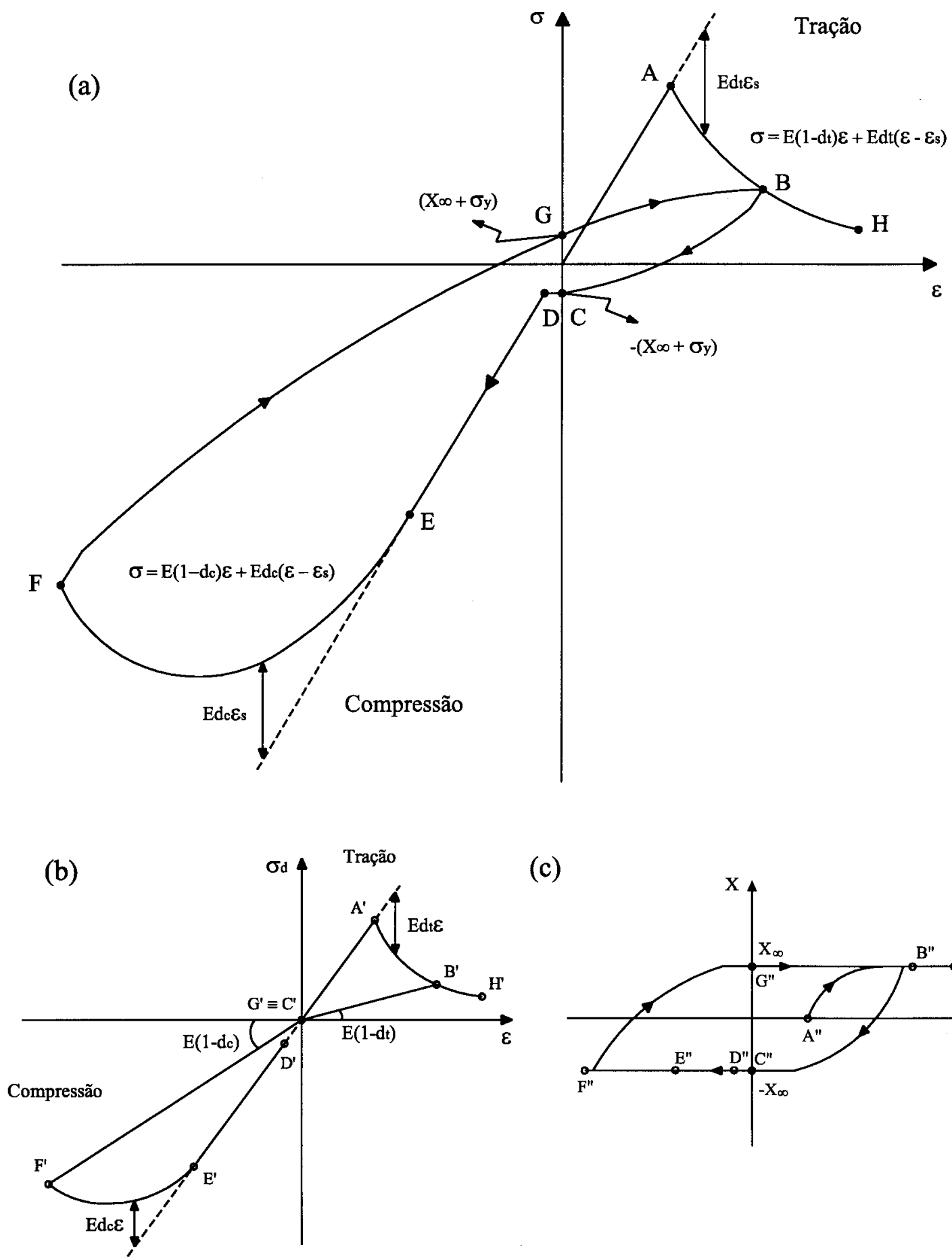

(c)

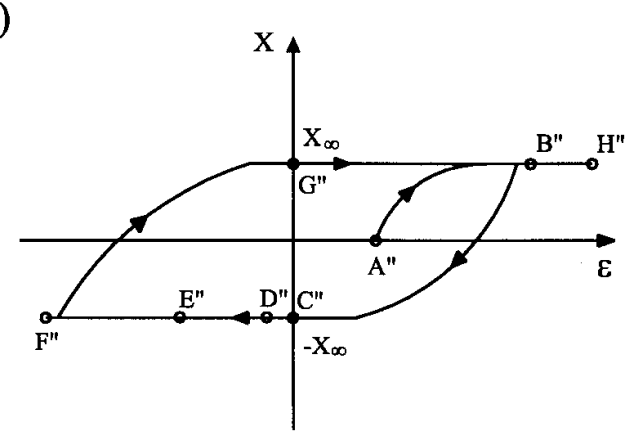

Figura 3.18 - Proposta para a inversão do carregamento: (a) tensão total,

(b) tensão elasto-danificada, (c) tensão por encruamento

Na figura 3.19a tem-se o resultado apresentado por MAZARS et al. (2000) onde foi considerada a inversão do carregamento, enquanto na figura $3.19 \mathrm{~b}$ tem-se a resposta obtida a partir da aplicação da proposta aqui apresentada. 
Os parâmetros utilizados na obtenção dos resultados apresentados nas figuras 3.19b, 3.20 e 3.21 são:

- Concreto: $\mathrm{E}_{\mathrm{c}}=23000 \mathrm{MPa}, v=0,24$.

- Escorregamento: $\sigma_{\mathrm{y}}=0,17 \mathrm{MPa} ; \mathrm{b}=1000 \mathrm{MPa} ; \mathrm{a}=5 \mathrm{MPa}^{-1} ; \mathrm{c}=0,09$.

- Dano: $\varepsilon_{\mathrm{do}}=0,0001 ; \mathrm{At}=0,995 ; \mathrm{Bt}=15500 ; \mathrm{Ac}=0,995 ; \mathrm{Bc}=1000$.

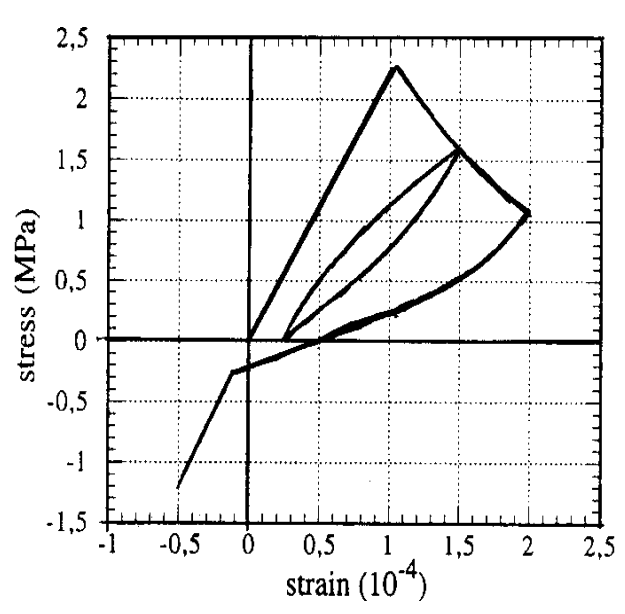

(a)

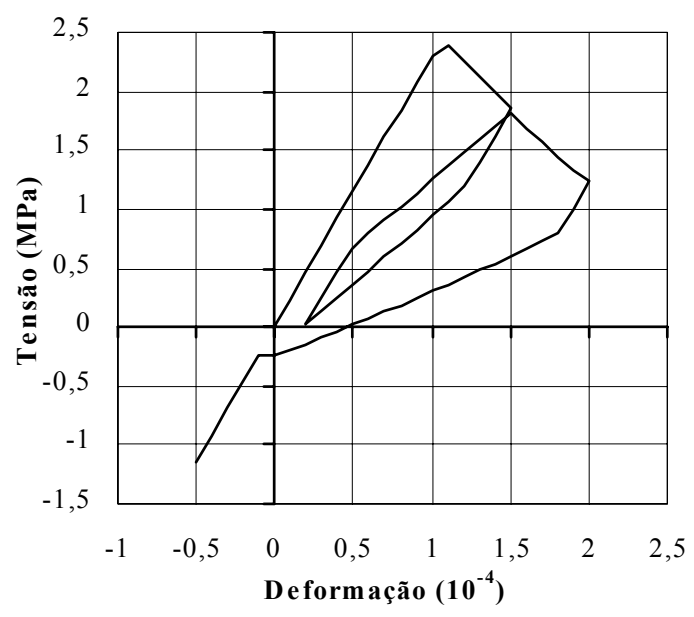

(b)

Figura 3.19 - Diagrama tensão-deformação com inversão do carregamento:

(a) MAZARS et al. (2000), (b) proposta apresentada neste trabalho

Na figura 3.20a tem-se a representação do diagrama tensão-deformação para o caso de um espécime submetido inicialmente a tração, descarregado e submetido a compressão, descarregado e submetido novamente a tração. A trajetória das deformações impostas é: $(0 \rightarrow 5 \rightarrow-7,5 \rightarrow 5) \cdot\left(10^{-4}\right)$. Na figura $3.20 \mathrm{~b}$ tem-se o comportamento da tensão por encruamento e na figura 3.20c os níveis atingidos pelas variáveis de dano em tração $d_{t}$ e em compressão $d_{c}$. 


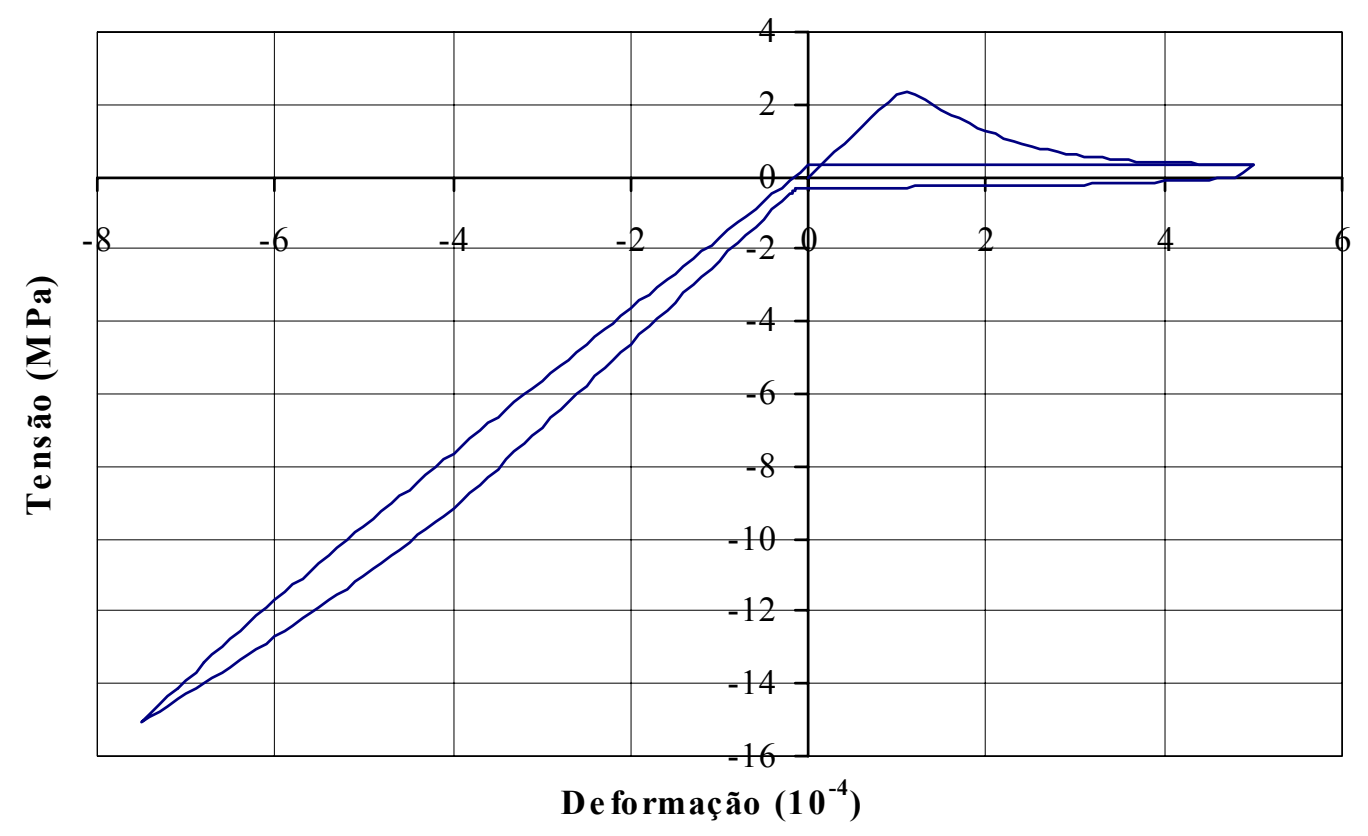

(a)

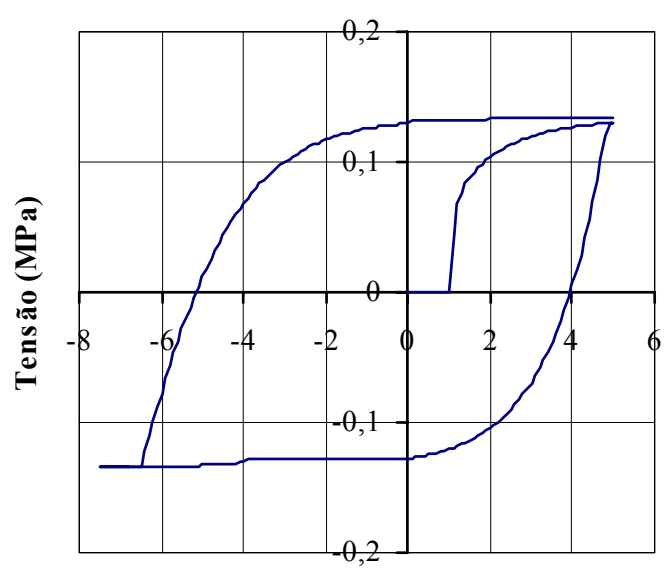

Deformação $\left(10^{-4}\right)$

(b)

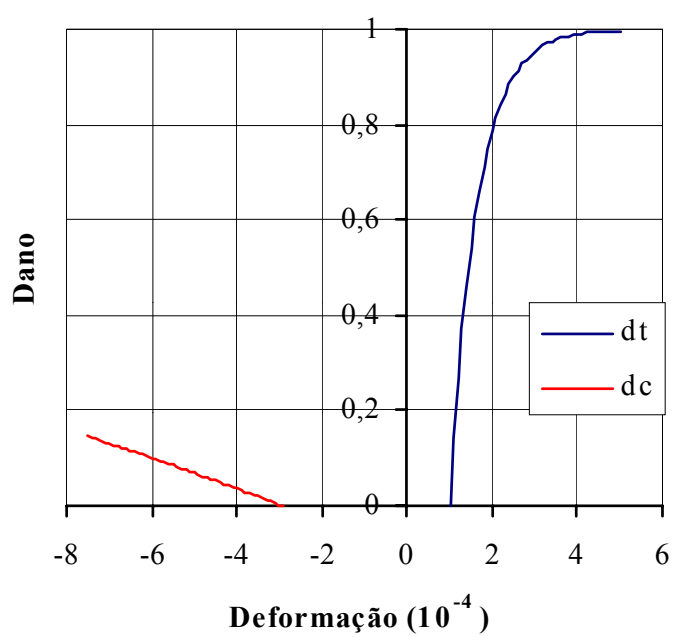

(c)

Figura 3.20 - Representação da inversão do carregamento:

(a) tensão total, (b) tensão de encruamento, (c) níveis de danificação

Na figura 3.21 tem-se a representação do diagrama tensão-deformação para o caso de um espécime submetido a dois ciclos com inversão do carregamento, começando a solicitação por tração. As trajetórias de deformações impostas são: ciclo 1 $(0 \rightarrow 5 \rightarrow-7,5 \rightarrow 5) \cdot\left(\mathrm{x} 10^{-4}\right), \operatorname{ciclo} 2(5 \rightarrow 10 \rightarrow-9 \rightarrow 10) \cdot\left({\left.\mathrm{x} 10^{-4}\right)}^{-}\right.$ 


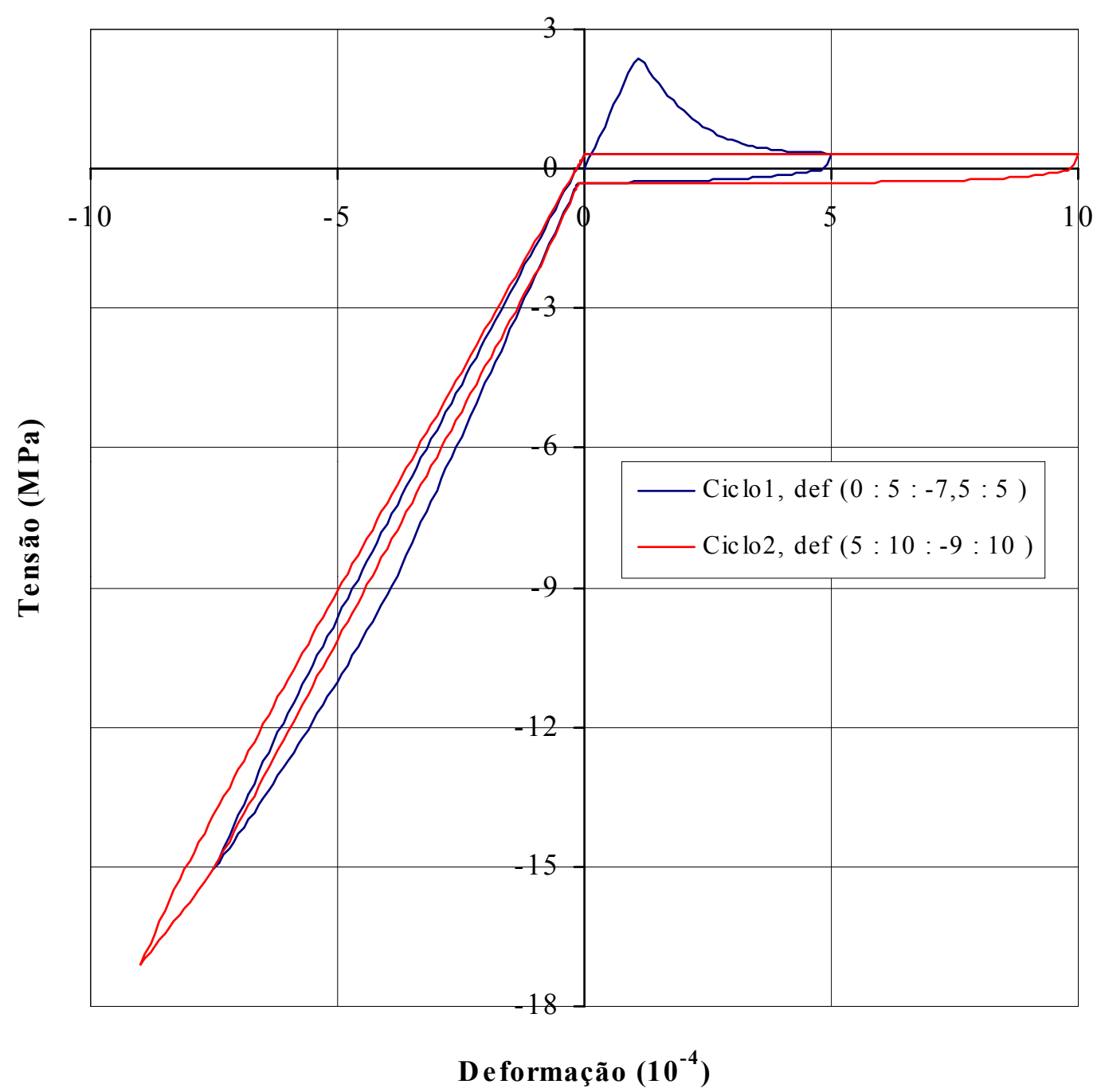

Figura 3.21 - Inversão do carregamento com dois ciclos completos 


\section{SIMULAÇÃO DE RESPOSTAS DINÂMICAS}

\subsection{INTRODUÇÃO}

No presente capítulo, faz-se uma avaliação do desempenho da proposta unidimensional, desenvolvida neste trabalho, para o modelo de MAZARS et al. (2000). Apresenta-se um estudo comparativo entre respostas dinâmicas obtidas utilizando-se esta proposta e as disponibilizadas por PAULA (2001). Nas respostas apresentadas por esta autora, a não-linearidade do concreto foi obtida utilizando-se o modelo de dano de MAZARS (1984) e o amortecimento é proveniente da utilização do modelo de amortecimento viscoso de Rayleigh. Tanto nas respostas apresentadas por PAULA (2001) quanto nas simulações apresentadas neste estudo, o aço é considerado como um meio elastoplástico com encruamento cinemático linear.

Como se sabe, nas estruturas elásticas o amortecimento decorre de efeitos da vinculação que introduzem processos dissipativos por atrito. Nesse sentido a equação do amortecimento introduz uma parcela dita de amortecimento viscoso. O modelo Rayleigh, COOK et al. (1989), pressupõe que o amortecimento viscoso é proporcional à massa e à rigidez estrutural. Porém, a danificação também pode introduzir uma parcela adicional de amortecimento. Assim, o objetivo principal neste capítulo é observar a diferença de resposta obtida quando o amortecimento é considerado apenas devido à dissipação por histerese (o que não exige a parcela de amortecimento viscoso na equação do movimento) ou quando ele é modelado pelo artifício da utilização da matriz de amortecimento viscoso de Rayleigh. Numa análise complementar, o amortecimento será simulado pela combinação do amortecimento histerético com o amortecimento viscoso. Essa combinação pode fazer sentido, uma vez que se considere tanto a 
influência da danificação quanto da dissipação por atrito nos vínculos, para a geração do amortecimento global da estrutura.

Observa-se que a proposta unidimensional para o modelo de MAZARS et al. (2000) apresentada neste trabalho foi implementada no programa de análise dinâmica desenvolvido por PAULA (2001) e todas as simulações foram realizadas utilizando-se este programa.

\subsection{INTEGRAÇÃO NO DOMÍNIO DO TEMPO}

O quadro 4.1 apresenta o algorítmo de integração numérica de Newmark combinado com o procedimento de Newton-Raphson utilizado por PAULA (2001) para a integração da equação de equilíbrio dinâmico no domínio do tempo.

Passo inicial: $\mathrm{t}_{0}=0$, calcula-se:

a força externa aplicada na estrutura $\rightarrow \mathrm{F}^{\mathrm{ext}}(0)$

faz-se $\mathrm{q}_{0}=0 ; \dot{\mathrm{q}}_{0}=0$ e calcula-se a aceleração inicial $\rightarrow \ddot{\mathrm{q}}_{0}=\underline{\mathrm{M}}^{-1}\left\{\mathrm{~F}^{\mathrm{ext}}(0)\right\}$

$\mathrm{n}=1$

Passo 1: "Loop" incremental do tempo $\rightarrow \mathrm{t}_{\mathrm{n}}=\mathrm{t}_{\mathrm{n}-1}+\Delta \mathrm{t}$

Passo 2: etapa de previsão:

$$
\left\{\begin{array}{l}
\ddot{\mathrm{q}}_{\mathrm{n}}=\ddot{\mathrm{q}}_{\mathrm{n}-1} \\
\dot{\mathrm{q}}_{\mathrm{n}}=\dot{\mathrm{q}}_{\mathrm{n}-1}+\Delta \mathrm{t}(1-\gamma) \ddot{\mathrm{q}}_{\mathrm{n}-1}+\Delta \mathrm{t} \gamma \ddot{\mathrm{q}}_{\mathrm{n}} \\
\mathrm{q}_{\mathrm{n}}=\mathrm{q}_{\mathrm{n}-1}+\Delta \mathrm{t} \dot{\mathrm{q}}_{\mathrm{n}-1}+\left(\frac{1}{2}-\beta\right) \Delta \mathrm{t}^{2} \ddot{\mathrm{q}}_{\mathrm{n}-1}+\beta \Delta \mathrm{t}^{2} \ddot{\mathrm{q}}_{\mathrm{n}}
\end{array}, \text { sendo } \gamma=\frac{1}{2} \text { e } \beta=\frac{1}{4}\right.
$$

Passo 3: Atualização do dano de acordo com o modelo constitutivo utilizado; 
Passo 4: Cálculo do vetor resíduo: $\Psi=F^{\text {ext }}-\left(\underline{\mathrm{M}} \ddot{\mathrm{q}}_{\mathrm{n}}+\underline{\mathrm{C}} \dot{\mathrm{q}}_{\mathrm{n}}+\mathrm{F}^{\text {int }}\right)$

Passo 5: Teste da convergência: $\|\Psi\| \leq$ TOL $?\left\{\begin{array}{l}\text { sim } \rightarrow \text { ir ao passo } 1 \\ \text { não } \rightarrow \text { ir ao passo } 6\end{array}\right.$

Passo 6: Cálculo do acréscimo de deslocamento: $\left[\underline{\mathrm{M}} \frac{1}{\beta \Delta \mathrm{t}^{2}}+\underline{\mathrm{C}} \frac{\gamma}{\beta \Delta \mathrm{t}}+\underline{\mathrm{K}}(\mathrm{d})\right] \Delta \mathrm{q}_{\mathrm{n}}=\Psi$

Passo 7: Correção: $\left\{\begin{array}{l}\mathrm{q}_{\mathrm{n}}=\mathrm{q}_{\mathrm{n}}+\Delta \mathrm{q}_{\mathrm{n}} \\ \dot{\mathrm{q}}_{\mathrm{n}}=\dot{\mathrm{q}}_{\mathrm{n}}+\frac{\gamma}{\beta \Delta \mathrm{t}} \Delta \mathrm{q}_{\mathrm{n}} \\ \ddot{\mathrm{q}}_{\mathrm{n}}=\ddot{\mathrm{q}}_{\mathrm{n}}+\frac{1}{\beta \Delta \mathrm{t}^{2}} \Delta \mathrm{q}_{\mathrm{n}}\end{array}\right.$

Passo 8: Ir ao passo 3

Quadro 4.1 - Algoritmo de Newmark com Newton-Raphson, PAULA (2001)

É importante observar que no algoritmo apresentado no quadro 4.1, $\underline{\mathrm{C}}$ é a matriz de amortecimento viscoso de Rayleigh. No caso de se considerar apenas o modelo de MAZARS et al. (2000) para reproduzir o amortecimento da estrutura, será adotado $\underline{\mathrm{C}}=\underline{0}$.

\subsection{SIMULAÇÕES NUMÉRICAS}

A estrutura escolhida para verificar a eficiência do modelo em estudo consiste em uma viga simplesmente apoiada cujos dados geométricos e de armadura estão apresentados na figura 4.1. O carregamento simulado consta de duas cargas aplicadas subitamente e mantidas constantes durante toda a análise. Nestas análises consideram-se duas situações de carregamento: $\mathrm{P}=10 \mathrm{KN}$ e $\mathrm{P}=25 \mathrm{KN}$. Os resultados são expressos pela relação deslocamento do ponto central da viga versus o tempo. 

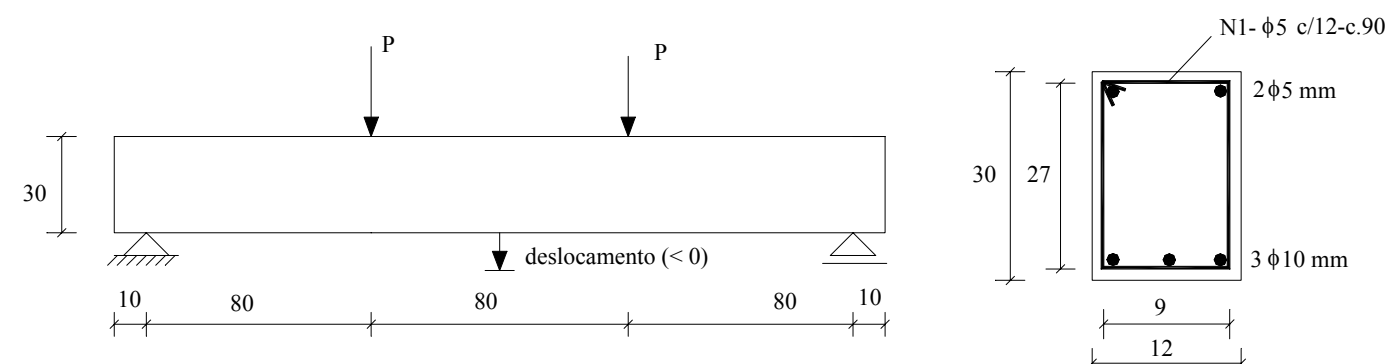

Figura 4.1 - Estrutura estudada para simulação de respostas, PAULA (2001)

A seguir tem-se as propriedades dos materiais e os parâmetros dos modelos de dano utilizados.

Propriedades do concreto: $\mathrm{E}_{\mathrm{c}}=29200 \mathrm{MPa} ; \mathrm{v}=0.2 ; \gamma_{\mathrm{c}}=2500 \mathrm{~kg} / \mathrm{m}^{3}$.

Propriedades do aço: $\mathrm{E}_{\mathrm{s}}=196000 \mathrm{MPa} ; \mathrm{f}_{\mathrm{y}}=420 \mathrm{MPa} ; \mathrm{E}_{\mathrm{st}}=19600 \mathrm{MPa}$; $\gamma_{\mathrm{s}}=7850 \mathrm{~kg} / \mathrm{m}^{3}$

Parâmetros do modelo de dano de MAZARS (1984): $A_{t}=0,995 ; B_{t}=8000$; $\mathrm{A}_{\mathrm{c}}=0,85 ; \mathrm{B}_{\mathrm{c}}=1050 ; \varepsilon_{\mathrm{d} 0}=0,00007$

Parâmetros do modelo de dano de MAZARS et al. (2000): $A_{t}=0,995 ; B_{t}=9500$; $\mathrm{A}_{\mathrm{c}}=0,865 ; \mathrm{B}_{\mathrm{c}}=1125 ; \varepsilon_{\mathrm{d} 0}=0,00007 ; \sigma_{\mathrm{yt}}=0,17 \mathrm{MPa} ; \sigma_{\mathrm{yc}}=0,10 \mathrm{MPa} ; \mathrm{b}_{\mathrm{t}}=1000 \mathrm{MPa} ;$ $b_{c}=5000 \mathrm{MPa} ; a_{t}=5 \mathrm{MPa}^{-1} ; a_{c}=3,9 \mathrm{MPa}^{-1} ; c=0,09$.

Na figura 4.2a e 4.2b apresenta-se uma comparação entre as envoltórias de tensão do concreto adotadas por PAULA (2001), ao utilizar o modelo de MAZARS (1984), e as envoltórias obtidas utilizando-se a proposta deste trabalho para o modelo de MAZARS et al. (2000), de acordo com os parâmetros apresentados. 


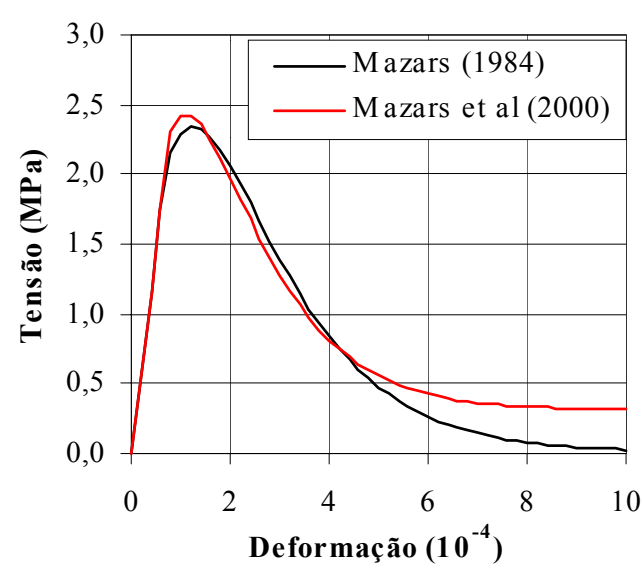

(a)

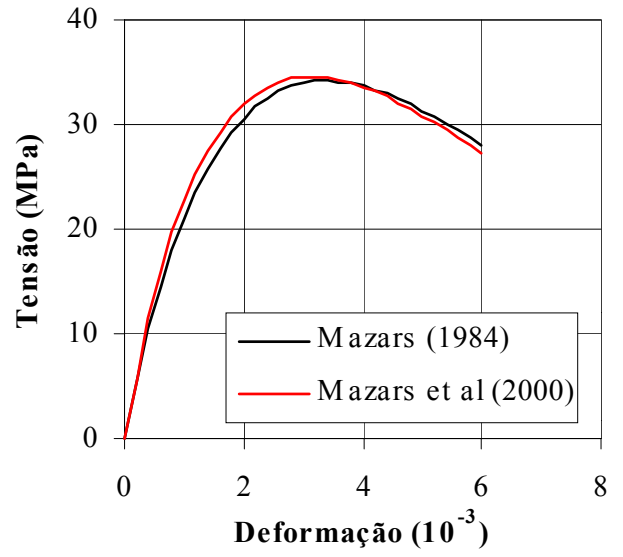

(b)

Figura 4.2 - Comparação das envoltórias de tensão para o concreto: (a) tração; (b) compressão

A estrutura foi discretizada em 12 elementos finitos iguais e o passo de tempo utilizado foi de $\Delta t=1 \times 10^{-5} \mathrm{~s}$. Para a integração numérica das matrizes de rigidez, massa e vetor das forças internas, foram empregados 6 pontos de Gauss-Lobato ao longo do comprimento e 10 pontos ao longo da altura dos elementos finitos.

As respostas apresentadas por PAULA (2001) utilizam o modelo de MAZARS (1984) e o modelo viscoso de Rayleigh quando da reprodução do amortecimento estrutural. As quais servirão de exemplos de confronto para as respostas obtidas com a utilização da proposta apresentada neste trabalho para o modelo de MAZARS et al. (2000).

Nas figuras 4.3 e 4.4 tem-se as respostas da estrutura para os casos dos carregamentos de $10 \mathrm{KN}$ e $25 \mathrm{KN}$, respectivamente, sem a consideração de amortecimento de Rayleigh.

Observando-se as curvas das figuras 4.3 e 4.4 constatasse a clara diferença de resposta uma vez que se utilize o modelo de dano de MAZARS (1984) sem o amortecimento Rayleigh, contra o modelo de dano de MAZARS et al. (2000). Neste modelo a realização dos laços de histerese possibilita a reprodução de amortecimento. Observa-se que quando a estrutura está submetida à carga de $10 \mathrm{KN}$ reproduz-se o mesmo deslocamento máximo para ambos os modelos de dano. Porém para o carregamento de $25 \mathrm{KN}$ os deslocamentos máximos obtidos são diferentes. De fato, os 
resultados sofrem claramente a influência da relação adotada para o modelo de MAZARS et al.(2000), ilustrada na figura 4.2a. Essa influência é menor para níveis menores de dano e maior para níveis maiores de dano.

Além disso, os valores residuais de deslocamento amortecido estão próximos, porém não coincidem com $\mathrm{o}$ valor médio de deslocamento oscilante sem amortecimento.

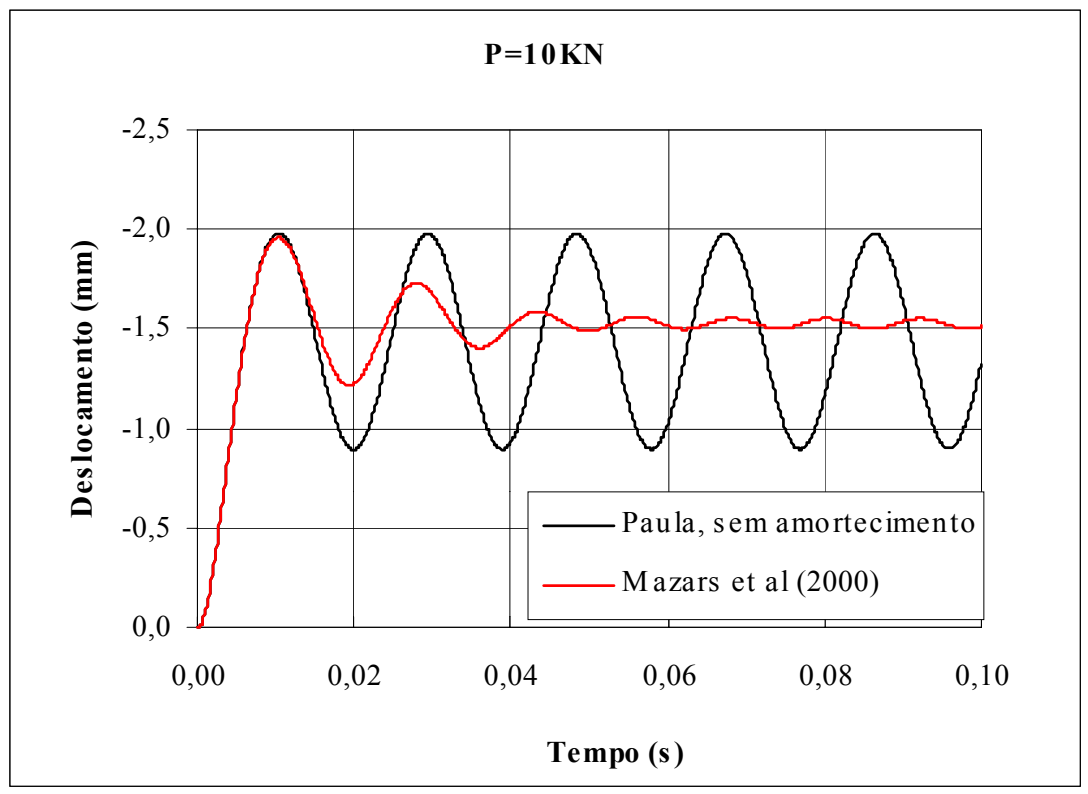

Figura 4.3 - Deslocamento versus tempo, $\mathrm{P}=10 \mathrm{KN}$ : sem amortecimento Rayleigh

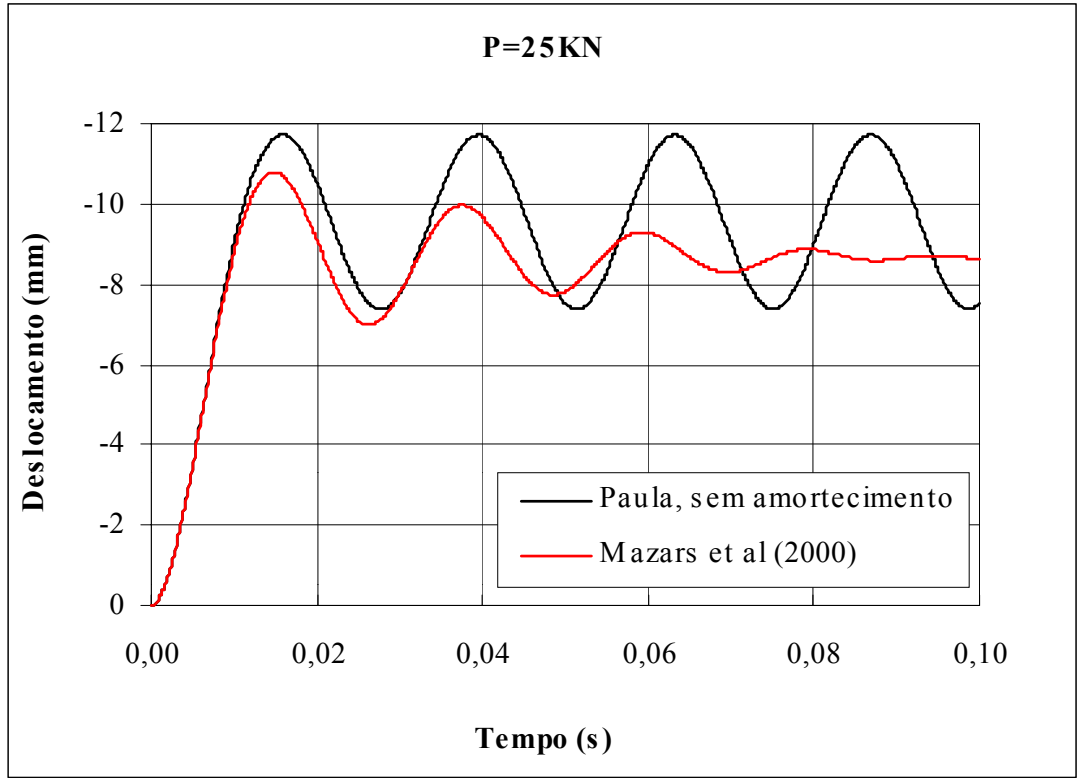

Figura 4.4 -Deslocamento versus tempo, $\mathrm{P}=25 \mathrm{KN}$ : sem amortecimento Rayleigh 
Nas figuras 4.5 e 4.6 tem-se as respostas da estrutura para o caso dos carregamentos de $10 \mathrm{KN}$ e $25 \mathrm{KN}$, respectivamente, considerando-se o amortecimento de Rayleigh, com taxas de amortecimento crítico de $3 \%$ e de $10 \%$, para o caso da utilização do modelo de MAZARS (1984), enquanto no modelo de MAZARS et al. (2000) o amortecimento é devido apenas ao comportamento de histerese reproduzido por este modelo.

É interessante observar a diferença de comportamento no deslocamento máximo da estrutura uma vez que se utilize apenas o amortecimento por histerese ou apenas o amortecimento viscoso. No primeiro caso o amortecimento só passa a agir após a obtenção do deslocamento máximo, o que é absolutamente coerente com o tipo de amortecimento que se pretende reproduzir com este modelo, pois é somente a partir do momento em que a estrutura passa a oscilar que serão produzidos laços de histerese devido ao descarregamento e recarregamento do concreto.

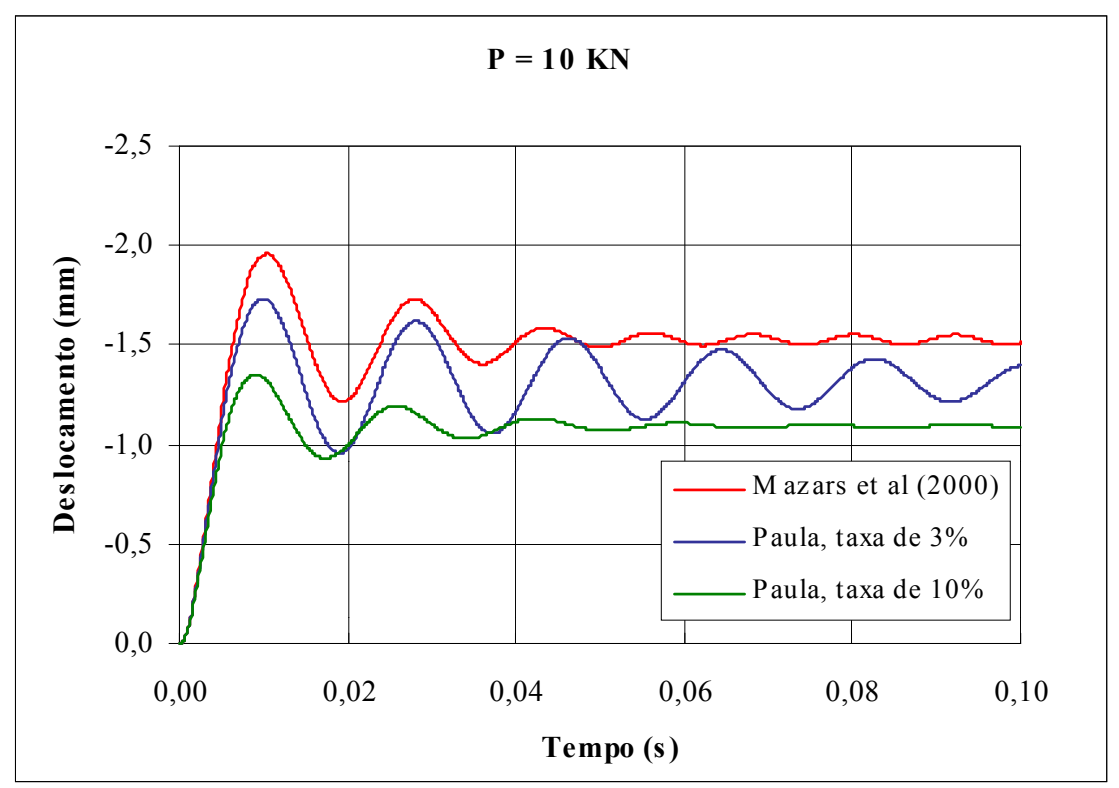

Figura 4.5 - Deslocamento versus tempo, $\mathrm{P}=10 \mathrm{KN}$ : amortecimento Rayleigh com taxas de $3 \%$ e de $10 \%$ para o modelo de MAZARS (1984) 


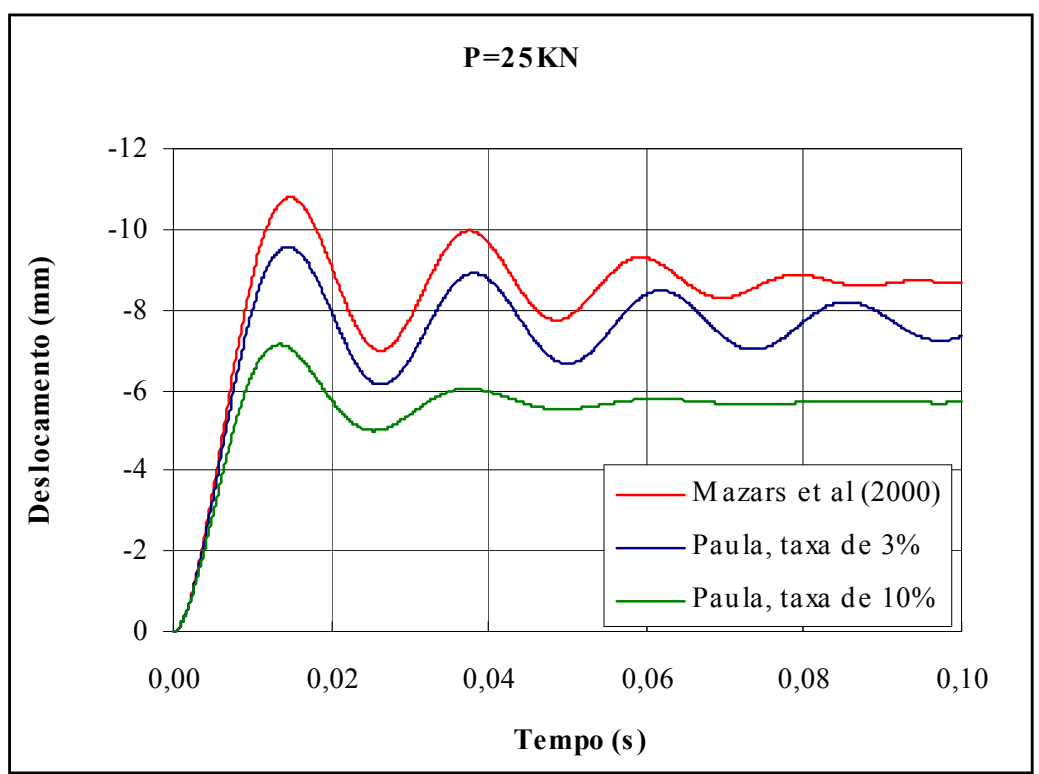

Figura 4.6 - Deslocamento versus tempo $\mathrm{P}=25 \mathrm{KN}$ : amortecimento Rayleigh com taxas de $3 \%$ e de $10 \%$ para o modelo de MAZARS (1984)

Nas figuras 4.7 e 4.8 tem-se a comparação das respostas da estrutura para o caso da consideração do amortecimento viscoso de Rayleigh nos dois modelos. Em ambos os casos consideram-se taxas de amortecimento crítico de $3 \%$ e de $10 \%$.

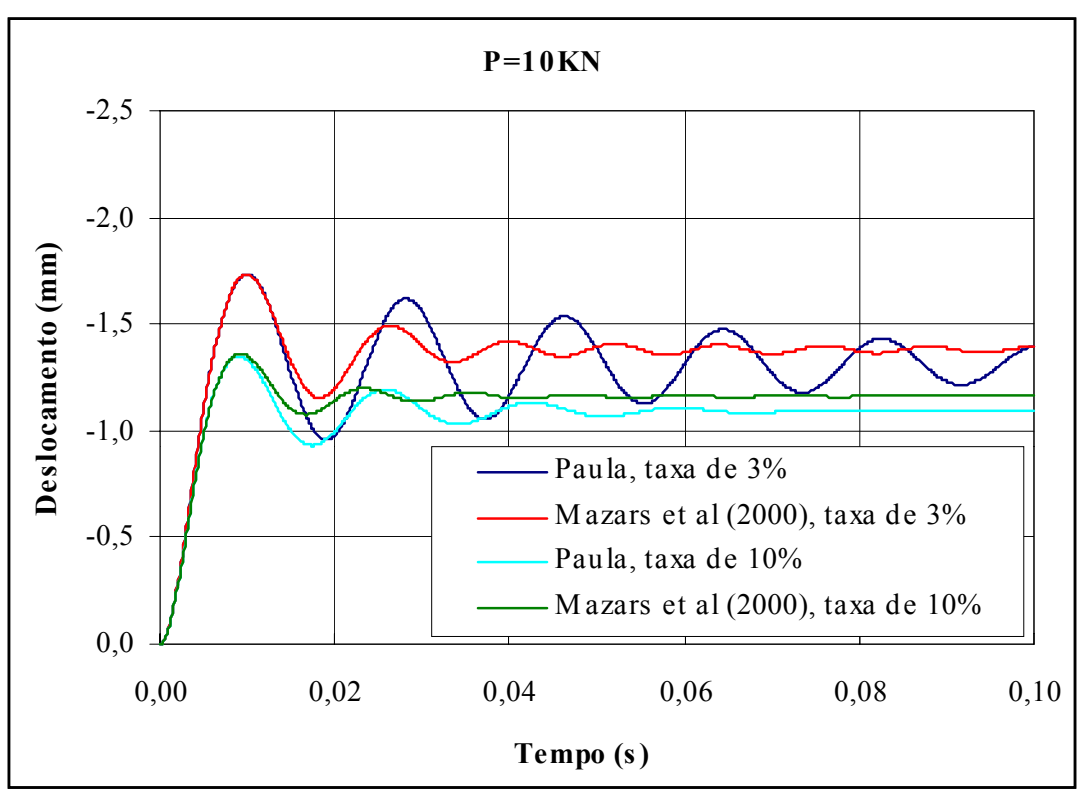

Figura 4.7 - Deslocamento versus tempo, $\mathrm{P}=10 \mathrm{KN}$ : Modelo de dano de MAZARS et al (2000) e MAZARS (1984) ambos com amortecimento viscoso de Rayleigh com taxa de 3\% e 10\% 


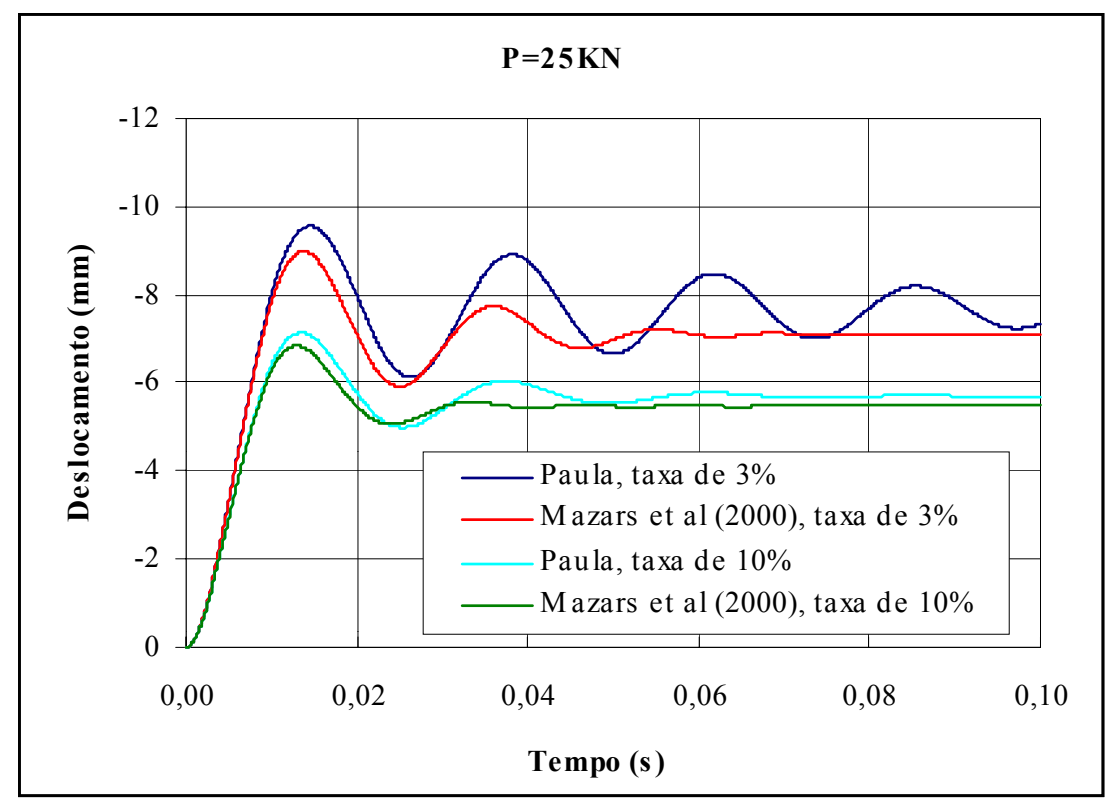

Figura 4.8 - Deslocamento versus tempo, $\mathrm{P}=25 \mathrm{KN}$ : Modelo de dano de MAZARS et al (2000) e MAZARS (1984) ambos com amortecimento viscoso de Rayleigh com taxa de 3\% e 10\%

Apesar da superposição dos efeitos de amortecimentos, o amortecimento por histerese não perdeu suas características e continua se manifestando somente após a obtenção do deslocamento máximo. Porém, observa-se que o seu efeito é o de aumentar o amortecimento global da estrutura, como era de se esperar.

Nas figuras 4.9 e 4.10 comparam-se ainda as respostas da estrutura considerando-se o amortecimento viscoso de Rayleigh em ambos os modelos. Foram consideradas taxas de amortecimento crítico de $3 \%$ e de $10 \%$, respectivamente. A diferença em relação ao caso anterior é que se faz a atualização da matriz de amortecimento viscoso, assim como dos parâmetros de proporcionalidade, devido à evolução do dano, considerando-se a equação 2.55. Neste caso considera-se o dano decorrente da estabilização do passo de tempo anterior para a atualização da matriz de amortecimento.

Novamente verifica-se, claramente, o efeito do amortecimento histerético sobre o amortecimento global da estrutura. $\mathrm{O}$ amortecimento de Rayleigh produz um efeito contrário, ou seja, esse modelo amortece menos uma vez que se considere a matriz de amortecimento calculada considerando-se a evolução do dano, equação 2.55. 


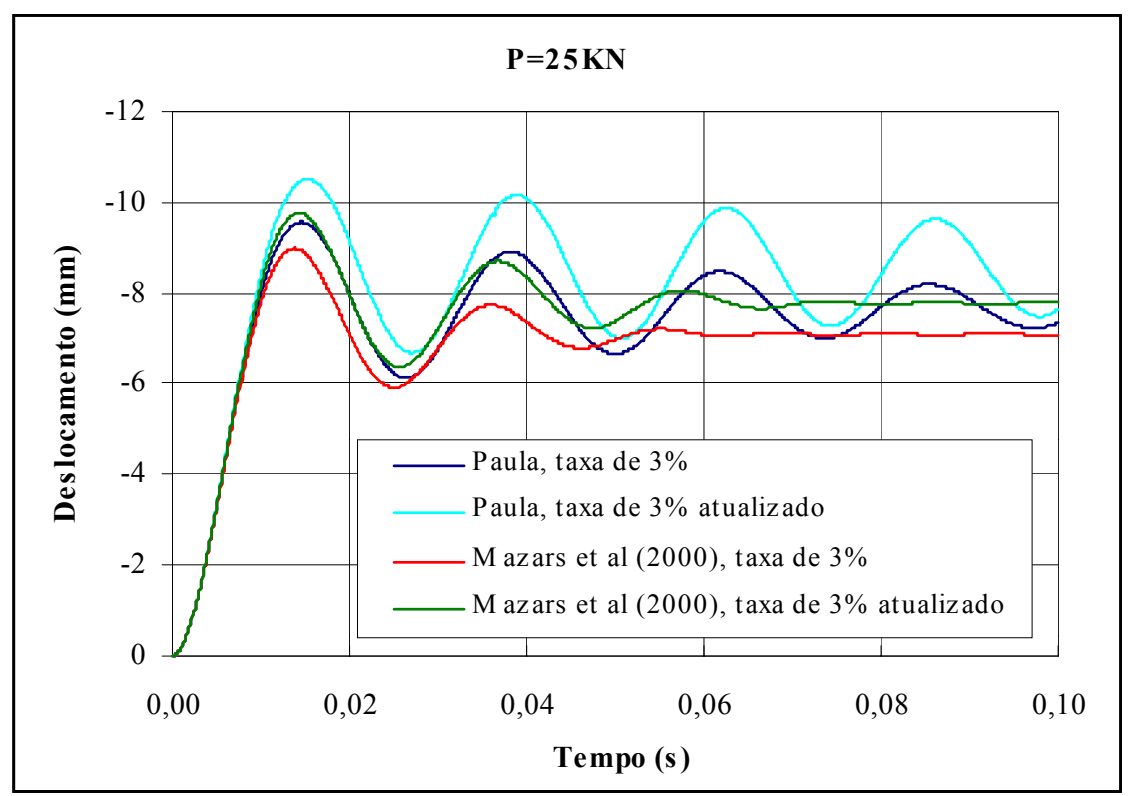

Figura 4.9 - Deslocamento versus tempo, $\mathrm{P}=25 \mathrm{KN}$ e taxa de $3 \%$ : Amortecimento Rayleigh não-atualizado e atualizado, quando sozinho e quando superposto com histerese

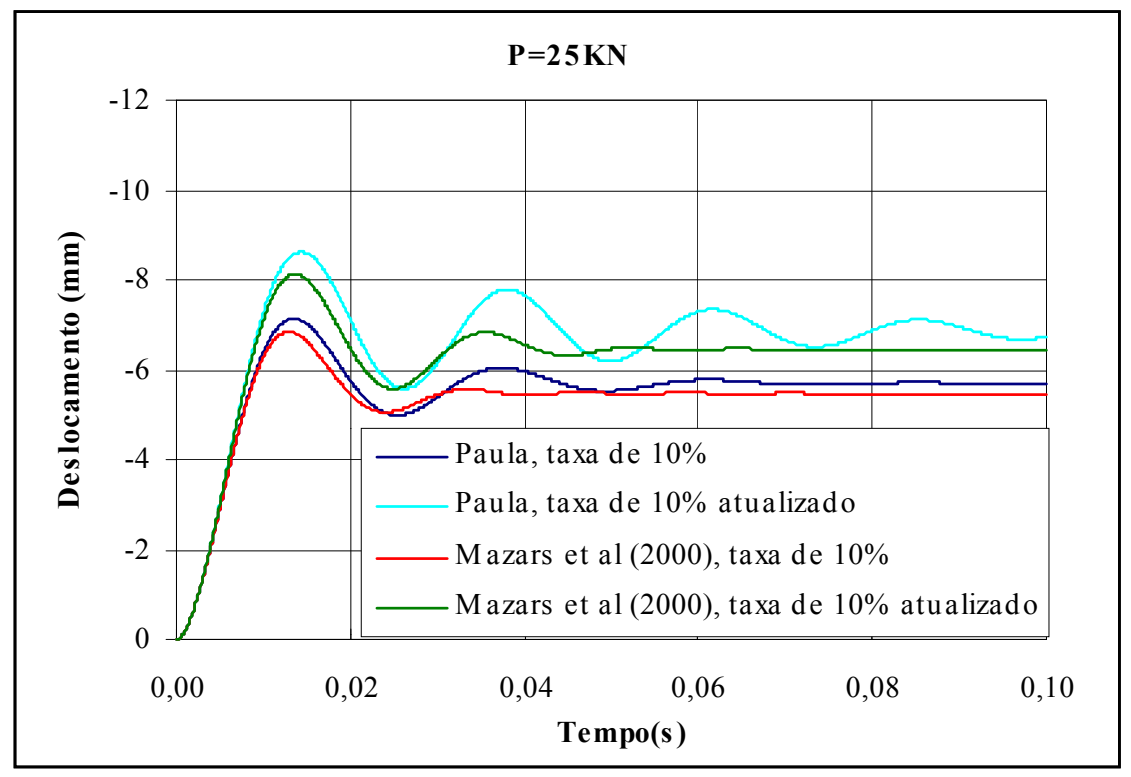

Figura 4.10 - Deslocamento versus tempo, $\mathrm{P}=25 \mathrm{KN}$ e taxa de $10 \%$ : Amortecimento Rayleigh não-atualizado e atualizado, quando sozinho e quando superposto com histerese

Na figura 4.11 observa-se o efeito da plastificação do aço na resposta da estrutura quando se considera o amortecimento por histerese. Constata-se que a plastificação do aço diminui a amplitude do deslocamento em relação ao aço elástico, efeito provocado por uma maior dissipação de energia nos processos de danificação e 
plastificação. É bastante visível a diferença de dissipação de energia em ambos os casos, o que afeta significativamente o processo de amortecimento por histerese.

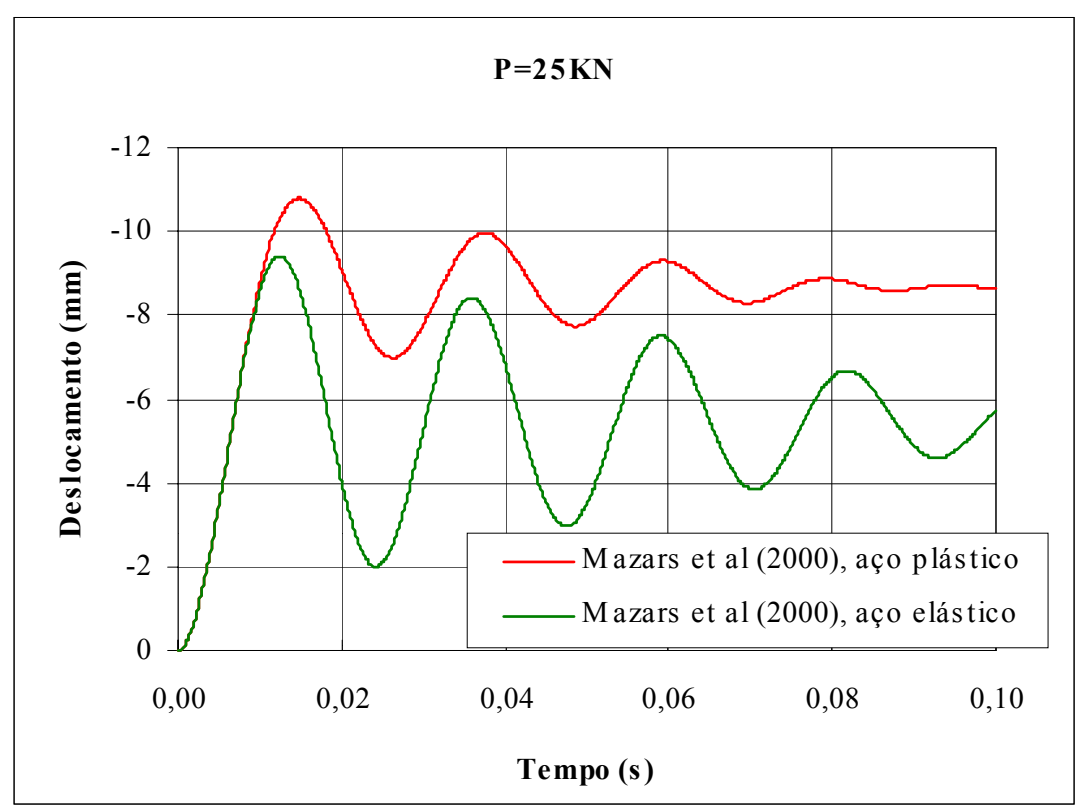

Figura 4.11 - Deslocamento versus tempo, $\mathrm{P}=25 \mathrm{KN}$ : efeito da plastificação do aço quando se considera amortecimento por histerese

Com o objetivo de demonstrar a influência da abertura do laço de histerese no amortecimento apresentado pela estrutura, apresentam-se em seguida comparações entre os amortecimentos obtidos quando os parâmetros de escorregamento são calibrados no sentido de se obter laços de histerese com aberturas diferentes. Na figura 4.12 mostra-se os diagramas tensão-deformação que resultam para o caso da tração. $\mathrm{O}$ laço1 é obtido ao se utilizar os parâmetros de escorregamento apresentados no início deste capítulo, enquanto o laço2 foi obtido adotando-se $\sigma_{\mathrm{yT}}=0,05 \mathrm{MPa}$. A diminuição do valor da tensão de escorregamento, devido a consideração de uma tensão $\sigma_{\mathrm{yT}}$ menor, afeta diretamente a abertura do laço. Não foram feitas alterações nos parâmetros relativos a compressão.

Nas figuras 4.13 e 4.14 tem-se as respostas da estrutura quando se consideram as curvas apresentadas na figura 4.12. Fundamentalmente quanto maior é a abertura dos laços de histerese, maior é o efeito do amortecimento resultante, pois é maior a energia dissipada no processo de fricção interna. 


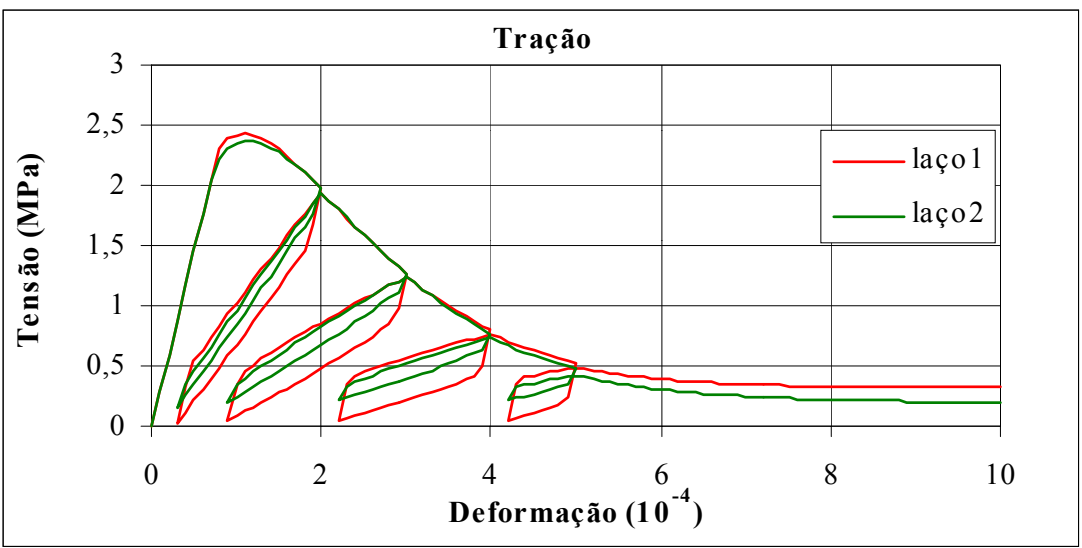

Figura 4.12 - Diagrama tensão-deformação: diferentes laços de histerese

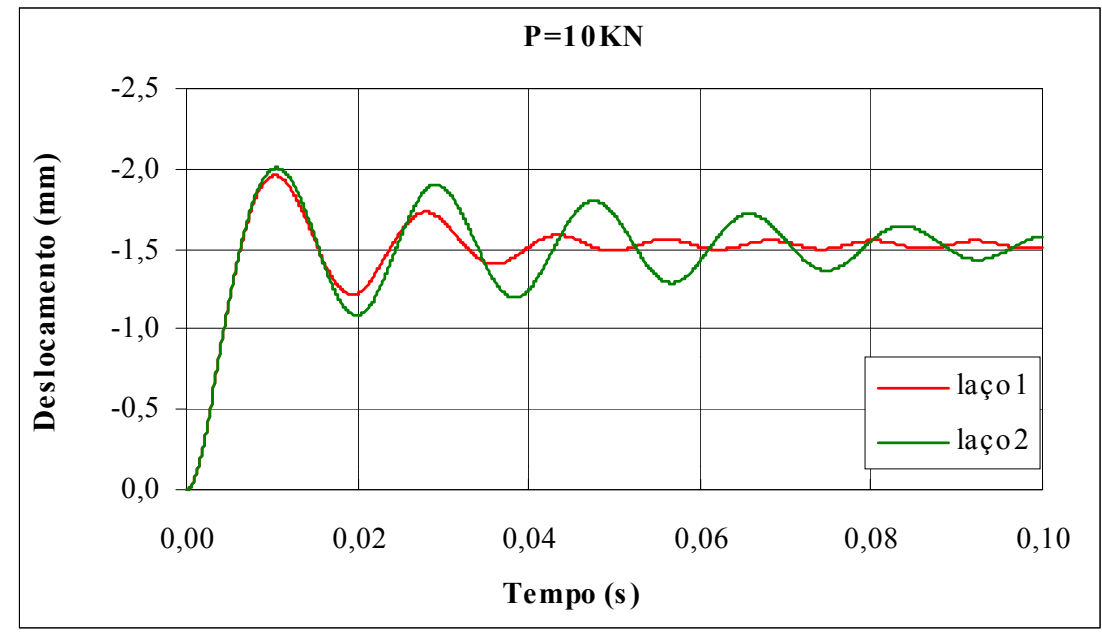

Figura 4.13 - Deslocamento versus tempo, $\mathrm{P}=10 \mathrm{KN}$ : diferentes laços de histerese

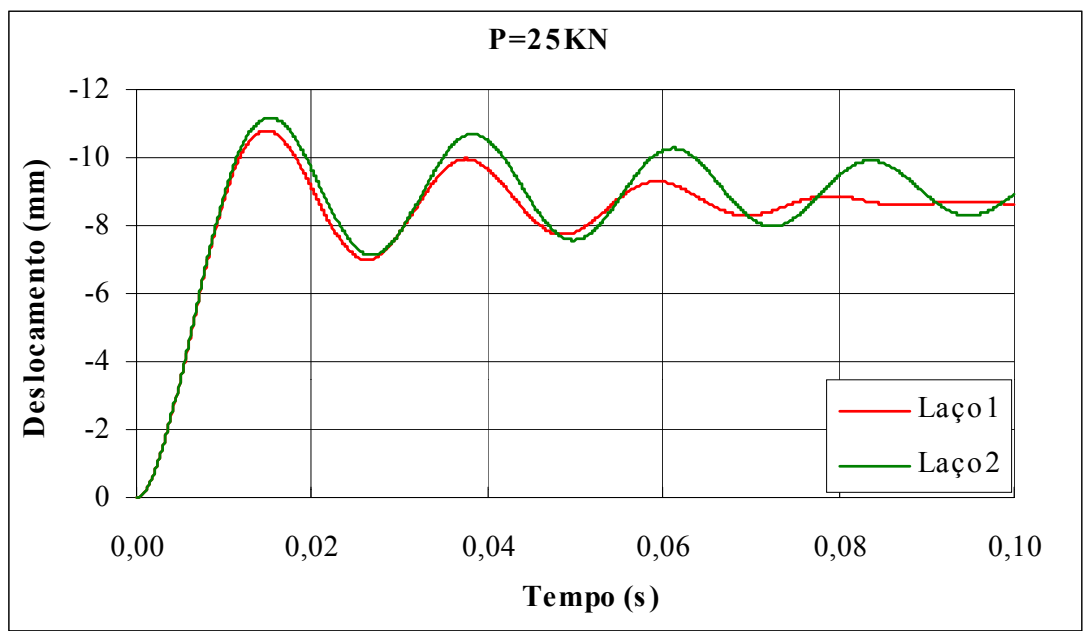

Figura 4.14 - Deslocamento versus tempo, $\mathrm{P}=25 \mathrm{KN}$ : diferentes laços de histerese 
$\mathrm{Na}$ figura 4.15 tem-se uma representação das fibras do concreto que foram consideradas para uma análise mais detalhada da deformação em pontos da seção central da viga em estudo. Neste caso foi empregado o elemento finito com múltiplas camadas retangulares. As dimensões estão em cm e a seção transversal foi discretizada em 10 camadas de iguais espessuras. Aqui, entende-se por fibra a linha de divisão entre dois estratos adjacentes no elemento finito com múltiplas camadas, como as fibras 3 e 5 , ou as linhas da base e do topo da viga, como a fibra 1 apresentada na figura 4.15 .

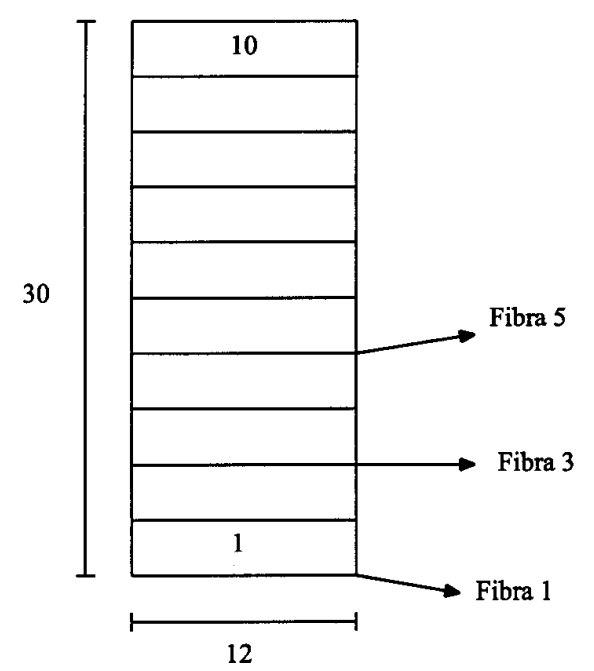

Figura 4.15 - Seção transversal da viga em estudo: discretização com múltiplas camadas

Na figura 4.16 ilustra-se as deformações ao longo do tempo apresentadas pelas fibras de concreto ilustradas na figura 4.15. Nesses resultados considera-se a envoltória de tensão definida para o laço2 da figura 4.12 e o carregamento de $\mathrm{P}=10 \mathrm{KN}$.

Na figura 4.17 tem-se as curvas tensão-deformação correspondentes as mesmas fibras de concreto ilustradas na figura 4.15. Observa-se que os laços de histerese estão de acordo com o esperado, tendendo a um fechamento, responsável pelo amortecimento da estrutura.

Há, contudo, que se notar que as fibras 3 e 5 apresentam inversão de sinal da tensão em alguns de seus laços. O efeito unilateral, responsável pela recuperação da rigidez com a inversão de sinal, não foi considerado nesta análise. 


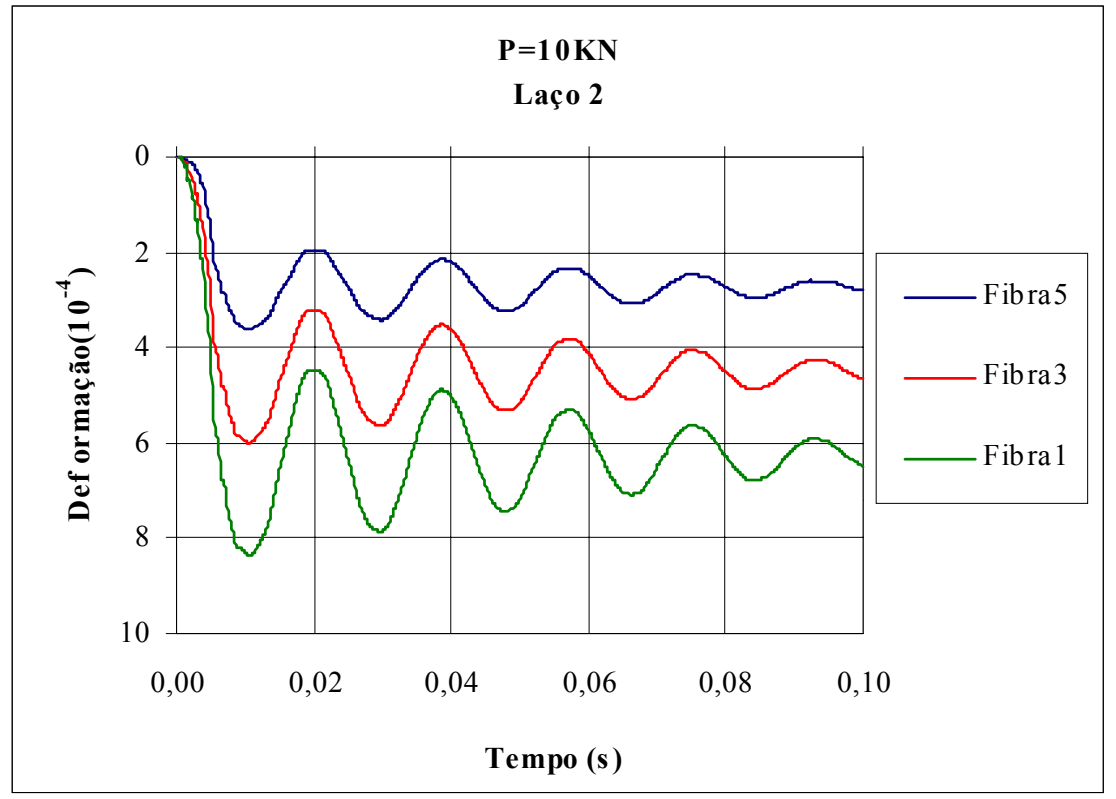

Figura 4.16 - Deformação versus tempo, $\mathrm{P}=10 \mathrm{KN}$ : fibras do concreto

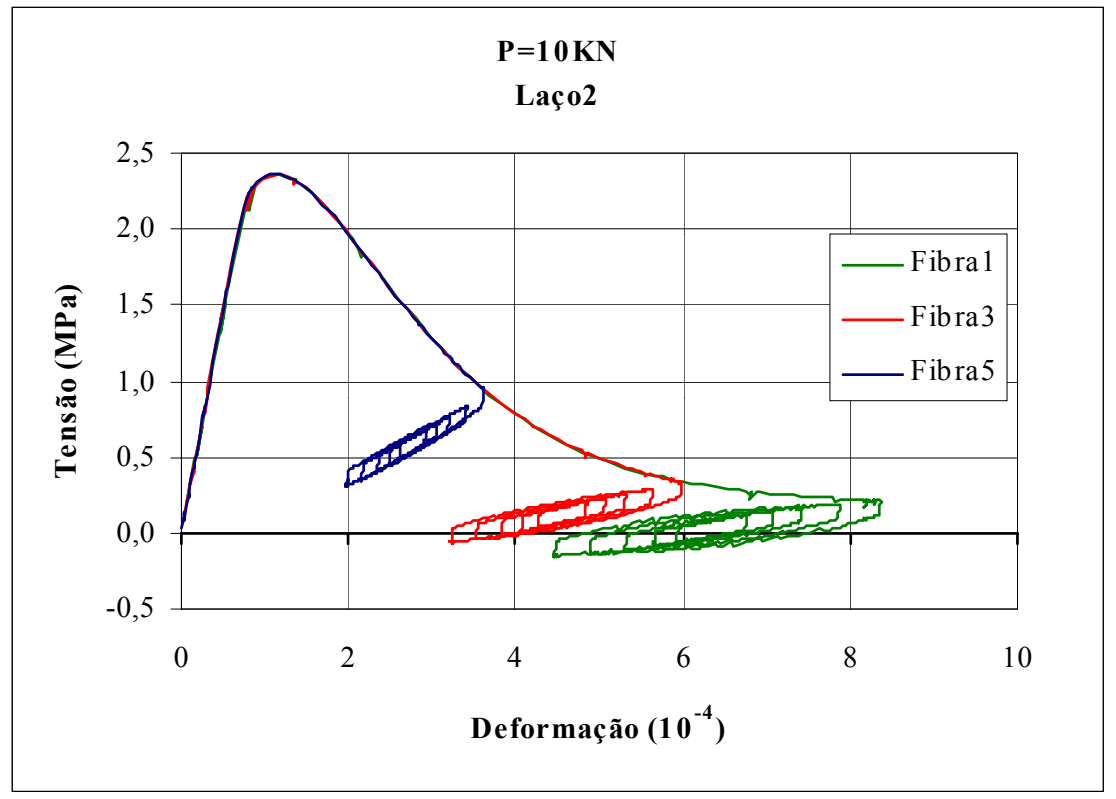

Figura 4.17 - Tensão versus deformação, $\mathrm{P}=10 \mathrm{KN}$ : fibras do concreto 


\section{CONCLUSÕES}

\subsection{CONSIDERAÇÕES FINAIS E CONCLUSÕES}

Este trabalho insere-se no campo da análise dinâmica de estruturas reticulares planas em concreto armado. Sendo a não-linearidade física do concreto considerada mediante modelos matemáticos de dano. Fundamentalmente procurou-se estender o estudo desenvolvido por PAULA (2001), que aborda o mesmo tema com aplicação aos pórticos planos em concreto armado, introduzindo-se um novo modelo de dano bem como fazendo implementações adicionais no programa fonte resultante de seu trabalho.

Entre as implementações adicionais, uma primeira contribuição consistiu em possibilitar a consideração de seções transversais diferentes da retangular, tais como seções em forma de "I" ou "T", via a utilização de elementos finitos de barras com múltiplas camadas ao longo da altura. Além disso, com vista a poder modelar melhor o processo de danificação, o módulo de elasticidade penalizado pelo dano passou a ser considerado com variação linear em cada camada. Para se verificar a eficiência do elemento finito gerado, realizou-se o confronto com dois resultados experimentais de vigas em concreto armado com seção transversal simétrica em forma de "I" e com diferentes taxas de armadura longitudinal. Os resultados numéricos obtidos mostraramse bastante satisfatórios, reproduzindo, com excelente coerência, as respostas experimentais obtidas no Laboratório de Estruturas da EESC/USP.

Posteriormente, apresenta-se uma proposta unidimensional para o modelo de dano proposto originalmente por MAZARS et al. (2000). Foram descritos os estudos relacionados à formulação termodinâmica, que visam esclarecer o comportamento das variáveis de estado introduzidas na modelagem e a influência dos parâmetros 
considerados para o material, sobretudo quando da realização dos laços de histerese. A proposta de simplificação do modelo original desenvolvida neste trabalho, mostrou-se capaz de reproduzir de forma satisfatória os resultados apresentados por MAZARS et al. (2000) para os diagramas tensão-deformação do concreto obtidos com aquele modelo. As respostas foram relativas a uma gama de laços de histerese considerando-se baixos e altos níveis de deformação, tanto para tração quanto para compressão. Adicionalmente, analisou-se a relação entre amortecimento e histerese e, como finalização da apresentação do modelo, formulou-se uma proposta simplificada para possibilitar a consideração da inversão em sinal do carregamento.

Em relação a proposta original de MAZARS et al. (2000) a proposta apresentada neste trabalho apresenta como modificações: o desenvolvimento de toda a formulação particularmente para o caso unidimensional, e a consideração do dano como uma variável escalar com lei de evolução exponencial idêntica a do modelo de MAZARS (1984).

Por fim, implementou-se a proposta unidimensional, para o modelo estudado, no programa de análise dinâmica desenvolvido por PAULA (2001) e foram simuladas diversas situações. Essas análises visaram confrontar o amortecimento devido exclusivamente à reprodução do comportamento de histerese do concreto. Com o amortecimento obtido da utilização do modelo viscoso de Rayleigh, modelo considerado nas respostas disponibilizadas por PAULA (2001).

A estrutura estudada consistiu de uma viga em concreto armado, de seção retangular, simplesmente apoiada, e submetida a carregamento constituído por duas forças aplicadas subitamente e mantidas constantes durante toda a análise. Foram considerados dois níveis de carregamento, cargas de $10 \mathrm{KN}$ e de $25 \mathrm{KN}$.

Os resultados obtidos em geral, evidenciam os seguintes aspectos:

- Constatou-se que a representação da dissipação de energia causada pela fricção interna entre as superfícies das fissuras, no concreto, tem grande importância para a consideração mais apurada dos efeitos da danificação sobre o comportamento estrutural;

- O amortecimento estrutural por efeito da histerese é diretamente proporcional à abertura do laço reproduzido no diagrama tensão-deformação do concreto durante os ciclos de descarregamento e recarregamento; 
- A integração da equação do movimento sem o termo proporcional à velocidade indica um efeito de amortecimento quando se emprega o modelo de MAZARS et al. (2000). Tal efeito é totalmente decorrente da danificação;

- Conforme verificado em PAULA (2001), um efeito de amortecimento pode também ser obtido, alternativamente, empregando-se o modelo clássico de MAZARS (1984), sem histerese, combinado com o modelo de amortecimento de Rayleigh na integração da equação do movimento. Constata-se uma clara diferença confrontando-se as respostas dinâmicas obtidas com a combinação amortecimento de RayleighMAZARS (1984) contra o amortecimento obtido a partir da reprodução da histerese do concreto. No primeiro caso o amortecimento afeta o pico de deslocamento que será maior quanto menor a taxa de amortecimento crítico considerada. No segundo caso o deslocamento máximo não é afetado pelo amortecimento, uma vez que somente a partir do início da oscilação da estrutura é que serão reproduzidos laços de histerese devido aos ciclos de descarregamento e recarregamento do concreto.

- A realização da superposição do amortecimento de Rayleigh com o amortecimento por histerese foi testada e produz, naturalmente, um efeito de aumento do amortecimento global da estrutura. Essa superposição pode fazer sentido, uma vez que se considere tanto a influência da danificação quanto da dissipação por atrito nos vínculos, para a geração do amortecimento global da estrutura.

\subsection{SUGESTÕES PARA TRABALHOS FUTUROS}

Sugere-se a generalização da proposta aqui apresentada para o caso multi-axial, inserindo-a, por exemplo, no modelo descrito em PITUBA (2003), capaz de considerar adicionalmente os efeitos unilaterais e a anisotropia gerada pela evolução da microfissuração do concreto.

Por fim, sugere-se o desenvolvimento de um programa experimental em laboratório para gerar resultados de confronto e validação das análises dinâmicas. 


\section{REFERÊNCIAS BIBLIOGRÁFICAS}

ÁLVARES, M. S. (1993). Estudo de um modelo de dano para concreto: formulação, identificação paramétrica e aplicação com o emprego do método dos elementos finitos. 123p. Dissertação (Mestrado) - Escola de Engenharia de São Carlos, Universidade de São Paulo, São Carlos. 1993.

ÁLVARES, M. S. (1999). Contribuição ao estudo e emprego de modelos simplificados de dano e plasticidade para a análise de estruturas de barra em concreto armado. 123p. Teste (Doutorado) - Escola de Engenharia de São Carlos, Universidade de São Paulo, São Carlos. 1999.

ALVES FILHO, A. (2000). Elementos finitos a base da tecnologia. São Paulo: Érica.

ARGYRIS, J.; MLEJNEK, H. P. (1991). Dynamics of structures. Noth-Holland. V.5

ASSAN, A. E. (1999). Método dos elementos finitos: primeiros passos. Campinas: UNICAMP.

BALBO, A. R. (1998). Contribuição à formulação matemática de modelos constitutivos para materiais com dano contínuo. 222p. Tese (Doutorado). - Escola de Engenharia de São Carlos, Universidade de São Paulo, São Carlos. 1998.

BATHE, K. J. (1996). Finite element procedures. New Jersey: Prentice Hall.

BOTTA, A. S. (1998). Cálculo de esforços e deslocamentos em estrutura reticuladas considerando-se a mecânica do dano para a modelagem do concreto armado. 98p. Dissertação (Mestrado) - Escola de Engenharia de São Carlos, Universidade de São Paulo, São Carlos. 1998.

CHABOCHE, J. L. (1998a). Contínuum damage mechanics: part I - general concepts. Journal of Applied Mechanics, v.55, p.59-64.

CHABOCHE, J. L. (1998b). Contínuum damage mechanics: part II - damage growth, crack initiation, and crack growth. Journal of Applied Mechanics, v.55, p.65-72. 
CHABOCHE, J. L. (1993). Cyclic viscoplastic constitutive equations, part I: Thermodynamically consistent formulation. Journal of Applied Mechanics, v.60, p.813-821.

CLOUGH, R. W.; PENZIEN, J. (1993). Dynamics of strutures. 2 $2^{\mathrm{a}}$ ed. New York: McGraw-Hill

COOK, R. D.; MALKUS, D.S.; PLESHA, M. E. (1989). Concepts and applications of element analysis. New York: John Wiley.

CRISFIELD, M. A. (1991). Non-linear finite element análisis of solids and structures. New York: John Wiley. V.1.

DRIEMEIER, L. (1995). Considerações sobre a fadiga em metais e o comportamento do concreto sob solicitação cíclica. 120p. Dissertação (Mestrado). - Escola de Engenharia de São Carlos, Universidade de São Paulo, São Carlos. 1995.

DRIEMEIER, L. (1999). Contribuição ao estudo da localização de deformações com modelos constitutivos de dano e plasticidade. 101p. Tese (Doutorado). - Escola de Engenharia de São Carlos, Universidade de São Paulo, São Carlos. 1999.

JANSON, J.; HULT, J. (1977). Fracture mechanics and damage mechanics a combined approach. Journal de Méchanique Appliquée, v.1, n. 1, p. 69-84.

LA BORDERIE, C. (1991). Phenomenes unilateraux dans un materiau endommageable: modelisation et application a l'analyse de structures en beton. These de Doctorat de l’Universite Paris.

LEMAITRE, J. (1992). A course on damage mechanics. Springer- Verlag

LEMAITRE, J.; CHABOCHE, J-L. (1985). Mechanics of solid materials. Cambridge: University Press.

MAZARS, J. (1984). Application de la mécanique de l'endommagement au compotaement non lineaire at à la rupture du béton de estructure. $\mathrm{PhD}$ thesis, Université Paris 6. 
MAZARS, J.; RAGUENEAU, F.; PIJAUDIER-CABOT, G. (2000). Continuum damage modelling for concrete structures in dynamic situations. In: CONTINUUM DAMAGE MECHANICS OF MATERIALS, Cachan, France, oct. 2000. Damage mechanics of materials and structures. Cachan, CNRS. 36p.(Lectures series).

NEVES, R. A. (2000). Cálculo de esforços e deslocamentos em estruturas de pisos de edifícios, considerando-se a influência das tensões cisalhantes. 113p. Dissertação (Mestrado). - Escola de Engenharia de São Carlos, Universidade de São Paulo, São Carlos. 2000.

ORTIZ, M.; SIMO, J. C. (1986). An analysis of a new class of integration algorithms for elastoplastic constitutive relations. International Journal for Numerical methods in Engineering, v.23, p.353-366.

PAULA, C. F. (2001). Contribuição ao estudo das respostas numéricas não-lineares estática e dinâmica de estruturas reticuladas planas. 128p. Tese (Doutorado) Escola de Engenharia de São Carlos, Universidade de São Paulo, São Carlos. 2001.

PAULA, C. F.; PROENÇA, S. P. B. (2001). Avaliação do modelo de amortecimento viscoso de Rayleigh na resposta dinâmica não-linear de uma viga em concreto armado. [CD-Rom]. In: XXII CILAMCE, São Paulo, 2001.

PAZ, M. (1991). Structural dynamics: theory and computation. New York: VNR.

PIMENTA, P. M. (1998). Análise não-linear de pórticos planos. Anais EPUSP, Engenharia Civil, Engenharia de Estruturas e Fundações, v.1, série A, pt.1, p.561582.

PITUBA, J.J.C. (1998). Estudo e aplicação de modelo constitutivo para o concreto fundamentado na mecânica do dano contínuo. 130p. Dissertação (Mestrado) Escola de engenharia de São Carlos, universidade de São Paulo, São Carlos. 1998.

PITUBA, J.J.C. (2003). Sobre a formulação de um novo modelo de dano para o concreto. 148p. Tese (Doutorado). - Escola de Engenharia de São Carlos, Universidade de São Paulo, São Carlos. 
PROENÇA, S. P. B. (2000). Introdução à Mecânica do Dano e Fratura - notas de aula. São Carlos. 300p.

PROENÇA, S. P. B. (2001). Análise Não-Linear de Estruturas - notas de aula. São Carlos. 270p.

RAGUENEAU, F.; LA BORDERIE, C.; MAZARS, J. (2000). Damage model for concrete-like materials coupling cracking and friction, contribution towards structural damping: first uniaxial applications. Mechanics of Cohesive-frictional Materials, v.5, p.607-625.

RODRIGUES, R. O. (1997). Análise dinâmica bidimensional não-linear física e geométrica de treliças de aço e pórticos de concreto armado. $275 \mathrm{p}$. Tese (Doutorado) - escola de Engenharia de São Carlos, Universidade de São Paulo, São Carlos. 1997.

SILVA, R. M. (1996). Análise não-linear de pórticos planos de concreto armado: modelagem numérica e avaliação dos métodos aproximados. 263p. Tese (Doutorado) - Escola de Engenharia de São Carlos, Universidade de São Paulo, São Carlos. 1996.

WARBURTON, G. B. (1976). The dynamical behaviour of structures. Pergamon Press.

ZIENKIEWICZ, O. C.; TAYLOR, R. L. (1989). The finite element method. 4.ed. London: McGraw-Hill. 